\title{
Energy Storage for Power Systems Applications: A Regional Assessment for the Northwest Power Pool (NWPP)
}

MCW Kintner-Meyer

PJ Balducci

$C$ Jin

TB Nguyen
MAElizondo

VV Viswanathan

$X$ Guo

FK Tuffner

April 2010

\section{Pacific Northwest}

NATIONAL LABORATORY

Proudly Operated by Battelle Since 1965 


\title{
DISCLAIMER
}

This report was prepared as an account of work sponsored by an agency of the United States Government. Neither the United States Government nor any agency thereof, nor Battelle Memorial Institute, nor any of their employees, makes any warranty, express or implied, or assumes any legal liability or responsibility for the accuracy, completeness, or usefulness of any information, apparatus, product, or process disclosed, or represents that its use would not infringe privately owned rights. Reference herein to any specific commercial product, process, or service by trade name, trademark, manufacturer, or otherwise does not necessarily constitute or imply its endorsement, recommendation, or favoring by the United States Government or any agency thereof, or Battelle Memorial Institute. The views and opinions of authors expressed herein do not necessarily state or reflect those of the United States Government or any agency thereof.

\author{
PACIFIC NORTHWEST NATIONAL LABORATORY \\ operated by \\ BATTELLE \\ for the \\ UNITED STATES DEPARTMENT OF ENERGY \\ under Contract DE-AC05-76RL01830
}

Printed in the United States of America
Available to DOE and DOE contractors from the Office of Scientific and Technical Information,
P.O. Box 62, Oak Ridge, TN 37831-0062;
ph: (865) 576-8401
fax: $(865) 576-5728$
email: reports@adonis.osti.gov

\begin{abstract}
Available to the public from the National Technical Information Service, U.S. Department of Commerce, 5285 Port Royal Rd., Springfield, VA 22161 ph: (800) 553-6847 fax: (703) 605-6900 email: orders@ntis.fedworld.gov

online ordering: http://www.ntis.gov/ordering.htm
\end{abstract}

This document was printed on recycled paper. 


\title{
Energy Storage for Power Systems Applications: A Regional Assessment for the Northwest Power Pool (NWPP)
}

\author{
M Kintner-Meyer M Elizondo \\ P Balducci V Viswanathan \\ C Jin \\ X Guo \\ T Nguyen \\ F Tuffner
}

April 2010

Prepared for

the U.S. Department of Energy

under Contract DE-AC05-76RL01830

Funded by the Energy Storage Systems Program of

the U.S. Department of Energy

Dr. Imre Gyuk, Program Manager

Pacific Northwest National Laboratory

Richland, Washington 99352 



\begin{abstract}
This report addresses several key questions in the broader discussion on the integration of renewable energy resources in the Pacific Northwest power grid. Specifically, it addresses the following questions: a) what will be the future balancing requirement to accommodate a simulated expansion of wind energy resources from 3.3 GW in 2008 to 14.4 GW in 2019 in the Northwest Power Pool (NWPP), and b) what are the most cost effective technological solutions for meeting the balancing requirements in the Northwest Power Pool (NWPP). A life-cycle analysis was performed to assess the least-cost technology option for meeting the new balancing requirement. The technologies considered in this study include conventional turbines (CT), sodium sulfur (NaS) batteries, Lithium Ion (Li-ion) batteries, pumped-hydro energy storage (PH), and demand response (DR). Hybrid concepts that combine 2 or more of the technologies above are also evaluated. The report also discusses the value of pumped hydro storage systems in the Bonneville Power Administration's footprint as an energy arbitrage instrument. This analysis was performed with collaboration by the Bonneville Power Administration and funded by the Energy Storage Systems Program of the U.S. Department of Energy.
\end{abstract}





\section{Summary}

Stationary energy storage for power system application has recently attracted significant interest and attention as an enabling technology for integrating the growing capacity of variable renewable energy resources into the electric grid. Energy storage systems are likely to become an essential contributor to grid modernization investments that will transition the North American power system to a modern grid that meets the future needs under low carbon emissions constraints. In the Pacific Northwest as well as in other U.S. regions, the electricity production from wind technology has increased significantly to meet the renewable portfolio standards targets imposed by 24 U.S. States and the District of Columbia.

For the Bonneville Power Administration (BPA) as the major grid operator in the Pacific Northwest, the growing wind generation poses some challenges to generation scheduling and the provision of ancillary services. To study the impacts of the variability in the wind generation on the regional grid operation and the role that energy storage may play to mitigate these grid impacts, Pacific Northwest National Laboratory (PNNL) collaborated with BPA to addresses the following key questions:

a. For the Northwest Power Pool (NWPP) what are the future balancing requirements necessary to accommodate an assumed expansion of wind energy resources from $3.3 \mathrm{GW}$ in 2008 to $14.4 \mathrm{GW}$ in 2019 ?

b. What are the most cost effective technological solutions for meeting the new balancing requirements?

c. Can energy storage be cost-effectively employed for arbitrage opportunities?

Pacific Northwest National Laboratory applied a stochastic approach to assess the total balancing requirements for the NWPP for the high wind penetration in 2019. A simplifying assumption was applied that reduced the entire NWPP footprint into one single balancing area. With this assumption, the total balancing-up capacity requirements (generation increment) is approximately $3900 \mathrm{MW}$. The balancingdown capacity (generation decrement) is estimated to be about -3700 MW. These figures are based on BPA's customary $99.5 \%$ probability bound that meets $99.5 \%$ of all balancing requirements. A fraction of the total balancing requirements were filtered out to represent the intra-hour (within the hour) balancing requirements that require high ramp rates. The intra-hour balance requirements are $1.85 \mathrm{GW}$ in either direction (increment and decrement). By filtering the intra-hour component out of the entire spectrum of balancing requirements, this study focuses only on one specific set of requirements. These requirements by definition require shorter cycling times for energy storage (less than one hour), however, they pose significant challenges on the ramp rate capabilities of steam turbine generators. During the execution of this project, the need and value for follow-on work was recognized that would focus on the remaining spectrum of the new balancing requirements to address the capacity requirements for inter-hour and intraday balancing.

A life-cycle cost analysis assessed the cost competition of a set of technologies to meet the future intra-hour balancing requirements. The technologies considered for meeting balancing requirements in this study include conventional turbines (CT), sodium sulfur (NaS) batteries, Lithium Ion (Li-ion) batteries, pumped-hydro energy storage (PH), and demand response (DR). Hybrid concepts that combine two or more of the technologies above are also evaluated. 
The technology cases considered in this analysis are:

Case 1: CT

Case 2: $\mathrm{NaS}$

Case 3: Li-ion

Case 4: PH with many mode changes per day ${ }^{1}$

Case 5: PH with 2 mode changes per day

Case 6: DR only

Extensive systems modeling was performed to estimate the power and energy capacity requirements to meet future (2019) balancing requirements. Each technology and technology group required careful simulation that incorporated the specific technical features of each technology as well as the interaction between technologies. Simulation results are a pairing of power capacity (GW) and energy capacity requirements expressed in gigawatt-hours (GWh) to meet future balancing needs.

Table E.1 presents the energy and power requirements modeled for each of the aforementioned 11 cases. Note that the capacity requirements are based on a $100 \%$ battery depth of discharge (DOD). Under this assumption, energy storage is fully utilized or cycled from fully charged to fully discharged. There are economic reasons for upsizing the battery to a DOD of less than $100 \%$ to improve the life of the battery, and the tradeoffs between DOD, energy capacity, and economic life are examined later in this report.

Table E.1. Power and Energy Requirements by Technology Case

\begin{tabular}{|c|c|c|c|}
\hline Cases & Technology & GW & GWh \\
\hline C1 & CT & 1.85 & - \\
\hline $\mathrm{C} 2$ & $\mathrm{NaS}$ & 1.85 & 0.91 \\
\hline C3 & Li-ion & 1.85 & 0.90 \\
\hline $\mathrm{C} 4$ & PH with many mode changes per day * & 3.06 & 1.0 \\
\hline C5 & PH with 2 mode changes per day * & 4.43 & 21.77 \\
\hline C6 & DR & 8.64 & - \\
\hline \multirow[t]{2}{*}{$\mathrm{C} 7$} & $\mathrm{NaS}$ & 1.49 & 0.73 \\
\hline & $\mathrm{DR}$ & 1.72 & - \\
\hline \multirow[t]{2}{*}{$\mathrm{C} 8$} & Li-ion & 1.49 & 0.72 \\
\hline & DR & 1.72 & - \\
\hline \multirow[t]{2}{*}{ C9 } & PH with many mode changes per day & 0.5 & 0.22 \\
\hline & $\mathrm{NaS}$ & 1.35 & 0.69 \\
\hline \multirow[t]{2}{*}{$\mathrm{C} 10$} & PH with 2 mode changes per day & 0.97 & 5.87 \\
\hline & $\mathrm{NaS}$ & 1.35 & 0.67 \\
\hline \multirow[t]{3}{*}{ C11 } & PH with many mode changes per day & 0.5 & 0.22 \\
\hline & $\mathrm{DR}$ & 1.72 & - \\
\hline & $\mathrm{NaS}$ & 0.98 & 0.50 \\
\hline
\end{tabular}

\footnotetext{
${ }^{1}$ PH has 2 modes: pumping and generating modes. Operation with multiple mode changes per day permits as many mode changes as are required to meet balancing signal.
} 
A cost analysis was performed for each of the 11 technology cases that established capital cost for 2010 and 2019. The analysis considered the costs associated with initial and recurrent capital costs, fixed and variable operations and maintenance (O\&M) costs, fuel costs, and emissions costs. All energy storage systems incur energy losses. The electric energy compensating for the storage losses is assumed to be generated by combined cycle plant operating on the margin most of the time. The fuel and emission cost associated with the make-up energy is accounted for in the analysis. Annual costs incurred over a 50-year time horizon were collapsed into a single present value cost for each scenario using a real discount rate of $10.3 \%$.

The results of the cost analysis are presented in Table E.1 and Figure E.1. Of the 11 cases examined in this paper, Case 2, which employs $\mathrm{NaS}$ batteries, is the least cost alternative at approximately $\$ 1.4$ billion, followed by Case 7 ( NaS and DR) in second place at estimated cost of about \$1.9 billion, or $35.2 \%$ more than those for Case 2. The third most cost effective option is Case 9 , which is $42.6 \%$ more expensive than Case 2. The costs associated with the demand response only case (Case 6) more than double those for the three aforementioned cases at $\$ 4.2$ billion. The reason for that result was that DR resources were sized to meet the largest balancing requirement at the time of lowest DR resource availability. As a consequence for most of the time, the DR resource remains underutilized. In the pumped hydro case with 40 mode changes per day (Case 4), total costs are also much higher at about $\$ 4.0$ billion. In most cases, the capital costs associated with the energy storage options are higher than those estimated for the combustion turbine case (Case 1) but these costs are offset by the higher fuel and emissions costs for combustion turbines.

Table E.2. Economic Analysis Results

\begin{tabular}{cccccc}
\hline Case & Capital & Fuel & O\&M & Emissions & Total \\
\hline 1 & 1,759 & 905 & 276 & 312 & 3,252 \\
2 & 1,076 & 125 & 129 & 43 & 1,372 \\
3 & 2,139 & 91 & 122 & 31 & 2,383 \\
4 & 3,720 & 120 & 120 & 41 & 4,000 \\
5 & 6,949 & 422 & 372 & 145 & 7,889 \\
6 & 4,222 & - & - & - & 4,222 \\
7 & 1,619 & 100 & 102 & 34 & 1,855 \\
8 & 2,425 & 73 & 97 & 25 & 2,620 \\
9 & 1,671 & 123 & 121 & 42 & 1,957 \\
10 & 2,550 & 205 & 190 & 71 & 3,016 \\
11 & 2,331 & 98 & 100 & 34 & 2,562 \\
\hline
\end{tabular}




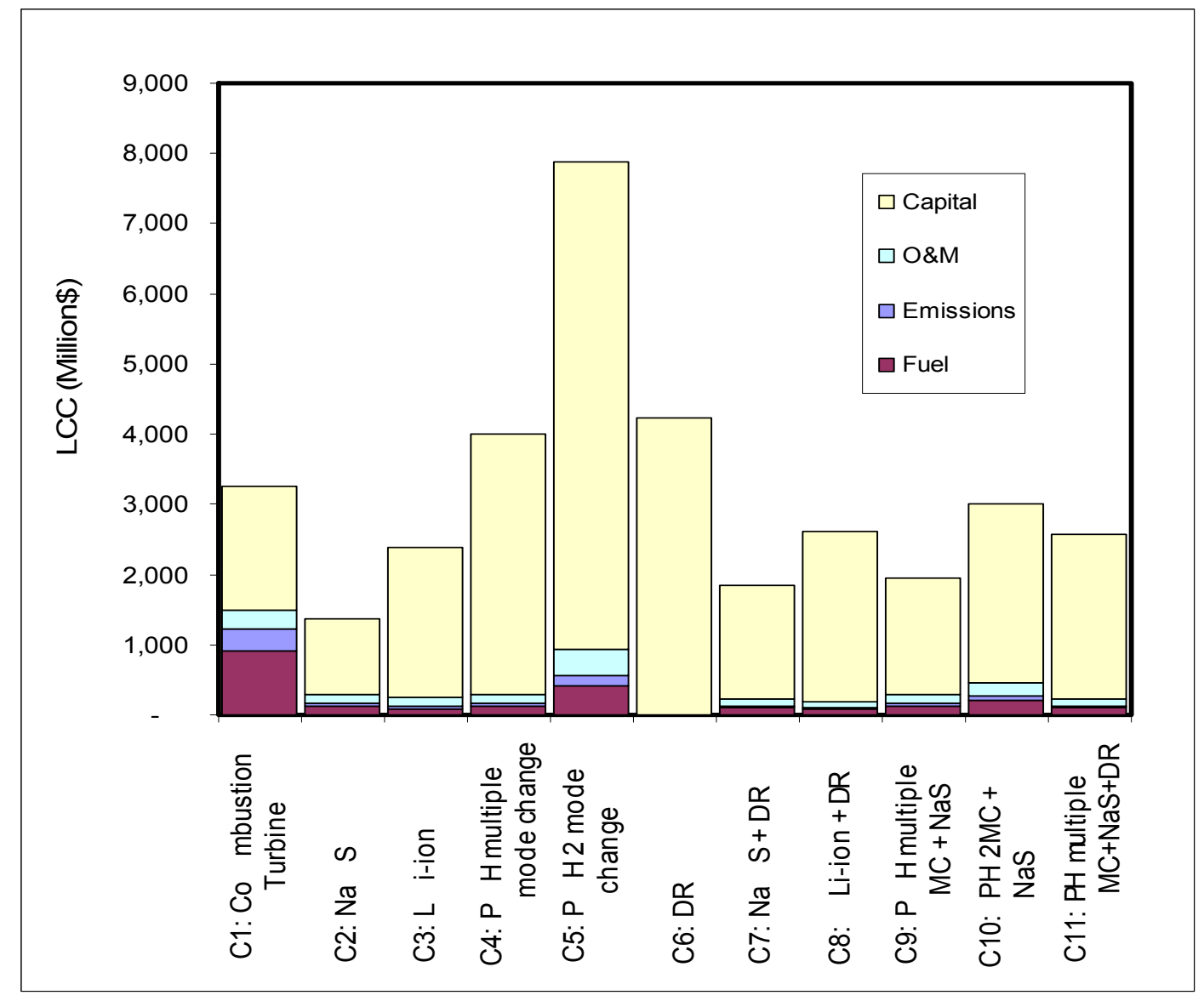

Figure E.1. Scenario Life Cycle Cost Estimates

This report also explores the financial feasibility of using pumped hydro systems for energy arbitrage in the BPA region. Pumped hydro systems are customarily used for energy arbitrage due to their energy storage capabilities. At low demand periods, low cost electric power is used to pump water from a lower reservoir to a higher one. At high demand periods when the cost of generating electric power is high, water is released through a turbine to generate electricity.

This study considers three pumped hydro energy arbitrage scenarios. The first scenario implements a $1 \mathrm{GW}, 10 \mathrm{GWh}$ pumped hydro system located at the Grand Coulee bus. The second scenario examines the $1 \mathrm{GW}$ system at Grand Coulee with an additional $3 \mathrm{GW}$ of wind power introduced in the MidColumbia Region. The final scenario examines four $0.25 \mathrm{GW}, 2.5 \mathrm{GWh}$ pumped hydro systems located at Grand Coulee, John Day, Malin, and Marion. Annual operating income (gross revenue minus operating costs) for the three scenarios were estimated at \$2.7 million (Grand Coulee), \$5.0 million (Grand Coulee with expanded wind power), and \$6.4 million (0.25 GW, $2.5 \mathrm{GWh}$ at four locations). With pumped hydro capital costs estimated at $\$ 1,750$ per $\mathrm{kW}$, each of these arbitrage scenarios fall significantly short of the revenue necessary for cost recovery. Thus, pumped hydro for arbitrage does not appear to be economically viable. 
The results of this study clearly indicate that energy storage, and particularly electro-chemical storage, technologies can compete with conventional combustion turbines when used to meet specific balancing requirements that isolated the high ramp rate requirements in the intra-hour timeframe. This finding has general applicability beyond the investigated Northwest Power Pool footprint. Regionspecific were only the amount and characteristics of the balancing requirements that were derived from BPA's understanding about the uncertainties in their load and wind production forecastings.

Energy arbitrage opportunities, however, may not be the key driver for large deployment of energy storage, at least not in the near term (i.e., 2010-2019 time horizon). Placement flexibility could be important for the economics of energy storage given that electro-chemical storage devices are not constrained to a specific geographic topology and hydrological system, unlike pumped hydro systems. In addition, there are other benefits that large-scale energy storage may provide that were not modeled in this study. For example, grid flexibility for transmission outage management is likely to improve with energy storage. Further studies with a particular focus on transmission system impacts are required to better explore these other value propositions. 



\section{Acknowledgments}

We are particularly thankful to Dr. Imre Gyuk, manager of the Energy Storage System Program of the U.S. Department of Energy, Office of Electricity Delivery and Energy Reliability for providing the funding for this project.

We would like to thank Stan Williams and Ravi Aggarwal of the Bonneville Power Administration for their technical guidance throughout this project. Rick Miller of HDR/DTA provided many insights into the cost and performance characteristics of pumped-hydro systems. We would also like to thank Heidi Pacini and Brad Nickell, staff of the Western Electricity Coordinating Council (WECC) and Mark Landauer, Columbia Grid, for their advice in the production cost modeling of the WECC system for a high wind penetration scenario. 



\section{Acronyms and Abbreviations}

\begin{tabular}{|c|c|}
\hline ACE & Area Control Error \\
\hline AEP & American Electric Power \\
\hline AEO & Annual Energy Outlook \\
\hline ANL & Argonne National Laboratory \\
\hline BA & Balancing Authority \\
\hline BASF & Badische Anilin- und Soda-Fabrik, Ludwigshafen, Germany \\
\hline $\mathrm{BC}$ & British Columbia \\
\hline $\mathrm{BOP}$ & Balance of Power \\
\hline $\mathrm{BPA}$ & Bonneville Power Administration \\
\hline $\mathrm{CC}$ & Combined Cycle \\
\hline $\mathrm{COB}$ & California Oregon Border \\
\hline CT & Combustion Turbine \\
\hline DOD & Depths of Discharge \\
\hline DR & Demand Response \\
\hline $\mathrm{E} / \mathrm{P}$ & energy/rated power \\
\hline GC & Grand Coulee \\
\hline GW & Gigawatt \\
\hline GWh & Gigawatt-hours \\
\hline ID & Idaho \\
\hline KEMA & Keuring Electrotechnisch Materieel Arnhem, Global consulting company \\
\hline $\mathrm{kW}$ & Kilowatt \\
\hline Li-ion & Lithium-ion \\
\hline LMP & Locational marginal price \\
\hline LRS & Load and Resource Subcommittee \\
\hline LTC & Lithium Technology Corp \\
\hline MT & Montana \\
\hline MW & Megawatt \\
\hline MWh & Megawatt-hour \\
\hline $\mathrm{NaS}$ & Sodium-sulfur \\
\hline NREL & National Renewable Energy Laboratory \\
\hline NW & Northwest \\
\hline NWPP & Northwest Power Pool \\
\hline $\mathrm{O} \& \mathrm{M}$ & operations and maintenance \\
\hline OR & Oregon \\
\hline $\mathrm{P} / \mathrm{E}$ & power to energy \\
\hline PC1 & Planning case \\
\hline
\end{tabular}


PCS

PG\&E

$\mathrm{PH}$

PHEV

PNNL

PROMOD

RPS

TEPPC

WA

WECC power conversion system

Pacific Gas \& Electric

Pumped hydroelectric

Plug in hybrid electric vehicles

Pacific Northwest National Laboratory

Production cost modeling software by Ventyx

Renewable portfolio standards

Transmission Expansion Planning and Policy Committee

Washington

Western Electricity Coordinating Council 


\section{Contents}

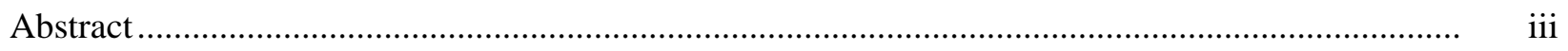

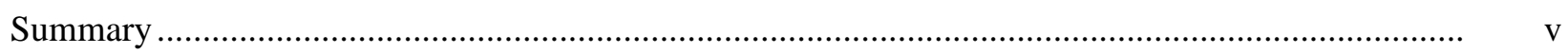

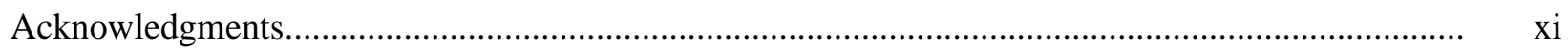

Acronyms and Abbreviations ................................................................................................. xiii

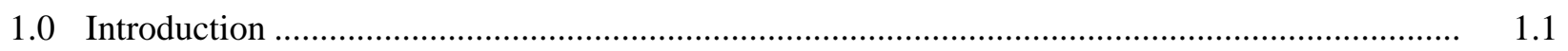

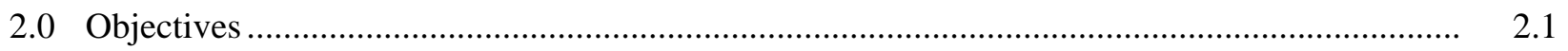

3.0 Technology Choices for Balancing Services .......................................................................

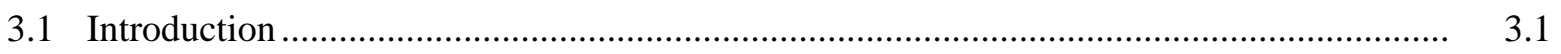

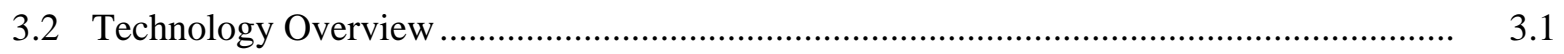

3.2.1 Combustion Turbine........................................................................................ 3.1

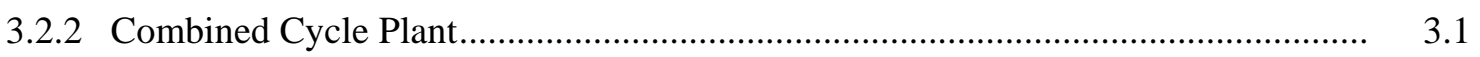

3.2.3 Energy Storage Technologies...................................................................... 3.2

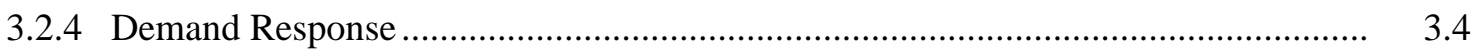

3.3 Technology Cost and Performance Characteristics........................................................ 3.5

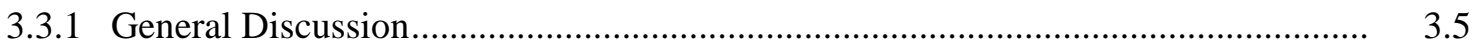

3.3.2 Summary of Capital, O\&M Costs and Efficiency for Batteries and Pumped
Hydro Systems ..............................................................................................

3.4 Definition of Technology Options ….......................................................................... 3.6

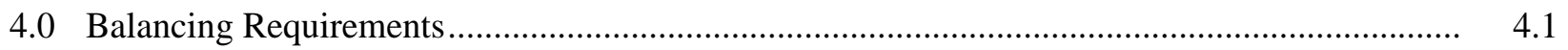

4.1 Overview of Analysis Framework .............................................................................. 4.1

4.2 Approach and Data Used to Determine Balancing Requirements .................................... 4.1

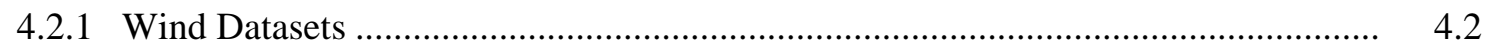

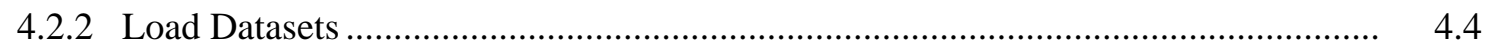

4.2.3 Balancing Service Requirement ..................................................................... 4.4

4.2.4 Consolidation of Balancing Areas..................................................................... 4.5

4.2.5 Resulting Total Balancing Signal .......................................................................... 4.6

4.2.6 Spectral Analysis and Extraction of Intra-Hour Balancing Signal.......................... 4.7

4.2.7 Capacity Requirements for Meeting 2019 Balancing Needs .................................. 4.9

5.0 Economic Analysis Methodology and Results ................................................................... 5.1

5.1 Cost Analysis Framework ................................................................................ 5.1

5.2 Economic Parameters ...................................................................................... 5.1

5.2.1 Capital Costs ................................................................................................. 5.1

5.2.2 Operations and Maintenance Costs .............................................................. 5.2

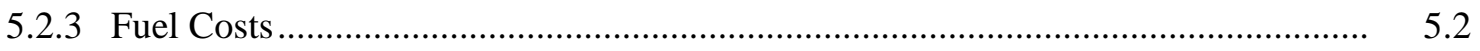

5.2.4 Emissions Costs............................................................................................... 5.3

5.3 Optimizing Battery Capacity .................................................................................... 5.3

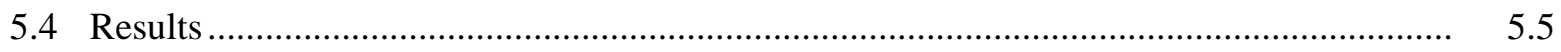




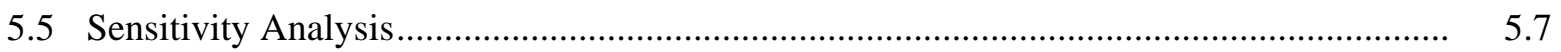

6.0 Arbitrage Opportunities for Energy Storage................................................................. 6.1

6.1 Arbitrage Analysis Framework ….............................................................................. 6.1

6.2 Simulation Results for a 1 GW, 10 GWh Pumped Storage at Grand Coulee...................... 6.3

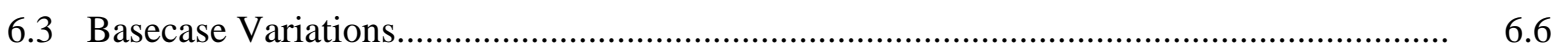

6.4 Cost Effectiveness of Energy Storage as Arbitrage Instrument ....................................... 6.6

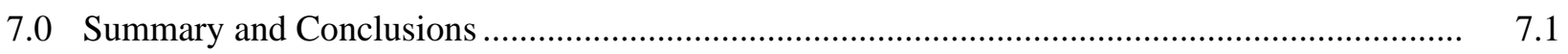

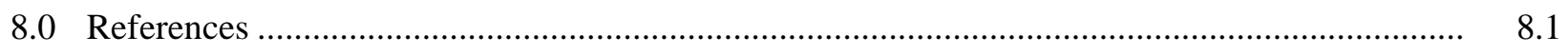

Appendix A - Detailed Technology Discussion ........................................................................... A.1

Appendix B - Specific Operational Strategies to Meet Balancing Requirements ............................ B.. B.

\section{Figures}

Figure 3.1. Load Curves for PHEV with Home and Work Charging, ......................................... 3.5

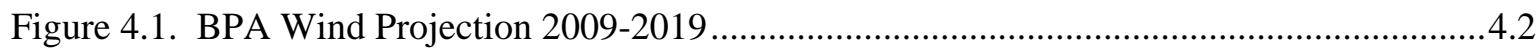

Figure 4.2. Distribution of Wind Capacity by States ................................................................. 4.3

Figure 4.3. Location of Existing and Arbitrarily Sited Future Wind Plants. ................................ 4.3

Figure 4.4. Illustration of Intra-Hour Balancing Signal............................................................. 4.5

Figure 4.5. Total Balancing Requirements for NWPP for the Month of August 2020 .................4.6

Figure 4.6. Total Balancing Requirements for NWPP for One Typical Day in August 2020 ........4.7

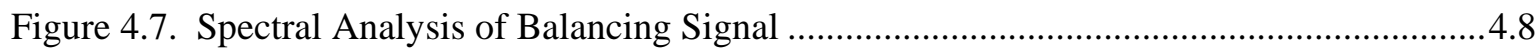

Figure 4.8. Components of Decomposed Balancing Signal .....................................................4.8

Figure 4.9. Power Requirements for all the Technologies to Meet Balancing Signal .................4.10

Figure 4.10. Energy Requirements for Storage Technologies to Meet Balancing Signal.............4.10

Figure 5.1. Case 3 Life Cycle Cost Estimates..................................................................................

Figure 5.2. Scenario Life Cycle Cost Estimates .......................................................................5.7

Figure 6.1. Key Congested Paths in NWPP and Neighboring Areas..........................................6.3

Figure 6.2. Typical Weekly Pumped Hydro Operation..............................................................6.3

Figure 6.3. Storage Locations at four Arbitrarily Selected Locations .........................................6.5

Figure 6.4. Histogram of LMP Difference Between Peak and Off-Peak Periods..........................6.6

Figure 6.5. Cost-effectiveness Results of Pumped Hydro of 1 GW/10 GWh................................6.7 


\section{Tables}

Table 3.1. Installed Capacity for Various Energy Storage Devices in the US and Worldwide .......3.2

Table 3.2. Summary of Capital and O\&M Costs for Technologies Analyzed. ................................6

Table 3.3. Definition of Technology Cases ..................................................................................

Table 4.1. Information About NREL Wind Integration Datasets .................................................. 4.2

Table 4.2. Statistics of Hour-Ahead Forecast Error ....................................................................... 4.4

Table 4.3. Frequency Limits of Components of the Balancing Signal ........................................4.8

Table 4.4. Power and Energy Requirements for Each Scenario .................................................4.9

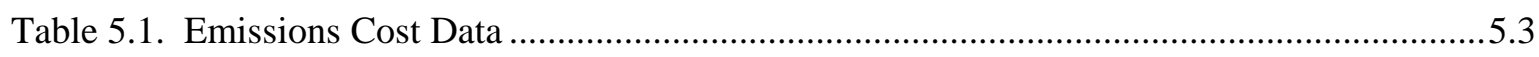

Table 5.2. Relationship between Effective Depth of Discharge, Battery Capacity, and Lifecycle -

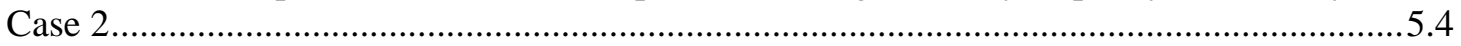

Table 5.3. Cost Minimizing DOD, Battery Capacity and Economic Life by Case. .......................5.5

Table 5.4. Economic Analysis Results..................................................................................... 5.6

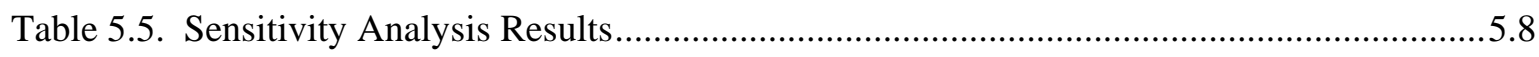

Table 6.1. Existing and Additional Installed Capacity (MW) for WECC, NWPP, and BPA.........6.2

Table 6.2. Number of Hours at 100\% Transfer Limits ................................................................6.4

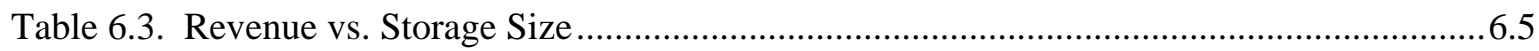

Table 6.4. Revenue from $1 \mathrm{GW} / 10 \mathrm{GWh}$ Storage for the Base Case and the Two Side-Cases......6.6 



\subsection{Introduction}

As the Bonneville Power Administration (BPA) and utilities across the United States consider options for reducing their carbon footprint while meeting expanding demand for electricity, service providers are actively searching for more cost effective and less environmentally damaging sources of energy. From 1995 to 2009, installed wind capacity expanded worldwide from less than $10 \mathrm{GW}$ to nearly $150 \mathrm{GW}$, and the growth trend is forecast to continue reaching roughly $240 \mathrm{GW}$ by 2012 (Thewindpower.net, 2010). Wind power technologies, however, cannot be dispatched because of its intermittent nature. Thus, while wind power presents a significant opportunity to BPA, because of its varying electricity output, integrating high levels of wind resources into power systems brings challenges to system generation scheduling and ancillary services.

Earlier studies have found that energy storage can compensate for the stochastic nature of intermittent energy sources by absorbing the excessive energy when generation exceeds predicted levels and providing it back to the grid when generation levels fall short. Energy storage could also be used to enhance the efficiency of the U.S. power system. During most hours, with the exception of peak hours, less than $50 \%$ of electricity system capacity is utilized. Thus, a significant amount of power system assets have been built to meet only a few hundred hours of peak demand each year. Including energy storage could reduce the peak demand by storing energy during off-peak hours and selling it back into the grid during peak times, offering an alternative to expanding power generation capacity.

In recent years, utilities have recognized that energy storage could be an important element of the future power system and have begun to install energy storage units in their systems. Examples of recent installations include:

- Pacific Gas \& Electric (PG\&E) has installed a flywheel at the Distributed Utility Integration Test (DUIT) development facility in San Ramon, CA and is planning to install a 4 MW, 28 MWh sodium sulfur (NaS) battery for energy, regulation and load following services.

- American Electric Power (AEP) built a 1.2 MW, 7.2 MWh NaS battery in 2006 for peak shaving, and has a goal of achieving 1,000 megawatts of advanced storage capacity on its system in the next decade.

- Austine Energy placed a 4 MW NaS battery into service in 2009.

While these and other recent energy storage investments signal an advance in the efficient management of the electric power system, additional engineering and economic analyses are required as part of grid operator energy storage planning prior to wide deployment of energy storage.

With the growing contributions of intermittent energy resources across the U.S. and in the Northwest Power Pool (NWPP), load balancing requirements are expected to grow. With sophisticated wind production forecasting methods, forecasting errors are expected to decline, however, only to a certain degree. A finite error in the wind production forecast will always remain, such that the total balancing requirements are likely to increase with continuing growth in intermittent energy resources. 
In this report, we present a general methodology for estimating balancing requirements for the 2019 timeframe under a 14.4 GW wind scenario in the NWPP. Further, we examine 11 cases for meeting balancing requirements using an array of technologies, including $\mathrm{NaS}$ and Li-ion batteries, combustion turbines (CT), demand response (DR), and pumped-hydro energy storage (PH).

This report is divided into seven sections with the first being this introduction. The second section of this report presents overarching study objectives. The third section presents an overview of the technologies designed to provide load balancing services, including cost and performance characteristics. The fourth section of this report provides an overview of the approach and data used to determine balancing requirements for the NWPP in 2019, and presents the results of the load balancing forecast. The fifth section of the report documents the cost analysis framework used in this study as well as cost analysis results for each of the 11 technology cases. Arbitrate opportunities for energy storage are presented in the sixth section of this report. The seventh, and final, section of the report presents conclusions. 


\subsection{Objectives}

This report addresses several key questions in the broader discussion on the integration of renewable energy resources into the Northwestern power grid. In particular, it focuses on the questions of how much total reserve or balancing requirement is necessary to accommodate the intermittent wind energy resources. As an extension of analytical methodology development during the summer of 2009, Pacific Northwest National Laboratory (PNNL) was asked by the Bonneville Power Administration (BPA) to utilize these techniques for a regional assessment of the Pacific Northwest, with a sufficiently high level of spatial resolution to capture key drivers that determine the balancing requirements relevant to BPA. The spatial scope was expanded to include the Northwest Power Pool. Key reasons for that decision were that an expanded scope offered greater diversity in the wind resources and that it would allow the study to assess the transmission impacts in a broader Pacific Northwest context.

The study discussed in this report established the balancing requirements for a time horizon of 2019 postulating a scenario of 14.4 Gigawatt (GW) of wind generation capacity in NWPP, which was based on a 20\% Renewable Portfolio Standards (RPS) scenario, primarily composed of wind resources. To provide a sense of reference the installed wind power capacity in NWPP in 2008 was 3.3 GW. The study determines the cost-optimal investment strategies of meeting the new balancing requirements for a high wind penetration scenario. A rich set of technology options is considered; it included conventional combustion turbines, as well as new advance utility-scale battery technologies, comprised of lithium-ion (Li-ion) and sodium sulfur (NaS) batteries, as well as pumped-hydro energy storage and demand response strategies. Hybrid energy storage options, comprised of NaS/pumped hydro and Li-ion/pumped hydro, with and without demand response strategies were comparatively assessed from a life-cycle cost point of view. This provides significant insights into the trade-off of capital cost versus operating cost and externalities such as emissions over the entire life of the storage project. In addition to estimating the balancing requirements and analyzing cost optimal technology investments to meet them, the study explores the cost effectiveness of energy arbitrage opportunities. BPA requested an analysis of the arbitrage value of a specific energy storage system at a specific location in the grid. The net revenue potential from energy arbitrage is quantified using a production cost model that simulated a securityconstrained unit commitment and cost-optimal generator dispatch for the Western Electricity Coordinating Council (WECC). To provide credibility of the underlying assumptions of the grid infrastructure for a high renewable energy resource scenario in 2019, we adopted the Transmission Expansion Planning Policy Council (TEPPC) base case model, developed by WECC staff with participation by a broad stakeholder group.

This report addresses the following questions:

- How much capacity is necessary to meet total balancing requirements for the NWPP for assuming 14.4 GW of wind energy?

- What are the cost-optimal technology options to meet the balancing requirements based on a lifecycle cost analysis considering value of emissions $\left(\mathrm{NO}_{\mathrm{x}}, \mathrm{SO}_{\mathrm{x}}, \mathrm{CO}_{2}\right)$ ?

- How cost effective is energy storage for a specific location in the BPA footprint for a specific size of energy storage? How sensitive are the results with respect to location and size?

- What are the key lessons learned from this study? 



\subsection{Technology Choices for Balancing Services}

\subsection{Introduction}

To mitigate the additional intermittency and fast ramps at higher penetration of intermittent energy resources (i.e., wind power in our case) in NWPP, the conventional solution is to build more peaking units such as combustion turbine units. However, the advancement of battery technology, smart grid concept coupled with demand response options, and the anticipated need for carbon reduction, places new emphasis on exploring non-conventional resources and a broader set of technology options for providing the ancillary services requirements that traditionally have been provided by fast-starting and flexible combustion turbines.

The following technologies are considered for this study:

- Combustion turbines, as the base-case technology

- Sodium sulphur (NaS) battery

- Li-ion battery

- Pumped-hydro energy storage

- Demand response

This following section provides a high level overview of the above technologies. A detailed discussion on the cost and performance characteristics of battery technology considered is provided in the Appendix A.

\subsection{Technology Overview}

\subsubsection{Combustion Turbine}

Combustion turbines, as applied in this study, are designed to provide an output of about $160 \mathrm{MW}$ while operating at an energy efficiency of $31.5 \%$. The efficiency is expressed in terms of a heat rate of 10,833 British Thermal Units per kilowatt-hour (Btu/kWh) at full load condition. It increases with lower part loads conditions (EIA 2008). In 2019, combustion turbine capital costs are estimated in the 2010 Annual Energy Outlook at $\$ 723$ per kW (EIA 2010). The economic life of the combustion turbines is estimated to be 15 years.

\subsubsection{Combined Cycle Plant}

Although the combined cycle plant is not directly applied as a technology option for providing balancing services, it provides the electric energy fed through the energy storage system. It is, thus, the energy provider on the margin that makes up for the energy losses in the storage device. The cost for fuel, operating and maintenance (O\&M), and emissions associated with the energy lost in storage are considered in the life-cycle cost analysis. 
The typical size of a combined cycle power plants is about 250 -300 MW. The design heat rate is commonly cited 7,196 Btu per kWh (EIA, 2008). The efficiency of a combined cycle power plant is generally higher than that of a combustion turbine. Typical design efficiencies are around $47 \%$. The economic life of the combined cycle power plants is estimated at 15 years. More detail regarding cost assumptions underlying both combustion turbines and combined cycle power plants is presented in Section 5. The capital costs associated with combined cycle power plants is not considered in this analysis because of the assumption that these units would already be on-line and available for use.

\subsubsection{Energy Storage Technologies}

The largest NaS battery system tested is a 34 MW battery system installed in Rokkasho village in Aomori, Japan( NGK Insulators, LTD), while the corresponding number for Li-ion system is $2 \mathrm{MW}$ (KEMA 2008). A 12-MW energy storage system is being installed by AES using Li-ion batteries supplied by A123 Systems (Parker 2010). Pumped hydro systems are available in the order of hundreds of MW and MWh.

Of the three energy storage technologies considered, pumped hydro energy storage is technologically most matured. The table below provides a perspective of the level of maturity based on installed capacity of grid-connected storage in the US and globally (Nourai 2009).

Table 3.1. Installed Capacity for Various Energy Storage Devices in the US and Worldwide

\begin{tabular}{lrc}
\hline & US (MW) & Global (MW) \\
\hline Pumped Hydro & 23,000 & 110,000 \\
Compressed Air & 110 & 477 \\
Batteries & 40 & 300 \\
Other & 5 & 10 \\
\hline
\end{tabular}

The table suggest that there is significant room for cost and performance improvements of the less matured technologies (compressed air and batteries), while pumped hydro technology, due its maturity, are not likely achieve cost reduction - at least on at the same rate as the nascent battery technologies.

\subsubsection{Sodium Sulphur (NaS) Battery}

The response time for both $\mathrm{NaS}$ and Li-ion battery systems is in the order of a few milliseconds (Divya and Østergaard 2009). This allows them to provide power instantaneously as demanded by the grid. While numbers as high as $90 \%$ have been used for battery efficiency, it is important to use appropriate efficiency values that correspond to power needs for various applications. It would also be useful to take into account battery degradation as a function of calendar and cycle life to incorporate losses in specific power/energy, power/energy density and efficiency losses as battery state of health degrades. For this analysis, a system efficiency of 78-80\% was used for both battery systems. This value also includes efficiency losses from the power conversion system (PCS).

$\mathrm{NaS}$ batteries currently commercially available are designed to discharge over periods as long as 7to10 hours (Kamibayashi et al. 2002, Nourai 2007). When these batteries are used for very small 
durations (in the order of seconds to minutes), the batteries can provide power as high as 5 times the rated power, where the rated power is defined as power for a 7-hour discharge (Kamibayashi et al. 2002). For

this study, peak power occurs for only 1 to 2 minutes, hence the required power rating of the battery that is needed could be as low as $1 / 5$ of the peak power. At present, NaS batteries are commercially available in an energy/rated power (E/P) ratio of 6-7. For this study, it has been assumed that in future, batteries with $\mathrm{E} / \mathrm{P}$ as low as 1 will be available to avoid over-sizing the batteries.

\subsubsection{Li-ion Battery}

Li-ion batteries are available from various sources, A 2-MW battery from AES, with the battery supplied by Altairnano, was tested under the direction of KEMA recently (KEMA 2008, Altair Nanotechnologies 2008). A battery management system monitored battery cell temperatures, balanced cell voltage and kept track of battery state of charge. Three single phase Parker Hannifin SSD power inverters were coupled to isolation transformers and fed into a step-up transformer with the battery side running at $480 \mathrm{~V}$ and the grid side at $13.8 \mathrm{kV}$. These voltage values are important, since capital cost of PCS depends on the minimum voltage at the battery side, as will be discussed later. These batteries performed well and dispatched power almost instantaneously. It remains to be seen how they would hold up over the long-term and what the impact would be of connecting several batteries in series/parallel configuration to provide the required output voltage and power.

\subsubsection{Pumped-Hydro Energy Storage}

Pumped-hydro (PH) energy storage technology has been used for various utility applications. One of its limitations is the need to wait prior to reversing direction from charge to discharge. Variable speed pumps/turbines allow better control of ramp rates, but cost more. A detailed discussion of PH is provided in the Appendix A.

The response time for pumped hydro systems is fast achieving high ramp rates of $3 \mathrm{MW} / \mathrm{s}$ ( First Hydro Company 2009). The calendar life was estimated to be 50 years (Schoenung 2001). There is however, a waiting period of several minutes every time the operating mode change. Through several consultations with turbine and pumped hydro storage system experts, it was determined that a delay of 4 minutes to switch operating modes in both directions (pumping to generation and vice versa) is applicable. This delay renders the machine inoperable. Thus, some additional resources must be assigned during that period as a 'back-up' resource. Chosen was a NaS battery to function as back-up resource.

\subsubsection{Pumped-Hydro Energy Storage Operating Design}

To meet the balancing requirements, two operating design options are investigated. The first option emulates the operation of a battery system that permits rapid changes between charging and discharging modes in accordance to the balancing requirements. Advancements in the turbine/pump design allows for frequent mode change between pumping (charging) and generating (discharging) modes. However, as noted above because of the significant hydrodynamic and mechanical inertia in the turbine, a delay of not insignificant duration is required. The estimated 4-minute delay is of sufficient significance for meeting the balancing requirements causing the backup resource to be sized quite large. 
The alternative and more commonly observed operation of pumped-hydro storage is a 2-mode operating schedule, whereby the machine is operated in a pumping mode during the off-peak hours and in a generating mode during the day. While in either of the modes, the machine can meet the balancing requirements. However, the pump/generator size must be upsized compared to 'multiple-mode-changes' mode because the balancing requirements must be met in both pumping and generating model individually. This requires a pump/generator size the covers the entire swing from full increment to full decrement. A very small NaS battery is applied as backup resource to meet the balancing requirements during the 2 mode change.

\subsubsection{Demand Response}

Demand response is an unused resource fully capable of providing balancing services. Similar to a generator that provides balancing services, a load customer who operate up and down from an original operating point create a balancing serve value. In fact, PJM allows large load customers to participate in the regulation services markets. Small loads such as residential and commercial customers can also deliver these services to the grid. The challenge is how to coordinate a large number of small devices to operate in a coordinated fashion such that they deliver value reliably at a sufficient scale.

Communications technology and smart grid control strategies will advance the access and, thus, the utilization of small residential and commercial end-use devices to deliver value to the grid.

For the purpose of this study, a short list of likely candidates of residential end-uses was selected for this particular demand response service. It was recognized that demand response in the balancing service context, would require end-use appliances to move their operating point according to the balancing signals. This requires the resource to be available 24-hours a day and 365 days a year and include device control technologies that enable these grid services (Lu and Hammerstrom 2006). Residential electric hot water heaters and plug-in hybrid electric vehicles (PHEVs) are selected as the two key candidates for this service, recognizing that other appliances may contribute as well at certain times. Residential hot water heaters have fairly established load profiles (Pratt 1989) and are one of the largest electricity consumers in residential homes. PHEV are not currently mass produced, and it will take some time for the PHEVs and other electric vehicles to gain market share to amount to a sizable load. However, significant efforts in standardizing the communication to the vehicles are underway to enable smart charging strategies. This would make electric vehicles a likely candidate for providing balancing services.

Currently in the entire NWPP footprint, there are 7.3 million housing units and the majority have an electric hot water heater. The number of light-duty vehicles (cars, sports utility vehicles (SUVs), van, pickup trucks) as of 2001 is about 11 million vehicles. The individual load profiles for a hot water and two charging profiles for one PHEVs are shown in Figure 3.1. 


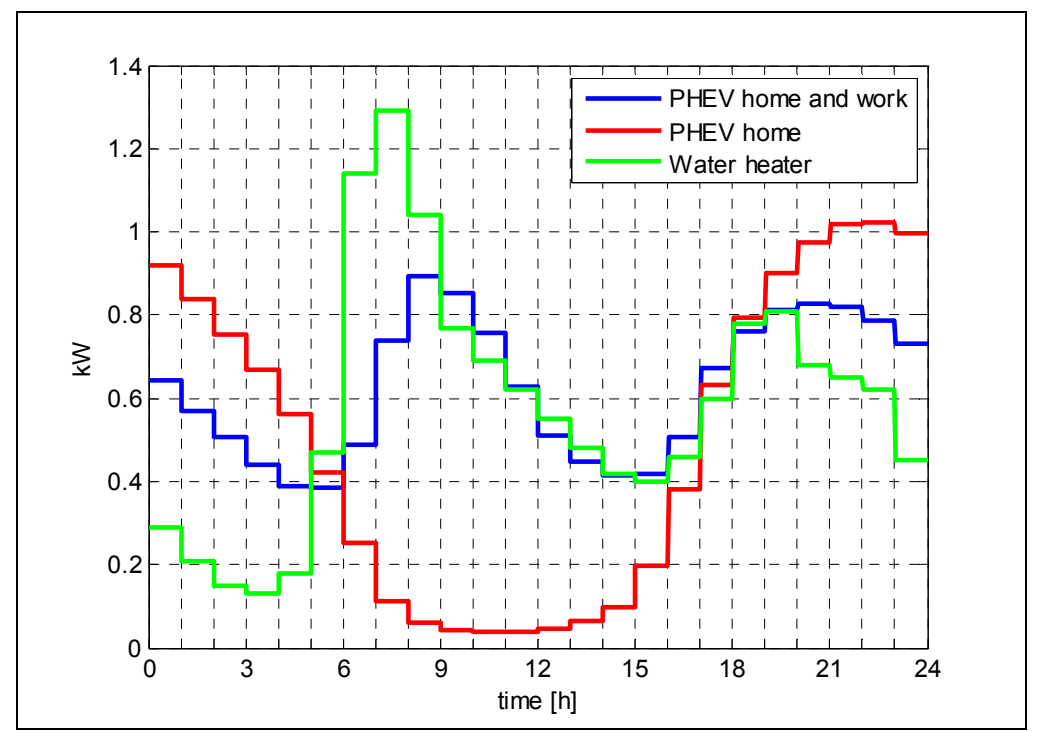

Figure 3.1. Load Curves for PHEV with Home and Work Charging, PHEV With Home Charging ${ }^{1}$, and Water Heater

\subsection{Technology Cost and Performance Characteristics}

\subsubsection{General Discussion}

Energy storage devices, unlike electric generators, have two capability ratings: 1) the power rating, expressed in $\mathrm{kW}$ or MW and the energy rating, expressed in $\mathrm{kWh}$ or MWh. This poses a challenge when comparing energy storage equipment with generators, which generally are not energy limited. To fully describe the incremental cost of an energy storage device, generally two specific cost indices must be used: cost per unit power $(\$ / \mathrm{kW})$ and cost per unit energy $(\$ / \mathrm{kWh})$. The literature is relatively inconsistent in this regard. Often battery devices are characterized by their incremental cost per unit energy ( $\$ / \mathrm{kWh})$ masking the cost associated with the balance of power (BOP) and PCS, which is scaled by the unit of power, or $\$ / \mathrm{kW}$. The costs for pumped hydro projects are most commonly specified in $\$ / \mathrm{kW}$, presuming that the cost associated with setting the energy content of the project is not scalable. In most cases, it is determined by the topology of a given location, which sets the size of the reservoir.

For the purpose of this report, a methodology of describing the incremental cost of energy storage devices was used that reveals both the cost that scales with the power rating $(\$ / \mathrm{kW})$, and the cost that scales with energy content of the device $(\$ / \mathrm{kWh})$.

To determine the capital costs, the energy storage device has to be sized based on the power and energy needs of the application. If the power needed is high compared to energy requirements for the application, the battery size is determined by the power; the selected battery clearly will have more energy than needed by the application. However, if the power requirement is much smaller than the energy needs, the battery size is determined by the energy needs of the application. The battery costs are typically given in $\$ / \mathrm{kWh}$, which can be converted to $\$ / \mathrm{kW}$, where the $\mathrm{kW}$ is rated power of the battery. Typically, rated power is continuous power, and is defined as power that can be sustained for at least 15

\footnotetext{
${ }^{1}$ Based on simulations using the USDOT 2001 National Household Travel Data (DOT 2003).
} 
minutes. Peak power typically is defined as pulse power for 2-second duration. The ratio of peak power/rated power is a function of battery chemistry and design.

\subsubsection{Summary of Capital, O\&M Costs and Efficiency for Batteries and Pumped Hydro Systems}

Based on the values obtained from an extensive literature review and through many consultations with domain experts, Table 3.2 summarizes the values used in this study, with 2019 values within parenthesis. More detailed cost and performance characteristics as well as ranges of cost as found in the literature are included in the Appendix A.

Table 3.2. Summary of Capital and O\&M Costs for Technologies Analyzed. Note values are representative for 2010 technologies. 2019 values are in parenthesis

\begin{tabular}{lcccccc}
\hline \multicolumn{1}{c}{ Parameter } & $\begin{array}{c}\text { NaS } \\
\text { battery }\end{array}$ & $\begin{array}{c}\text { Li-ion } \\
\text { battery }\end{array}$ & $\begin{array}{c}\text { Pumped } \\
\text { hydro }\end{array}$ & $\begin{array}{c}\text { Combustion } \\
\text { turbine }\end{array}$ & $\begin{array}{c}\text { Combined } \\
\text { cycle }\end{array}$ & $\begin{array}{c}\text { Demand } \\
\text { response }\end{array}$ \\
\hline Battery Capital cost $\$ / \mathrm{kWh}^{1}$ & $415(230)$ & $1000(510)$ & & & & \\
System Capital cost $\$ \mathrm{~kW}$ & & & $1750(1890)$ & $695(723)$ & Not used & 489 \\
PCS $(\$ / \mathrm{kW})$ & $200(150)$ & $200(150)$ & & & & \\
BOP $(\$ / \mathrm{kW})$ & 100 & 100 & & & & \\
O\&M fixed $\$ / \mathrm{kW}$-year & $0.46^{2}$ & 0.46 & 4.6 & 12.75 & & \\
O\&M fixed $\$ / \mathrm{kW}$-year $(\mathrm{PCS})$ & 2 & 2 & & & \\
O\&M variable cents/kWh & 0.7 & 0.7 & 0.4 & 0.376 & 0.217 \\
Round trip efficiency & 0.78 & 0.80 & 0.81 & 0.315 & & \\
\hline
\end{tabular}

\subsection{Definition of Technology Options}

The set of technologies mentioned above can be applied individually or in combination with other technologies. Technology 'packages' of up to three technologies are investigated. These technology packages can be thought of as a portfolio of resources that in most cases will be dispersed through the NWPP area. Only in the case of pumped hydro energy storage would a single location, or potentially a few locations be viable based on the topology to support upper and lower reservoirs. For most of technologies, the actual capacity will be widely disperse. This is particularly the case for demand response. Table 3.3 shows the 11 single technology packages, which we will call 'cases'.

\footnotetext{
${ }^{1}$ The battery capital cost is per unit energy, while PCS and BOP costs are per unit power

${ }^{2} \$ / k W h$
} 
Table 3.3. Definition of Technology Cases

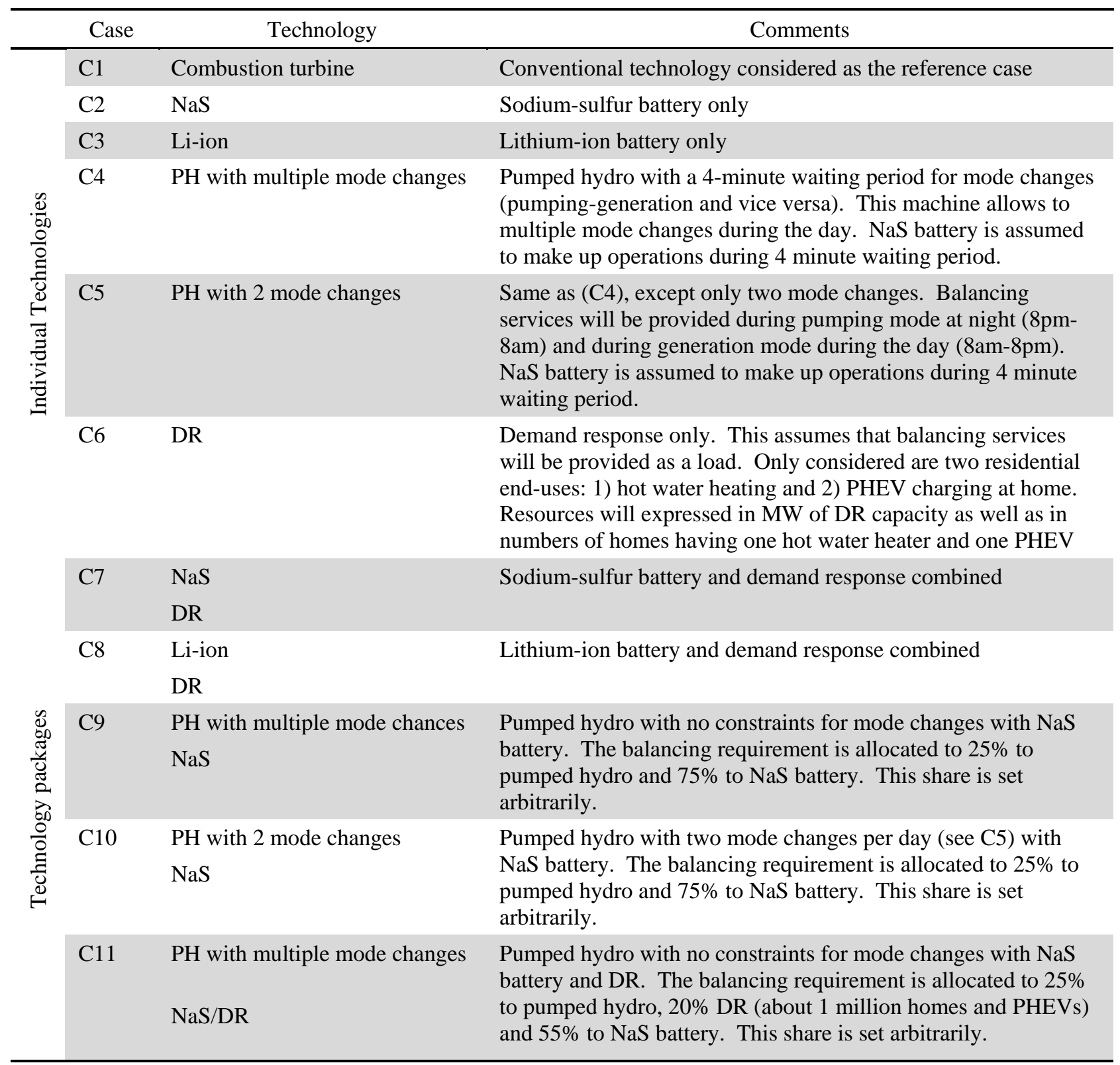





\subsection{Balancing Requirements}

\subsection{Overview of Analysis Framework}

PNNL developed a stochastic analysis framework to estimate the balancing requirements associated with forecasting errors for both load and for generation from intermittent energy resources. This analysis framework includes tools for estimating balancing requirements expressed in terms of maximum power required and maximum energy required (if energy storage is chosen) to meet the requirements. It provides a set of sizing tools to dispatch one or several resources to meet the balancing requirements. The resources can be energy limited, such as energy storage devices, commonly used generator or demand response strategies. Several different dispatch strategies have been developed to dispatch an ensemble of several storage devices or bundled resources comprised of demand response, energy storage systems, and generators. The output of this tool are size requirements of all resources, as well as dispatch profile by resource, fuel requirements, and emissions. The size requirements are expressed as a pairing of power and energy capacities necessary to meet the balancing requirements. As part of the analytics suite, a lifecycle cost optimizer was developed that compares different hybrid energy storage system options based on a life-cycle cost to seek the lowest cost technology option.

\subsection{Approach and Data Used to Determine Balancing Requirements}

The fundamental approach of the PNNL methodology is outlined below. A full description of the methodology can be found in (Makarov et al. 2010). The approach uses historic load data and understanding of how the load forecasting errors are statistically distributed. In addition, wind profile data are necessary both from existing wind farms and new hypothetical wind resources that are presumed to be developed in the foreseeable future. The analytical approach includes the following components and individual steps:

1. Determine a future renewable portfolio standard (RPS) scenario and determine the necessary intermittent resource requirements to approximately meet the standards. Selection of wind resources for meeting the RPS standards.

2. Placement of resources: Place hypothetical wind farms at plausible wind sites that have high capacity factors.

3. Scale existing wind and load forecasting errors from BPA's existing wind sites to new hypothetical wind sites to obtain new balancing requirement components from intermittency of the wind resource. Combine load forecasting error from BPA with that of the NWPP load.

4. Develop a stochastic process that generates a minute-by-minute balancing requirement for the entire NWPP footprint. This assumes a consolidation of all of the existing balancing authorities into one unified balancing area. Furthermore, the output will be the total balancing requirements, derived from total loads and the entire wind capacity.

5. Define a set of technology options that will meet the total balancing requirements.

6. Analyze the life-cycle cost of technology options over a 50-year time horizon. 


\subsubsection{Wind Datasets}

As a starting point, BPA's existing wind production data (with a 1-minute time scale) was used within the BPA footprint. For the wind capacity additions (both within BPA service territory and outside), the National Renewable Energy Laboratory (NREL) Wind Integration Datasets (NREL 2009) were utilized, which provided 10-minute interval production schedules for over 30,000 hypothetical wind sites. The projection of BPA's wind capacity addition as seen in Figure 4.1, guided the approach to allocate sufficient new wind resources into the BPA service territory.

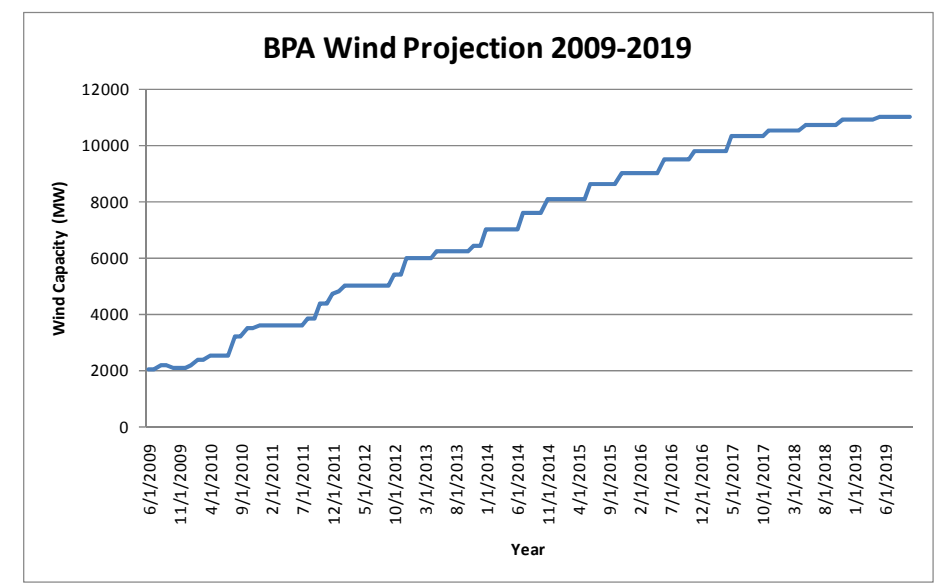

Figure 4.1. BPA Wind Projection 2009-2019

The Wind Integration Datasets from NREL are wind production simulated for 32,043 wind sites in the WECC system with 10-minute intervals. The information of the datasets is briefly shown in Table 4.1.

A 20\% wind penetration scenario is hypothesized. In other words, the installed capacity of wind generation will reach 14.4 GW in NWPP by 2019. The placement of the new wind capacity is done by considering both the best wind resource and proximity to load or transmission lines. The selection of wind sites is done with some degree of arbitrariness. Even when selecting only the best wind class (6 and 7) land areas in proximity to transmission above $230 \mathrm{kV}$, the supply of available wind resource was significantly larger than what was needed for the $14.4 \mathrm{GW}$ addition. Figure 4.2 shows the selected wind capacity distribution by state. The average capacity factor (CF) of the new wind sites is around 35\%. Figure 4.3 illustrates all the planned wind sites and currently existing wind sites in NWPP.

Table 4.1. Information About NREL Wind Integration Datasets

\begin{tabular}{ll}
\hline & Western Dataset \\
\hline Produced by & 3 Tier \\
Mesoscale Model & WRF \\
Number of Output Points & 32,043 \\
Size of Output Point & 1 arc-minute \\
Output Point Capacity (MW) & 30 \\
Model Output Heights (m agl) & $100 \mathrm{~m}$ \\
Turbine Power Curves & Vestas V-90 3MW \\
\hline
\end{tabular}




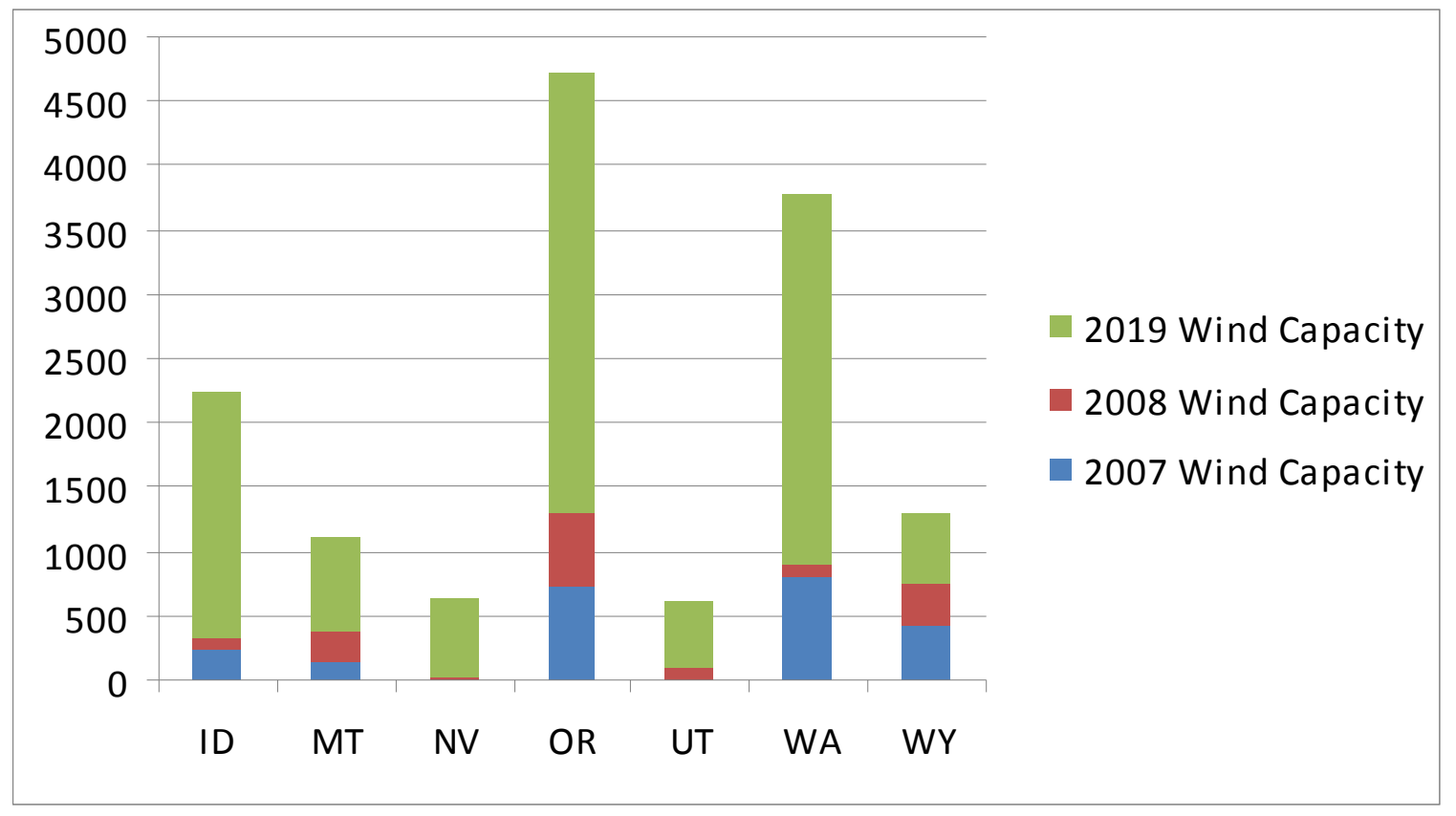

Figure 4.2. Distribution of Wind Capacity by States

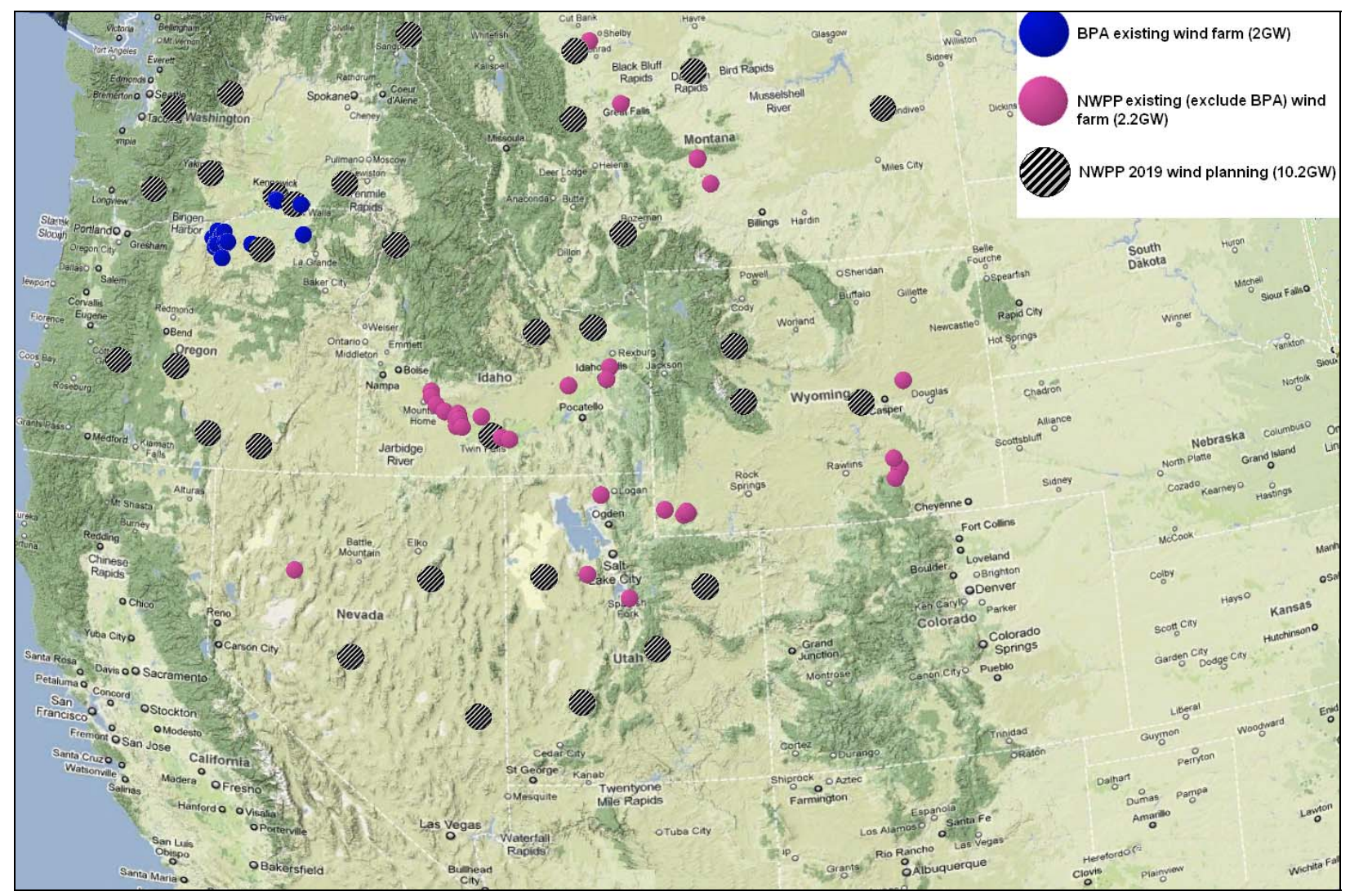

Figure 4.3. Location of Existing and Arbitrarily Sited Future Wind Plants. Total NWPP Capacity Assumed to be 14.4 GW in 2019 
To obtain the balancing requirements, minute-by-minute wind production data are desirable. However, for the hypothetical wind sites, only 10-minute interval datasets are available. Therefore, the 10-minute interval data are interpolated to generate the required minute by minute data. The implication of the interpolation is that we underestimate the balancing requirements for fluctuations with a period of less than 10 minutes (or $1 / 600 \mathrm{~Hz}$ ). Wind hourly forecast is obtained by averaging wind production of every hour and superimposing BPA wind forecast error on the hourly average. Wind production in 2019 of each wind plant is assumed the same as that of today, and the statistical characteristics of the wind forecast error match the truncated normal distribution (parameters of the distribution such as mean, standard deviation, and autocorrelation are consistent with the statistical features of the BPA wind forecast). The statistical information of BPA hour-ahead wind forecast error is shown in Table 4.2.

\subsubsection{Load Datasets}

The minute-by-minute actual load data and hour-ahead load forecast for the BPA service territory are obtained from BPA. In this analysis, we assume the hourly generation schedule is the same as the hourahead load forecast. BPA's annual load growth projections throughout the period to 2019 is used, which is assumed to be about $1.19 \%$ annual growth. No modifications of the current load shape were assumed. For the remaining balancing authorities within the NWPP, hourly load data from Ventyx PowerBase ${ }^{\circledR}$ are utilized with similar annual load growth assumptions as used for the BPA footprint.

Hourly data are interpolated to generate minute-by-minute actual load data. For the whole NWPP, the hourly load forecast is generated by adding load forecast error to the hourly average of load. The load forecast error is assumed to have a truncated normal distribution with the same statistical characteristics as BPA current load forecast. Table 4.2 shows the statistics for both the load and wind production forecast errors.

Table 4.2. Statistics of Hour-Ahead Forecast Error

\begin{tabular}{lcc}
\hline & $\begin{array}{c}\text { Wind } \\
\text { Forecast }\end{array}$ & $\begin{array}{c}\text { Load } \\
\text { Forecast }\end{array}$ \\
\hline Mean error & $0 \%$ & $0 \%$ \\
Standard deviation & $7 \%$ & $2 \%$ \\
Auto correlation & 0.6 & 0.9 \\
\hline
\end{tabular}

\subsubsection{Balancing Service Requirement}

The power system control objective is to minimize its area control error (ACE) to the extent that complies with the North American Electric Reliability Corporation (NERC) Control Performance Standards. Therefore, the "ideal” regulation/load following signal is the signal that minimizes deviations of ACE from zero when they exceed a certain thresholds:

$$
\begin{aligned}
& -A C E=-\left(I_{a}-I_{s}\right)+\underbrace{10 B\left(F_{a}-F_{s}\right)}_{\text {Neglected }} \\
& \approx G_{a}-L_{a} \rightarrow \min
\end{aligned}
$$


where the $a$ subscript denotes actual, $s$ denotes schedule, $G_{a}$ is the actual generation, and $L_{a}$ is the actual load within the control area. Extending the generation component in the ACE equation,

$$
G_{a}=G_{s}+G_{I B}
$$

is obtained where the subscript s denotes hour-ahead schedule, and $I B$ denotes the generation required to meet intra-hour balancing requirement. The generator output is assume to not deviate from its schedule. That is,

$$
G_{s}=L_{f_{-} h a}
$$

where $f_{\text {_ }}$ ha denotes hour-ahead forecast, and set $A C E$ to zero. The intra-hour balancing signal can be calculated by equation below.

$$
G_{I B}=L_{a}-L_{f_{-} h a}
$$

When wind generation is included, wind is counted as negative load. Therefore,

$$
G_{I B}=L_{a}-L_{f_{-} h a}-\left(G_{a}^{w}-G_{f_{-} h a}^{w}\right)
$$

Figure 4.4 illustrates the concept of over- and under-generation as a result of the forecasting errors for both the load and the wind energy production. The over-and under-generation is then the balancing signal, which balances generation and load and minimizes the ACE.

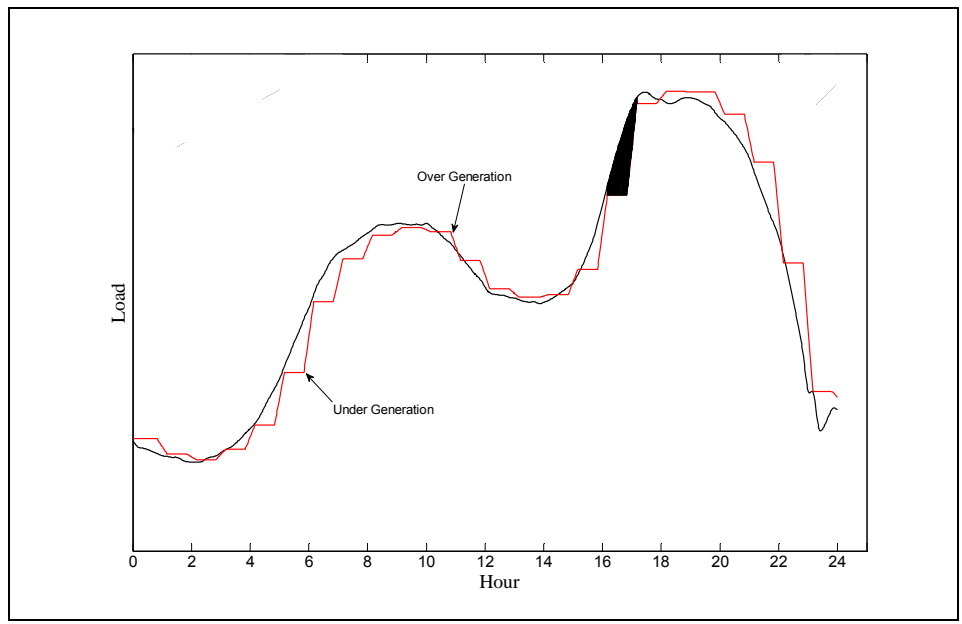

Figure 4.4. Illustration of Intra-Hour Balancing Signal

\subsubsection{Consolidation of Balancing Areas}

To simplify the analysis, one single consolidated balancing authority (BA) comprised of all individual balancing authorities in the NWPP is assumed. This simplification reduce the analysis complexity significantly. Instead of performing a BA-by-BA analysis and combining the results for the NWPP, the consolidation collapsed the complexity into a single zone. There are implications to this simplification. 
The consolidation of balancing authorities will provide greater sharing of balancing and reserve resources among all constituents and offer opportunities to more effectively utilize the higher degrees of diversity of the intermittent renewable energy resources across the entire NWPP footprint. As a consequence, the balancing requirements are likely to be smaller in a consolidated large BA area than the sum of all individual BA areas as they currently exist. This will lead to an underestimation of the future requirements under the existing $\mathrm{BA}$ regime.

\subsubsection{Resulting Total Balancing Signal}

The total balancing requirements of the NWPP are estimated utilizing the wind and load datasets as discussed above. Figure 4.5 and Figure 4.6 illustrate the resulting balancing requirements signal for the NWPP for the whole month of August 2019 and one typical day in August 2019, respectively. These estimated values represent the total requirements, as opposed to additional requirements. The balancingup (in BPA parlance: increment or inc.) power capacity requirement is $3916 \mathrm{MW}$ and the balancing-down (in BPA parlance: decrement or dec.) power capacity is -3683 MW. These figures are based on BPA's customary $99.5 \%$ probability bound that meets $99.5 \%$ of all balancing requirements. That means that $0.5 \%$ of all of the anticipated balancing capacity exceeds that bound. For a $100 \%$ probability bound, the maximal balancing requirements are about $5000 \mathrm{MW}$ in for the increments and about $-4000 \mathrm{MW}$ for the decrement.

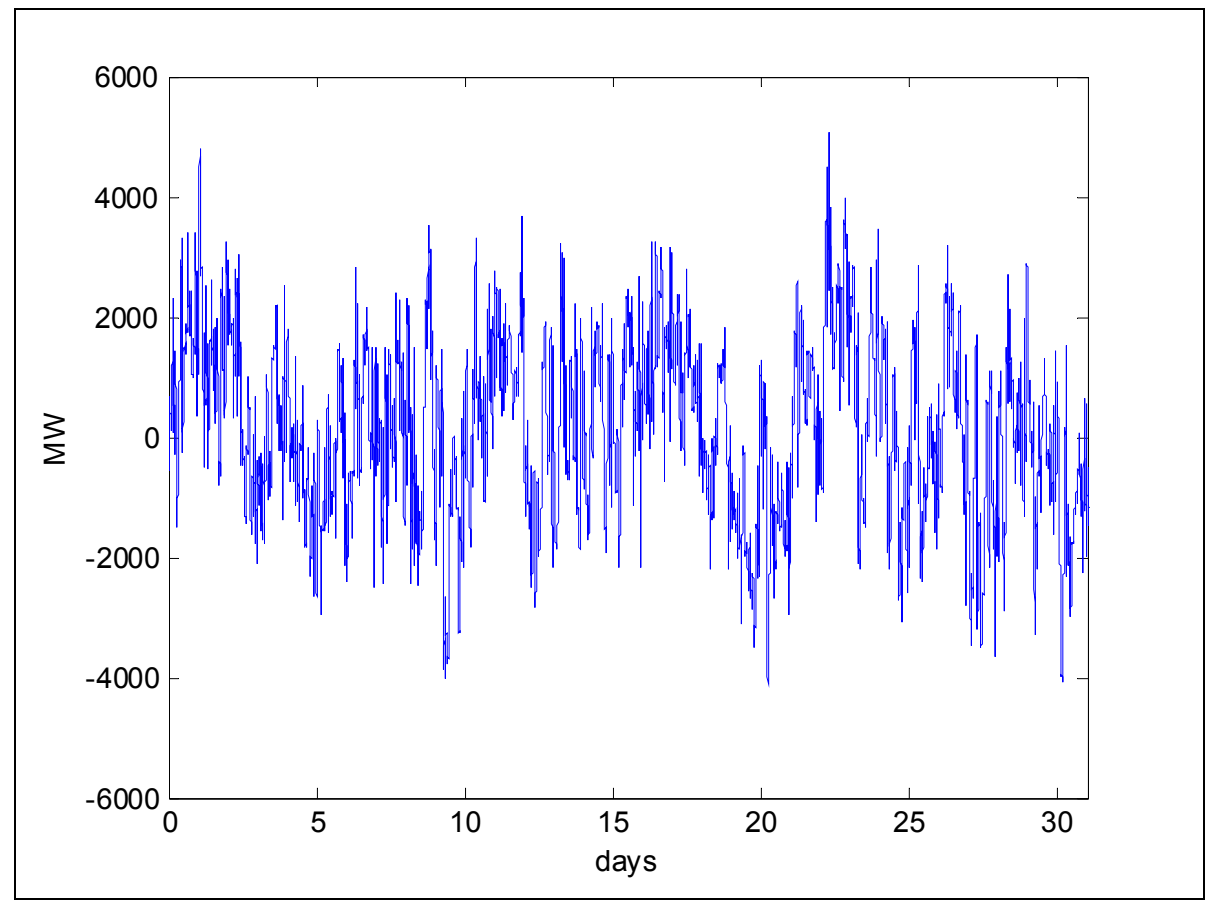

Figure 4.5. Total Balancing Requirements for NWPP for the Month of August 2020 


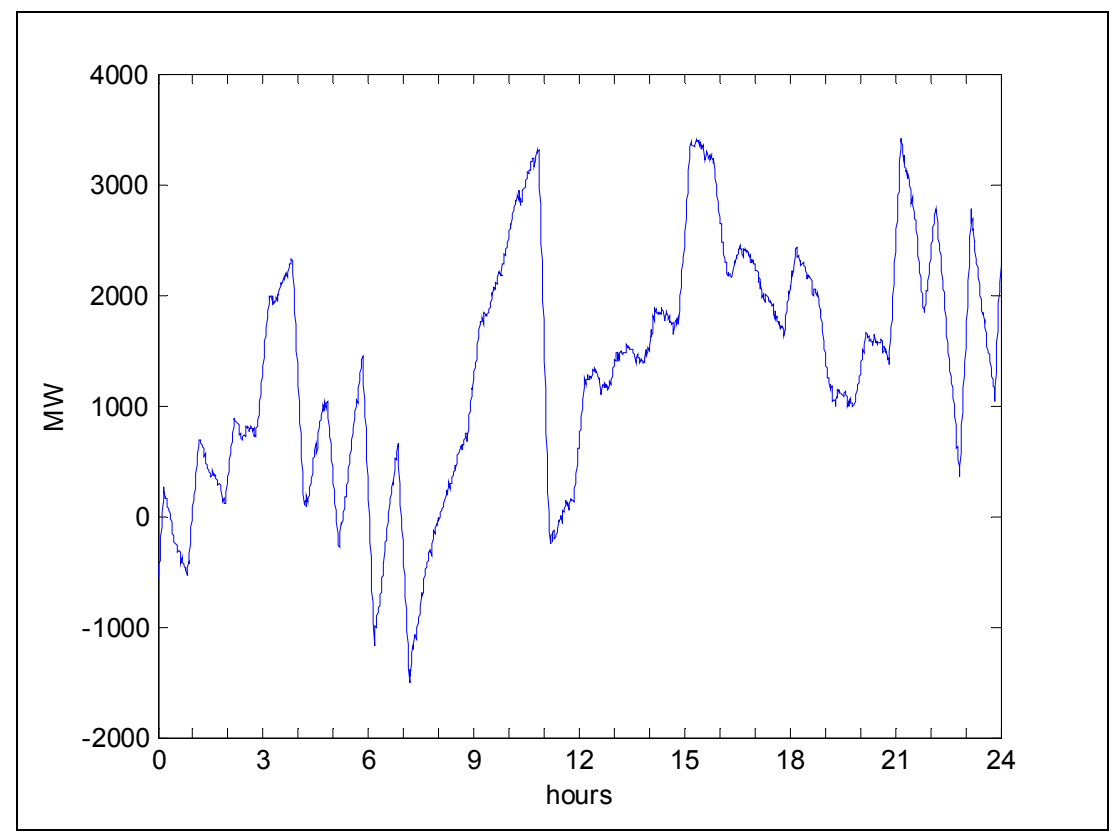

Figure 4.6. Total Balancing Requirements for NWPP for One Typical Day in August 2020

The balancing signal shown in Figure 4.6 exhibits a spectrum of cycling or oscillatory content. Cycles at lower frequencies with periods of several hours (intra-day) are considered to be addressed by the energy markets that re-dispatch generators on an hourly basis. The deviations from the day-ahead schedule generally do not require fast ramp rates and, thus, are not considered part of the balancing requirements in this study. Cycles within the hour (intra-hour balancing) are a key focus of this analysis. The following section discusses the filtering strategies to the extract the intra-hour cycling from the original balancing signal.

\subsubsection{Spectral Analysis and Extraction of Intra-Hour Balancing Signal}

A high-pass filter was designed to filter out the fast cycles (intra-hour and real-time components) from the original balancing signal (Makarov et al. 2010). The cut-off frequencies for the filter were $f_{l}=1.157 \mathrm{e}-5 \mathrm{~Hz}$ and $f_{u}=0.2 \mathrm{~Hz}$. The spectral analysis of the balancing signal illustrates the oscillatory content in the signal. The results of the spectral analysis are shown conceptually in Figure 4.7 and Figure 4.8. Table 4.3displays the frequency limits for the high-pass filter design. 


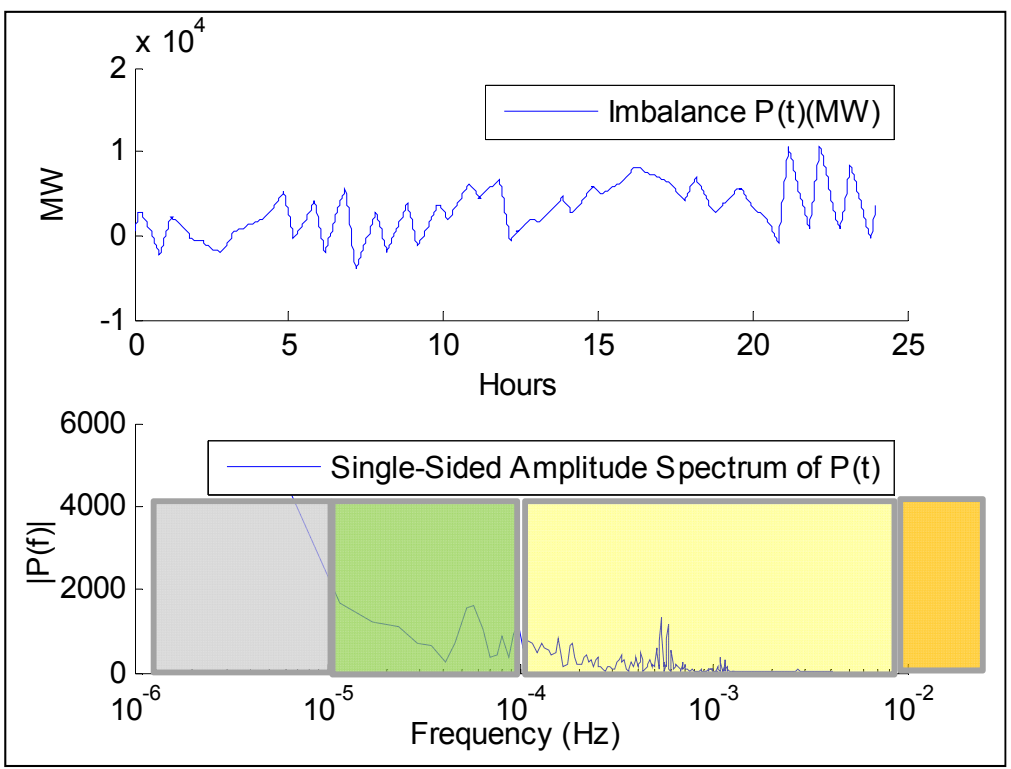

Figure 4.7. Spectral Analysis of Balancing Signal

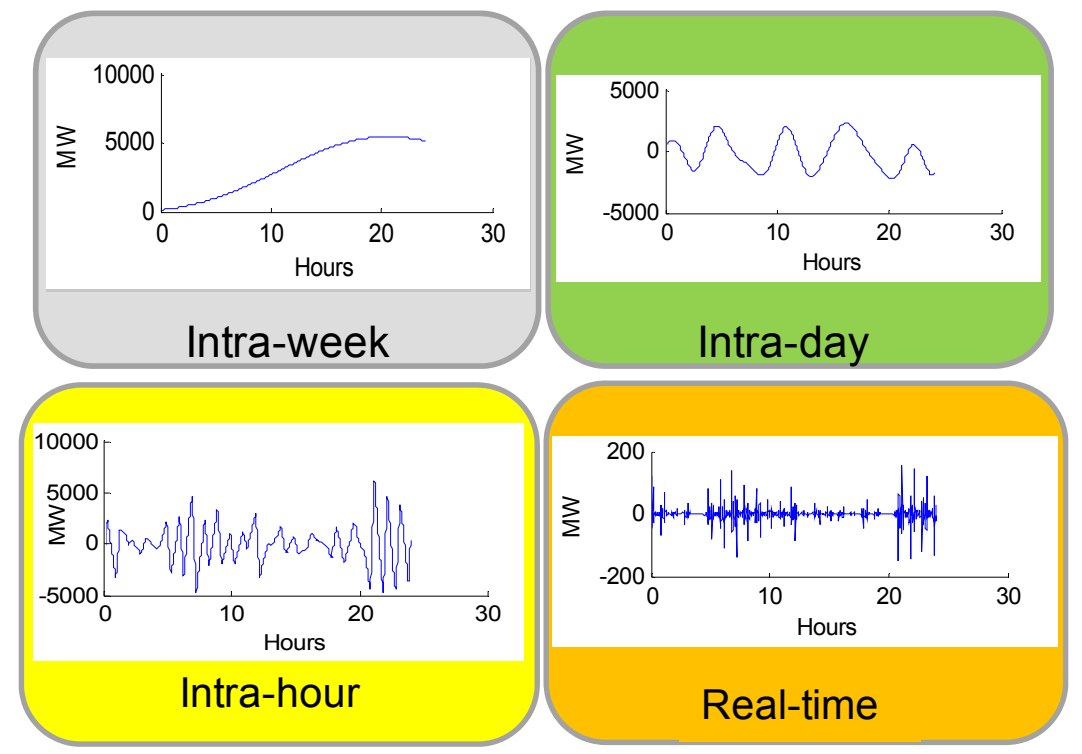

Figure 4.8. Components of Decomposed Balancing Signal

Table 4.3. Frequency Limits of Components of the Balancing Signal

\begin{tabular}{|c|c|c|c|c|c|}
\hline No. & Component & $f_{l}(\mathrm{~Hz})$ & $f_{u}(\mathrm{~Hz})$ & Period of $f_{l}$ & Period of $f_{u}$ \\
\hline 1 & Intra-week & 0 & $1.157 \mathrm{e}-05$ & Inf & 24 hours \\
\hline 2 & Intra-day & 1.157e-05 & $1.388 \mathrm{e}-04$ & 24 hours & 2 hours \\
\hline 3 & Intra-hour & 1.388e-04 & 0.0083 & 2 hours & 2 minutes \\
\hline 4 & Real-time & 0.0083 & 0.2 & 2 minutes & 5 seconds \\
\hline
\end{tabular}




\subsubsection{Capacity Requirements for Meeting 2019 Balancing Needs}

Extensive systems model were performed to estimate the power and energy capacity requirements to meet the future balancing needs. Each technology and technology group required careful simulation that incorporated the specific technical features of a technology, as well as the interaction with each other if more than one technology was modeled. The results of the simulations were a pairing of power (GW) capacity, and energy (GWh) capacity requirements to meet future balancing needs. A detailed discussion of how the technologies were dispatched individually or within an ensemble of other technologies, can be found in the Appendix B.

Table 4.4 and Figure 4.9show the results of energy and power requirements for all the scenarios in this study. It should be noted that the capacity requirements or the minimal size of the battery is based on $100 \%$ DOD of the battery. This means that the size of the energy storage is fully utilized. The storage will be cycled from fully charged to fully discharged. As will be discussed, there are good economic reasons for upsizing the battery to a DOD of less than $100 \%$ to improve the life of the battery. For instance, a battery with a DOD of 50\% only uses its energy storage capability to $50 \%$. Significant simulation efforts were performed to determine the minimal capacity (power and energy rating) for the various technology options. The key driver that set the size of the technology was specific operational constraints that force the technology to be operated in a certain way, for instance, the limited change modes and the change over delay of the pumped-hydro technology.

Table 4.4. Power and Energy Requirements for Each Scenario. Note: the energy capacity (GWh) for the batteries is nominated at a depth of discharge of $100 \%$.

\begin{tabular}{|c|c|c|c|}
\hline Cases & Technology & GW & GWh \\
\hline C1 & CT & 1.85 & - \\
\hline $\mathrm{C} 2$ & $\mathrm{NaS}$ & 1.85 & 0.91 \\
\hline C3 & Li-ion & 1.85 & 0.90 \\
\hline \multirow{2}{*}{$\mathrm{C} 4$} & PH with multiple mode changes & 1.85 & 0.83 \\
\hline & Backup NaS battery to cover 4 minute delay during mode change & 1.21 & 0.17 \\
\hline \multirow{2}{*}{ C5 } & PH with 2 mode changes & 3.61 & 21.72 \\
\hline & Backup NaS battery to cover 4 minute delay during mode change & 0.82 & 0.05 \\
\hline C6 & DR & 8.64 & - \\
\hline \multirow{2}{*}{ C7 } & $\mathrm{NaS}$ & 1.49 & 0.73 \\
\hline & DR & 1.72 & - \\
\hline \multirow{2}{*}{ C8 } & Li-ion & 1.49 & 0.72 \\
\hline & $\mathrm{DR}$ & 1.72 & - \\
\hline \multirow{2}{*}{ C9 } & PH with multiple mode changes & 0.5 & 0.22 \\
\hline & $\mathrm{NaS}$ & 1.35 & 0.69 \\
\hline \multirow{2}{*}{$\mathrm{C} 10$} & PH with 2 mode changes & 0.97 & 5.87 \\
\hline & $\mathrm{NaS}$ & 1.35 & 0.67 \\
\hline \multirow{3}{*}{ C11 } & PH with multiple mode changes & 0.5 & 0.22 \\
\hline & DR & 1.72 & - \\
\hline & $\mathrm{NaS}$ & 0.98 & 0.50 \\
\hline
\end{tabular}




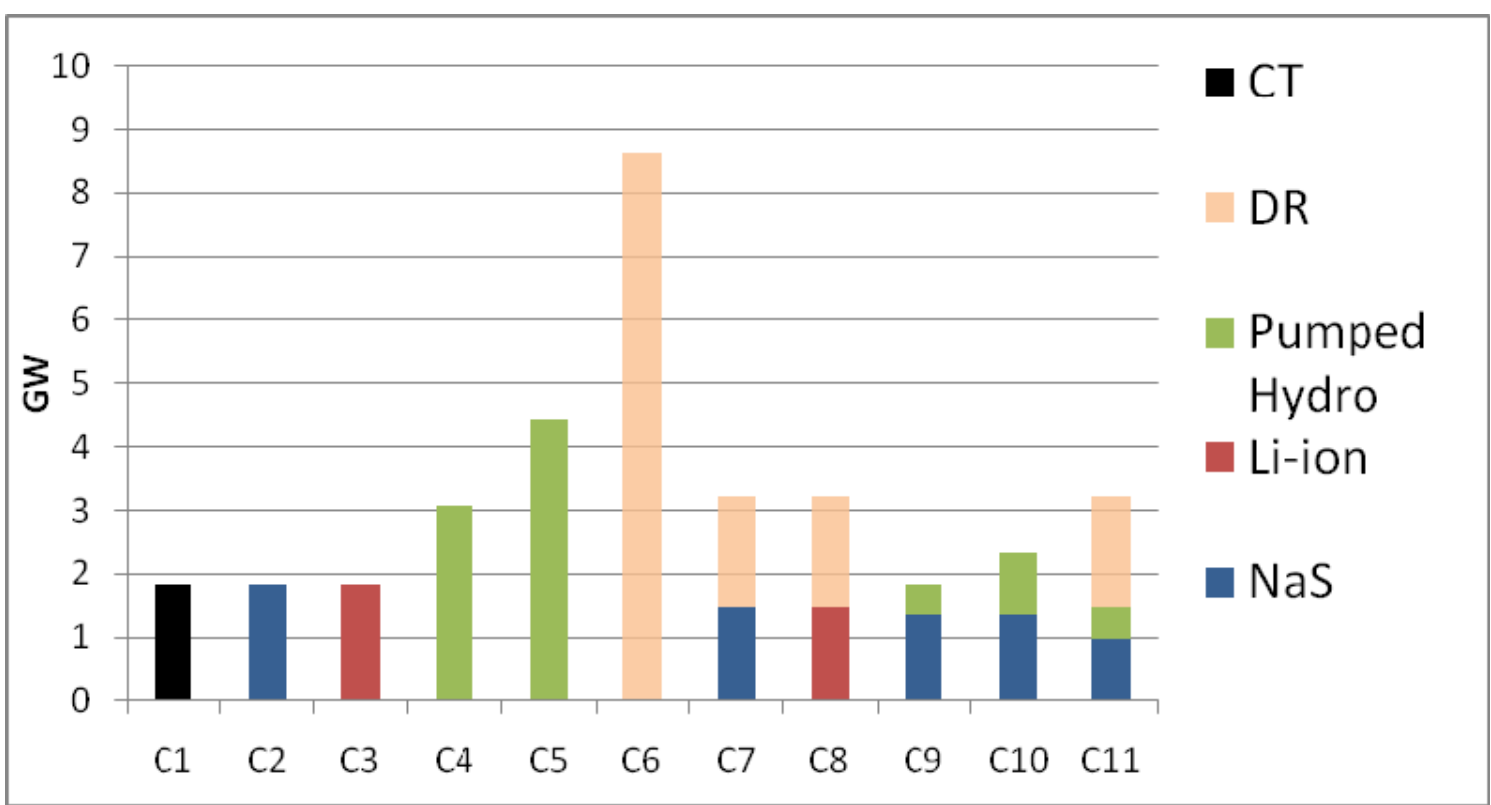

Figure 4.9. Power Requirements for all the Technologies to Meet Balancing Signal

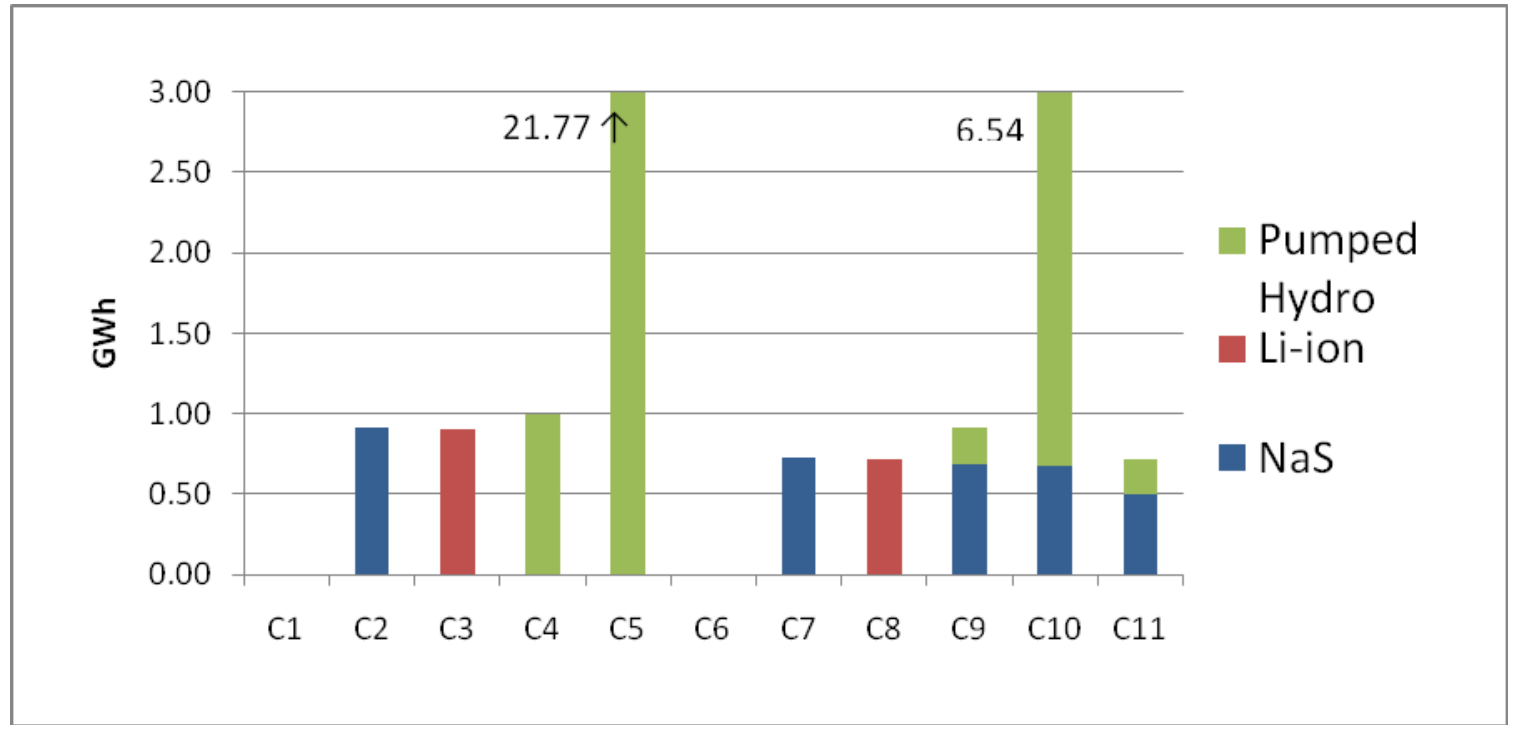

Figure 4.10. Energy Requirements for Storage Technologies to Meet Balancing Signal

The size for the combustion turbine is set by the requirements for generation increment, not the sum of increment and decrement. This is based on the notion that the existing combustion turbine capacity is operating at the zero balancing point already and would be able to provide generation decrements. 


\subsection{Economic Analysis Methodology and Results}

\subsection{Cost Analysis Framework}

The cost model used to support this analysis has the capacity to examine all initial and recurrent costs, property and income taxes, depreciation, borrowing costs, and insurance premiums. The cost model expresses cost in terms of constant 2010 dollars, treats interest and inflation in a systematic manner, and distinguishes between costs that occur annually and those that occur in a single year. The cost model generates total cost estimates required to meet the balancing requirements in the BPA region, with total costs expressed in a lump-sum present value manner.

Based on input provided by BPA analysts, much of the cost elements typically considered in utility financial analysis (e.g., property and income taxes, depreciation, borrowing costs, and insurance premiums) were excluded from this analysis. Thus, this analysis considers the annual costs associated with initial and recurrent capital costs, fixed and variable operations and maintenance costs, fuel costs, and emissions costs.

These annual costs were, in turn, collapsed into a single present value cost using a real discount rate of $10.3 \%$. This discount rate was computed by subtracting a $1.7 \%$ inflation assumption from a $12 \%$ nominal discount rate.

\subsection{Economic Parameters}

The cost analytical framework outlined in the previous section and the cost model supporting this research rely on a number of assumptions regarding major cost elements, including capital costs, operations and maintenance (O\&M) costs, fuel costs, and emissions costs. Costs are segmented according to each of these four cost categories within each of the cases considered in the results section of this report. The remainder of this section details the assumptions underlying each cost component.

\subsubsection{Capital Costs}

Section 3 presents capital cost estimates for each technology, and documents the basis for each estimate. Based on the economic lives of each technology, interim capital costs are incurred as necessary to provide required service over the 50-year analysis time horizon. For each option, results are examined using forecast 2019 prices, as outlined in Section 3. In all cases, with the exception of sensitivity analyses presented in Section 5.3, present value costs of investments made in future years are discounted at a real rate of $10.3 \%$ and are expressed in 2010 constant dollars.

In addition to the capital costs outlined in Section 3, one case considers the capital costs of combustion turbines and several cases include capital costs associated with demand response. Note that the costs of implementing DR are assumed to be $\$ 50.70$ per $\mathrm{kW}$ per year (EPRI 2009). Over 50 years, the present value of DR capital costs is $\$ 489$ per $\mathrm{kW}$, discounted at $10.3 \%$. Combustion turbine capital costs are estimated at $\$ 723$ per $\mathrm{kW}$ based on the latest estimates presented in the 2010 Annual Energy Outlook (EIA 2010). Note that combined cycle capital costs are not included in this analysis, because those costs are assumed to be sunk within the existing system. Thus, no additional investments in combined cycle 
plants are required to meet the requirements of the examined cases. The costs of operating those combined cycle plants are included in the cost estimates presented for each case.

\subsubsection{Operations and Maintenance Costs}

For combustion and combined cycle turbines, O\&M costs are expressed in variable terms based on data presented in the 2009 Annual Energy Outlook. For combustion turbines, fixed O\&M costs are $\$ 12.75$ per kW and variable O\&M costs are \$3.76 per MWh. Combined cycle O\&M costs are estimated at \$13.79 per kW and \$2.17 per MWh for fixed and variable, respectively (EIA 2010).

For batteries technologies, O\&M costs were also split into fixed and variable components. The fixed component is incurred every year regardless of the energy requirement, while the variable component is proportional to electrical energy (kWh) discharged through the energy storage system. Fixed O\&M costs are estimated at $\$ 0.50$ per $\mathrm{kWh}$ of energy storage capacity while variable O\&M costs are estimated at $\$ 0.007$ per kWh for all battery types. These costs are detailed in Section 3.3.2. In addition to these costs, power conversion system (PCS) O\&M costs are included and estimated at \$2 per kW of installed capacity.

Pumped hydro O\&M costs are expressed in terms of fixed and variable components as well. Fixed O\&M costs are estimated at $\$ 4.60$ per $\mathrm{kW}$ of installed capacity, while variable O\&M costs are estimated at $\$ 0.004 \mathrm{kWh}$ through the pumped hydro station.

\subsubsection{Fuel Costs}

Fuel costs for each alternative were developed using average daily energy requirements as measured in million Btu (MMBtu). These energy requirements were generated based on the combustion and combined cycle turbine production schedules designed to meet load balancing requirements for the BPA region in 2019.

In each scenario, fuel costs associated with combustion turbine alternatives are higher than those estimated for each of the combined cycle turbine, pumped hydro, or battery alternatives. Fuel cost differentials are caused by varying heat rates. The energy requirements of the combined cycle plus battery alternatives were calculated as the product of the efficiency levels associated with each component.

Average monthly energy requirements were expanded to annual energy requirements, which were in turn multiplied by natural gas prices ( $\$ 9.34$ per MMBtu) to compute annual fuel costs for each alternative. The fuel price used in this analysis represents the average real price forecast for the 2010 to 2040 time horizon. ${ }^{1}$ Unlike for the CT scenario, the fuel component of the storage alternatives represents the electric energy lost during a full round-trip charge/discharge cycle. The energy is assumed to be provided by a combined cycle power plant operating at the margin. The combustion turbine requires fuel to meet the balancing requirements.

\footnotetext{
${ }^{1}$ Natural gas prices from 2010 to 2030 are based on EIA (2010). Prices were extended from 2030 to 2039 using the average annual growth rate reflected in the EIA 2009 forecasts.
} 


\subsubsection{Emissions Costs}

Fuel combustion levels assigned through the approach described previously were used to establish emissions levels through the application of U.S. Environmental Protection Agency (EPA) coefficients for converting quadrillion Btus into metric tons, as outlined in Table 5.1 (EPA 1995). These emissions levels were, in turn, used to construct emissions cost estimates.

Prices for emissions allowances for $\mathrm{NOx}, \mathrm{SO}_{2}$, and $\mathrm{CO}_{2}$ are presented in Table 5.1. $\mathrm{NO}_{\mathrm{x}}$ prices were obtained from the July 2009 NO$_{\mathrm{x}}$ Market Monthly Market Update (annual NOx allowances) published by Evolution Markets (Evolution Markets 2009). $\mathrm{SO}_{2}$ prices were also obtained through Evolution Markets in the June $\mathrm{SO}_{2}$ Monthly Market Update. Prices for $\mathrm{CO}_{2}$ allowances ( $\$ 45$ per ton) were derived from the Sixth Northwest Power Plan (Northwest Power and Conservation Council 2010).

Table 5.1. Emissions Cost Data

\begin{tabular}{ccccc}
\hline Emissions Data & & $\mathrm{SO}_{2}$ & $\mathrm{NOx}$ & $\mathrm{CO}_{2}$ \\
\hline Allowances & \$/metric ton & $\$ 71.75$ & $\$ 600$ & $\$ 45$ \\
EPA Coefficients & Metric tons / quadrillion Btu & 267 & 978 & $53,060,000$ \\
\hline
\end{tabular}

\subsection{Optimizing Battery Capacity}

An important in minimizing the costs associated with each alternative involving energy storage is optimizing the battery capacity. In effect, one could size up the energy storage capacity to reduce the depth of discharge during each cycle and increase the life of the battery systems, as demonstrated in Table 5.2.

The minimum battery SOC, SOC-min, was set to various levels in the 5 to $95 \%$ range during battery operation to do tradeoff between life time and battery size. The effective DOD for the battery is then defined as 1-SOC_min. Clearly, as effective DOD decreases, a larger battery size is needed. This decreases the DOD for each cycle during the intra-hour balancing, thereby increasing the cycle life of the battery.

While increasing the battery capacity drives up initial capital costs, it also reduces the depth of discharge requirements, thus extending the cycle life of the batteries and reducing interim capital costs. It is important to note that the life cycle calculations presented in Table 5.2 do not account for the natural rate of decline associated with material components of a battery occurring regardless of the energy storage requirements. To address this component, the maximum life for Li-ion batteries was constrained to 10 years, while the maximum life cycle for $\mathrm{NaS}$ batteries was constrained to 13 years.

For each case considered in this analysis, the research team prepared a table similar to Table 5.2 comparing the effective depth of discharge as defined above, battery capacity, and life cycle. Table 5.2 presents the data computed for Case 2 - NaS plus combined cycle.

While essential, the data in Table 5.2 are not sufficient to determine the optimum battery capacity required to minimize costs. Though increasing the effective depth of discharge (or reducing SOC_min) 
reduces the initial capital costs associated with investments in energy storage options, the cycle life falls significantly, thus requiring numerous interim capital investments in future years.

Table 5.2. Relationship between Effective Depth of Discharge, Battery Capacity, and Lifecycle - Case 2

\begin{tabular}{ccc}
\hline Effective DOD & Battery Capacity $(\mathrm{kWh})$ & Life Cycle(Years) \\
\hline $5.0 \%$ & $21,001,908$ & 390.0 \\
$10.0 \%$ & $10,500,954$ & 132.0 \\
$15.0 \%$ & $6,983,134$ & 69.8 \\
$20.0 \%$ & $5,250,477$ & 44.7 \\
$25.0 \%$ & $4,200,382$ & 31.4 \\
$30.0 \%$ & $3,465,315$ & 21.9 \\
$40.0 \%$ & $2,625,238$ & 12.9 \\
$50.0 \%$ & $2,100,191$ & 8.5 \\
$75.0 \%$ & $1,396,627$ & 4.3 \\
$85.0 \%$ & $1,234,912$ & 3.5 \\
$95.0 \%$ & $1,104,700$ & 3.0 \\
\hline
\end{tabular}

Parameters in this cost minimization problem include effective depth of discharge, battery capacity, lifecycle, cost reductions resulting from battery technology advancement, and relevant discount rates. These parameters are used to establish the optimum battery size based on an assessment of the present value costs for each effective depth of discharge level, as demonstrated in Figure 5.1. Figure 5.1 demonstrates the cost minimizing effective depth of discharge level (50\%) under Case 3.

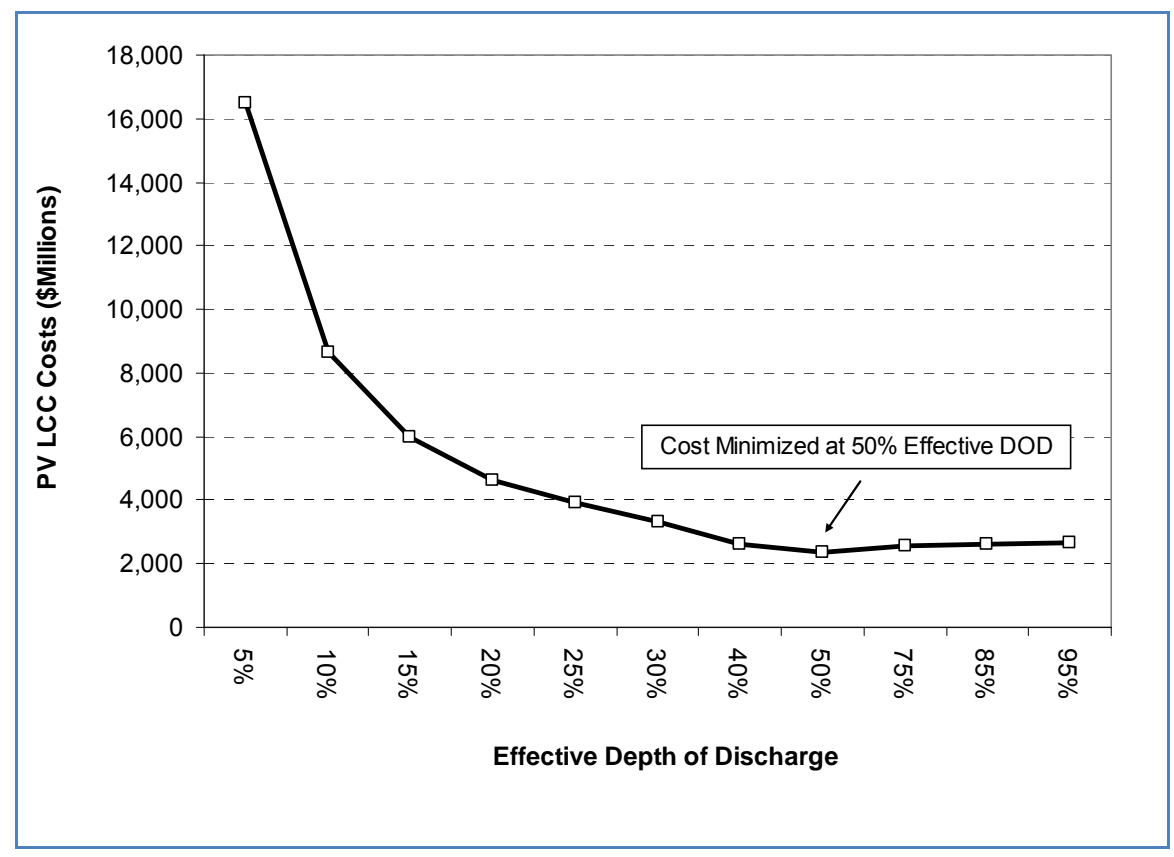

Figure 5.1. Case 3 Life Cycle Cost Estimates 
For each of the 11 cases, costs are computed for depth of discharges ranging from 5 to $95 \%$. Results for the cost-minimizing effective depth of discharge for each case are presented in Table 5.3. As shown, the cost minimizing effective depth of discharges fall between 40 and $50 \%$ for all scenarios with the exception of Cases 4 and 5. For both of these cases, the cost minimizing depth of discharge is 95\%. The higher effective depth of discharge under these scenarios is due to the heavy reliance on pumped hydro with minimal demand placed on the battery systems. In the absence of heavy use, these systems can withstand higher effective depths of discharge.

Table 5.3. Cost Minimizing DOD, Battery Capacity and Economic Life by Case.

\begin{tabular}{cccc}
\hline Case & $\begin{array}{c}\text { Effective } \\
\text { DOD }\end{array}$ & Battery Capacity (GWh) & Economic Life \\
\hline 1 & -- & -- & -- \\
2 & 0.40 & 2.6 & 9.3 \\
3 & 0.50 & 2.5 & 8.1 \\
4 & 0.95 & 0.2 & $13^{(\mathrm{a})}$ \\
5 & 0.95 & 0.1 & $13^{(\mathrm{a})}$ \\
6 & -- & -- & -- \\
7 & 0.40 & 1.8 & 12.9 \\
8 & 0.50 & 1.4 & 8.4 \\
9 & 0.50 & 1.4 & 8.7 \\
10 & 0.40 & 1.7 & 12.9 \\
11 & 0.50 & 1 & 8.7 \\
\hline
\end{tabular}

(a) The maximum battery life is 13 years regardless of energy throughput

\subsection{Results}

The economic assessment methodology detailed in the preceding section of this report was used to compute cost estimates for 11 cases using combinations of several energy generation or storage technologies - combustion turbines, combined cycle, $\mathrm{NaS}$ and Li-ion batteries, pumped hydro and demand response. For each case, the objective was to meet the load balancing requirements for the NWPP region over a 50-year time horizon. As outlined previously in Section 3.4, the cases considered within this analysis are as follows:

Case 1: CT

Case 2: $\mathrm{NaS}$

Case 3: Li-ion

Case 4: PH with many mode changes per day ${ }^{1}$

\footnotetext{
${ }^{1} \mathrm{PH}$ has 2 modes: pumping and generating modes. Operation with multiple mode changes per day permits as many mode changes as are required to meet balancing signal.
} 
Case 5: PH with 2 mode changes per day

Case 6: DR only

Case 7: NaS plus DR

Case 8: Li-ion plus DR

Case 9: PH with many mode changes per day plus $\mathrm{NaS}$

Case 10: PH with 2 mode changes per day plus $\mathrm{NaS}$

Case 11: PH plus NaS batteries plus DR

The results of the economic analysis for the base or reference case are presented in Table 5.4 and Figure 5.2. Of the 11 cases examined in this paper, Case 2, which employs NaS batteries plus combined cycle plants, is the least cost alternative at $\$ 1.4$ billion. Note that the values presented in Table 5.4 represent the present value of the stream of capital, O\&M, fuel, and emissions costs over a 50-year time horizon, using the 2019 capital cost value presented in Section 3.3.2, discounted at 10.3\%.

Total costs under Case 7 are estimated at $\$ 1.9$ billion, or 35.2\% more than those for Case 2. The third most cost effective option is Case 9 , which is $42.6 \%$ more expensive than Case 2 . The costs associated with the demand response only case (Case 6) more than double those for the three aforementioned cases, registering at $\$ 4.2$ billion. In the predominantly pumped hydro case with 40 mode changes per day (Case 4), total costs are also much higher at $\$ 4.0$ billion.

In nearly all cases, the capital costs associated with the energy storage options are higher than those estimated for the combustion turbine case (Case 1) but these costs are offset by the higher fuel and emissions costs estimated for combustion turbines.

Table 5.4. Economic Analysis Results

\begin{tabular}{cccccc}
\hline Case & Capital & Fuel & O\&M & Emissions & Total \\
\hline 1 & 1,759 & 905 & 276 & 312 & 3,252 \\
2 & 1,076 & 125 & 129 & 43 & 1,372 \\
3 & 2,139 & 91 & 122 & 31 & 2,383 \\
4 & 3,720 & 120 & 120 & 41 & 4,000 \\
5 & 6,949 & 422 & 372 & 145 & 7,889 \\
6 & 4,222 & - & - & - & 4,222 \\
7 & 1,619 & 100 & 102 & 34 & 1,855 \\
8 & 2,425 & 73 & 97 & 25 & 2,620 \\
9 & 1,671 & 123 & 121 & 42 & 1,957 \\
10 & 2,550 & 205 & 190 & 71 & 3,016 \\
11 & 2,331 & 98 & 100 & 34 & 2,562 \\
\hline
\end{tabular}




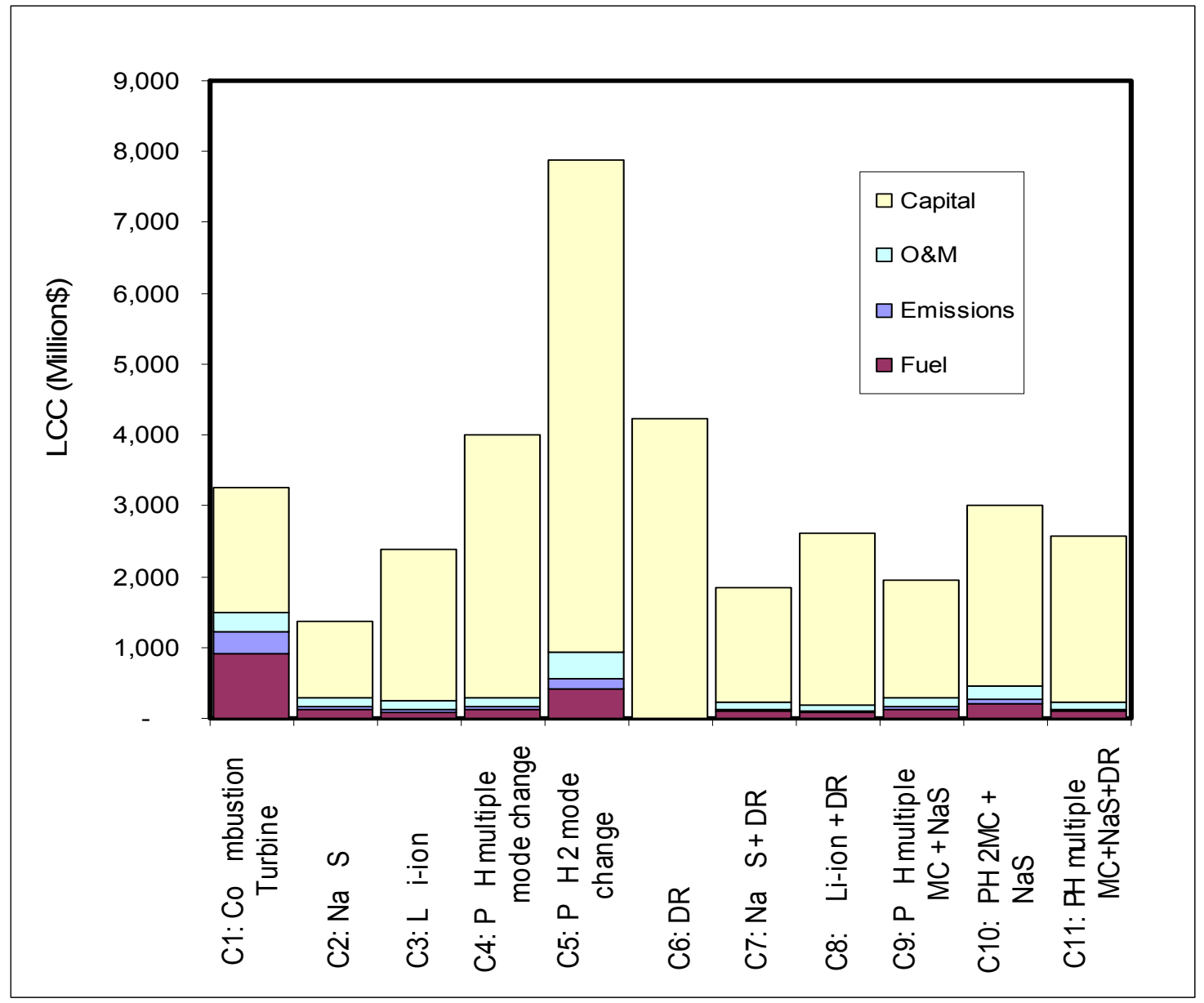

Figure 5.2. Scenario Life Cycle Cost Estimates

\subsection{Sensitivity Analysis}

To explore the sensitivity of the results to varying a small number of key assumptions, the research team conducted a sensitivity analysis. Sensitivity analysis was performed by making the following adjustments to the assumptions underlying the results:

1. Use capital cost for each technology estimated for current state-of-the-art technology in 2010

2. Decrease the discount rate to 4 and $7 \%$

3. Consider minimum plausible variation around the capital costs for battery technologies and PH

4. Significantly increase variable O\&M costs for PH. Applied to PH cases with multiple mode changes.

Table 5.5 presents the results of the four sensitivity analyses. Note that the $2^{\text {nd }}$ sensitivity analysis, which focuses on discount rate adjustments, includes two options. 
Table 5.5. Sensitivity Analysis Results

\begin{tabular}{ccccccc}
\hline Case & Base Case & SA 1 & $\begin{array}{c}\text { SA 2 } \\
(7 \% \text { DR })\end{array}$ & $\begin{array}{c}\text { SA 2 } \\
(4 \% \text { DR })\end{array}$ & SA 3 & SA 4 \\
\hline 1 & 3,252 & 3,184 & 4,228 & 6,097 & 3,252 & \\
2 & 1,372 & 2,091 & 1,686 & 2,277 & $1,269-1476$ & \\
3 & 2,383 & 4,254 & 3,041 & 4,270 & $2,004-2,762$ & \\
4 & 4,000 & 3,818 & 4,144 & 4,415 & $3,292-4,708$ & 4,387 \\
5 & 7,889 & 7,420 & 8,306 & 9,080 & $6,522-9,255$ & \\
6 & 4,222 & 4,222 & 6,046 & 9,411 & 4,222 & \\
7 & 1,855 & 2,362 & 2,454 & 3,566 & $1,783-1,928$ & \\
8 & 2,620 & 3,991 & 3,474 & 5,061 & $2,343-2,897$ & \\
9 & 1,957 & 2,364 & 2,237 & 2,758 & $1,700-2,215$ & 2,064 \\
10 & 3,016 & 3,342 & 3,337 & 3,938 & $2,582-3,450$ & \\
11 & 2,562 & 2,841 & 3,141 & 4,214 & $2,324-2,801$ & 2,669 \\
\hline
\end{tabular}

In the first sensitivity analysis case, current technology prices are used. The underlying assumption governing this first case is that the cost adjustments forecast in the base case are not realized. The capital cost forecasts for combustion turbines, combined cycle plants and hydro are taken from the U.S. Department of Energy's Annual Energy Outlook (AEO) 2010 reference case, which includes forecast costs out to 2030 (EIA 2010).

The costs for these technologies are forecast to grow in real terms over the next 5 to 6 years because construction costs for all plant types have risen significantly in recent years.

This cost growth is forecast based on a commodity cost index that was implemented for the AEO 2009. Growth in the cost index is tied to rising commodity prices, such as steel, copper, cement, and other construction materials. In the long-run, the commodity prices do decline and technology growth leads to cost reductions in the latter years of the forecast. On balance, however, the AEO 2010 reference case forecasts cost growth for combustion turbines, combined cycle plants, and hydro power during the 2010 to 2019 time horizon.

The battery costs used in the base case ( $\$ 415$ per $\mathrm{kWh}$ for Li-ion and $\$ 230$ per $\mathrm{kWh}$ for NaS) reflect significant cost reductions forecast over the 2010 to 2019 time period. When using current (2010) cost data for these battery types, costs are significantly higher ( $\$ 1,000$ per $\mathrm{kWh}$ for Li-ion and \$415 per kWh for $\mathrm{NaS}$ ).

As a result of the forecasts underlying the base case, which include cost reductions for battery technologies and cost increases for all other systems, using current prices makes scenarios involving pumped hydro and demand response more cost efficient. The results of Sensitivity Analysis 1 show a closing gap between Case 2 and Cases 7 and 9, which are both 13\% more expensive when using 2010 price data. Note that under the base case, Cases 7 and 9 were $35.2 \%$ and $42.6 \%$ more expensive than Case 2, respectively. 
The discount rate was reduced in the Sensitivity Analysis from the $10.3 \%$ used in the base case to 4 and $7 \%$. By reducing the discount rate, the present value of the interim capital costs associated with battery replacement in the out years of the 50-year analysis time horizon is increased. When the discount rate is reduced, the pumped hydro scenarios become more cost efficient because the asset is long-lived (50 years) and does not require interim capital costs. Reducing the discount rate to $4 \%$ increases the costs associated with Case 2 ( $\mathrm{NaS}$ batteries plus combined cycle) from $\$ 1.4$ billion to $\$ 2.3$ billion but increases the costs for Case 9 (NaS batteries plus combined cycle plus pumped hydro with 40 mode changes per day) from $\$ 2.0$ billion to $\$ 2.8$ billion.

The final two sensitivity analyses, which include variability with respect to capital costs and increased variable O\&M costs for pumped hydro, do not appear to lead to a re-ordering of the most cost efficient options. Under Sensitivity Analysis 3, Li-ion battery costs are varied by $+/-20 \%$, NaS battery costs are varied by $+/-12.4 \%$, and pumped hydro capital costs are varied by $+/-20 \%$. Under Sensitivity Analysis 4 , O\&M variable costs for pumped hydro are increased from $\$ 0.004$ per $\mathrm{kWh}$ to as high as $\$ 0.04$ per $\mathrm{kWh}$ under Cases 4, 9, and 11. 



\subsection{Arbitrage Opportunities for Energy Storage}

Pumped hydro systems are customarily used for energy arbitrage opportunities because of their significant energy storage capabilities. At low demand periods, low cost electric power is used to pump water from a lower reservoir to a higher reservoir. At high demand periods, where electric power price is high, water is released through a turbine to generate electricity. Only when the differential between peak and off-peak prices is sufficiently large to compensate for the energy losses incurred during round-trip charge/discharge cycle, does it make economic sense to dispatch energy storage.

Besides the energy arbitrage potential, energy storage can provide operating reserves (contingency reserves) and system balancing services to the grid because of its fast response characteristics. Its competitiveness among other technology options has been discussed for the system balancing service in the previous section. Of interest here is the discussion about the cost-effectiveness of energy storage as an arbitrage instrument to mitigate congestion-induced high electricity prices and/or to reduce potential low load conditions in cases, when there is insufficient load (commonly at night) coincident with large electricity production by the growing wind generation capacity. This discussion solely focuses on the arbitrage value proposition, excluding the valuation of the balancing services as part of the ancillary services. The exclusion of the balancing service value is made primarily based on the difficulty of valuing ancillary services in the future. The cost-effectiveness of a $1 \mathrm{GW} / 10 \mathrm{GWh}$ storage facility in the BPA footprint is discussed. The size of the unit was recommended by BPA staff from preliminary analyses performed by BPA. Likewise, a recommendation for a potential location of a pumped hydro storage plant was made. Banks Lake was suggested as a potential location. Impacts of an alternative storage size, as well as a distributed placement of the total energy storage size into four locations were analyzed and their impacts to the overall results discussed.

\subsection{Arbitrage Analysis Framework}

To quantify the arbitrage value of energy storage, it was decided to apply a cost-effectiveness approach that contrasts the annual revenue requirements from the capital expenditure to the revenue potential from arbitrage. The revenue potential analysis is based on a production cost approach using PROMOD IV ${ }^{1}$ from Ventyx as an analysis tool. PROMOD is a production cost software that solves security constrained unit commitment and dispatch problems in power systems at either zonal or nodal transmission level. In this analysis, a WECC system model developed by the Western Electricity Coordinating Council's Transmission Expansion Planning and Policy Committee (TEPPC) was used for the 2019 time horizon. This model was slightly modified in this analysis to implement a $1 \mathrm{GW}$, and 10 GWh energy storage resource at the Grand Coulee bus. This model has been vetted by TEPPC and can be considered as a plausible and best-judgment scenario for the 2019 WECC system. The particular case analyzed was based on the TEPPC 2019 PC1 RPS Base Case. This is the nodal transmission model of the WECC system. This case was built based on 2012 PC6 case (median hydro case), and then updated generation, load, and transmission lines for the 2019 case. The load forecasts for 2019, reported by BA submissions to the Loads and Resource Subcommittee (LRS), were used as the base case loads; updated resources were based on LRS submittal. Over 61\% of the incremental generation added to 2019 PC1 is renewable generation. Updates to transmission lines were based on Studies Working Group transmission

\footnotetext{
${ }^{1}$ PROMOD IV is an Energy Planning and Analytics Software developed by Ventyx http://www.ventyx.com/analytics/promod.asp
} 
team's work. A total of 24 transmission projects were added to the 2019 PC1 basecase. The TEPPC base case assumes a total of about $9.1 \mathrm{GW}$ of wind capacity in the NWPP. As will be discussed later, we analyze a case with additional $3 \mathrm{GW}$ in the Columbia Gorge region increasing the total wind energy capacity12.1 GW. This is a slightly lower capacity value than what was assumed for the balancing service analysis (14.4 GW). The existing and additional installed capacity for WECC, NWPP, and BPA is shown in Table 6.1.

Table 6.1. Existing and Additional Installed Capacity (MW) for WECC, NWPP, and BPA

\begin{tabular}{|c|c|c|c|c|c|c|}
\hline \multirow[b]{2}{*}{ Category } & \multicolumn{2}{|c|}{ WECC } & \multicolumn{2}{|c|}{ NWPP } & \multicolumn{2}{|c|}{ BPA } \\
\hline & $\begin{array}{c}\text { Existing } \\
(2008) \\
{[\mathrm{MW}]} \\
\end{array}$ & $\begin{array}{c}\text { New } \\
\text { capacity } \\
{[\mathrm{MW}]}\end{array}$ & $\begin{array}{c}\text { Existing } \\
(2008) \\
{[\mathrm{MW}]}\end{array}$ & $\begin{array}{c}\text { New } \\
\text { capacity } \\
{[\mathrm{MW}]}\end{array}$ & $\begin{array}{c}\text { Existing } \\
(2008) \\
{[\mathrm{MW}]} \\
\end{array}$ & $\begin{array}{c}\text { New } \\
\text { capacity } \\
\text { [MW] } \\
\end{array}$ \\
\hline Biomass & 944 & 1020 & 257 & 121 & 47 & 53 \\
\hline CC & 47456 & 7673 & 6704 & 0 & 2766 & 0 \\
\hline Coal & 37162 & 2085 & 4477 & 0 & 1456 & 0 \\
\hline Conventional hydro & 63514 & 3161 & 33496 & 0 & 21553 & 0 \\
\hline CT & 18589 & 6468 & 1106 & 192 & 102 & 0 \\
\hline $\begin{array}{l}\text { Demand Side } \\
\text { Management (DSM) }\end{array}$ & 4484 & 0 & 0 & 0 & 0 & 0 \\
\hline Geothermal & 2753 & 2354 & 0 & 52 & 0 & 0 \\
\hline Internal Combustion (IC) & 544 & 163 & 24 & 0 & 0 & 0 \\
\hline Negative Bus Load & 549 & 0 & 148 & 0 & 0 & 0 \\
\hline Nuclear & 9681 & 0 & 1161 & 0 & 1160 & 0 \\
\hline Other, steam & 658 & 7 & 298 & 0 & 131 & 0 \\
\hline Pumped storage & 3601 & 40 & 0 & 0 & 0 & 0 \\
\hline Pumping load & 2543 & 0 & 0 & 0 & 0 & 0 \\
\hline Small Hydro RPS & 1690 & 419 & 406 & 139 & 272 & 0 \\
\hline Solar & 538 & 12062 & 0 & 0 & 0 & 0 \\
\hline Steam & 19982 & 60 & 0 & 0 & 0 & 0 \\
\hline Wind & 7804 & 19411 & 2771 & 6349 & 1679 & 5221 \\
\hline Total & 222492 & 54923 & 50847 & 6853 & 29166 & 5274 \\
\hline
\end{tabular}

Simulation results of the base case reveal that there are several congested paths in the system. The most congested path is the interface between Alberta and British Columbia (BC). A few congested paths (in red) in NWPP and between NWPP and neighboring areas are shown in Figure 6.1. 


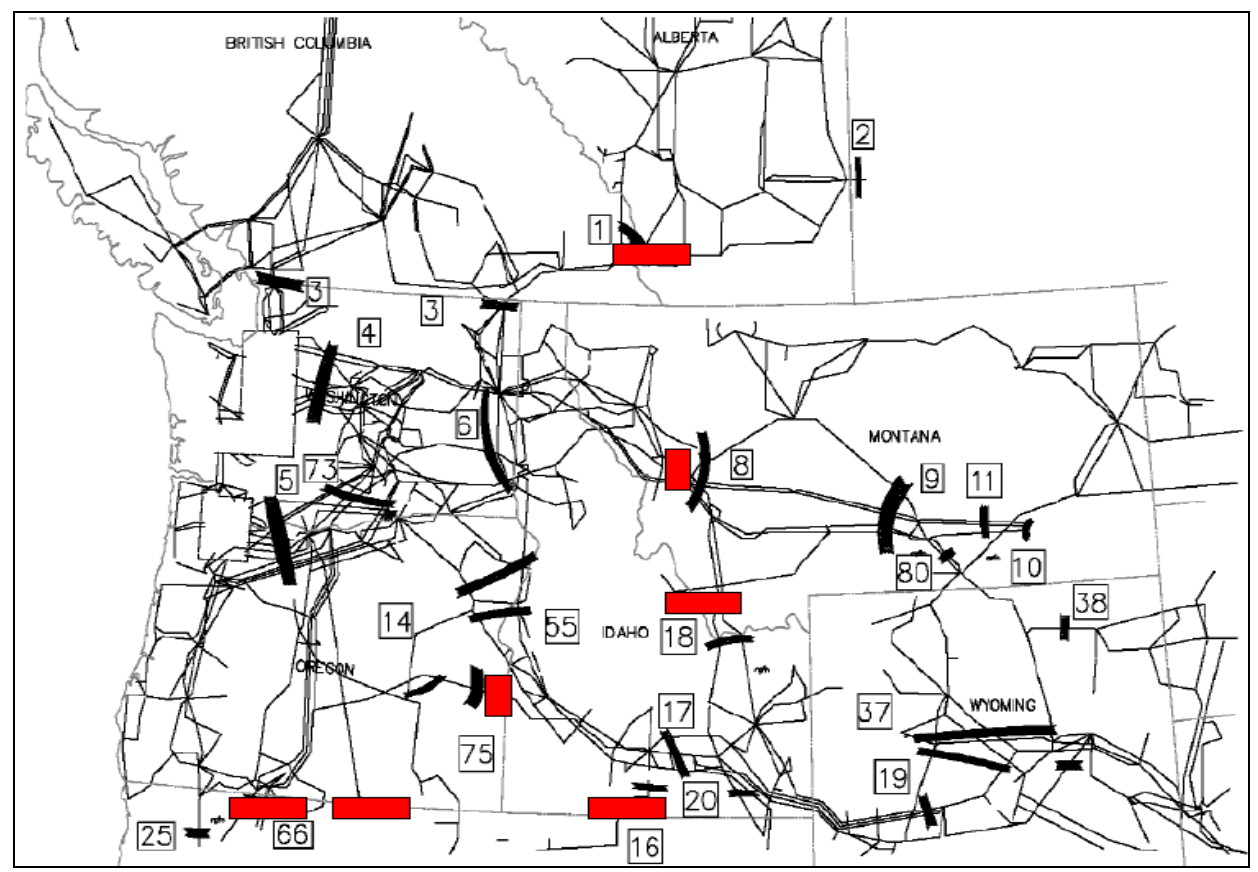

Figure 6.1. Key Congested Paths in NWPP and Neighboring Areas

\subsection{Simulation Results for a $1 \mathrm{GW}, 10 \mathrm{GWh}$ Pumped Storage at Grand Coulee}

To study arbitrage value of a pumped storage, a $1 \mathrm{GW}$ and $10 \mathrm{GWh}$ pumped hydro system with 75\% efficiency is added at Grand Coulee (GC) bus. PROMOD is used to run the simulation for the entire year of 2019. A typical optimal weekly schedule of the pumped-hydro system is shown in Figure 6.2.

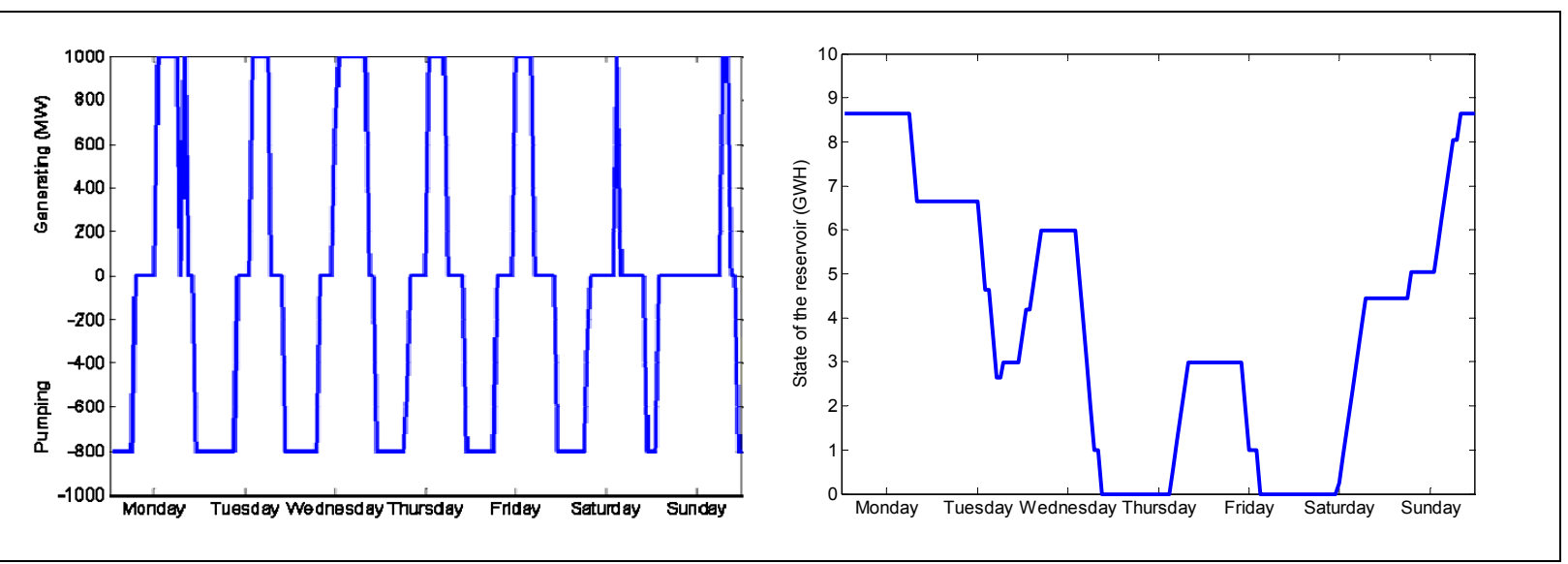

Figure 6.2. Typical Weekly Pumped Hydro Operation (note: during the charging mode system is assumed to be de-rated by $20 \%$ to $800 \mathrm{MW}$ )

To analyze the cost effectiveness of energy storage as an arbitrage instrument, the revenue potential of this $1 \mathrm{GW} / 10 \mathrm{GWh}$ hypothetical resource is examined The revenues are calculated for the Grand Coulee bus as: 


$$
\text { Revenue }=\sum_{i=1}^{8760}\left(G_{i}-L_{i}\right) L M P_{i}
$$

where $G_{i}, L_{i}$, and $L M P_{i}$ are the generation in [MWh], pumping load in [MWh], and Locational Marginal Price (LMP) in $[\$ / \mathrm{MWh}]$ at hour $i$, respectively. The revenues obtained from the storage operation in this case are $\$ 2.67 \mathrm{M}$.

The status of congested paths does not change much from that of the base case, although the California-Oregon Border (COB) and Midpoint-Summer Lake interfaces are slightly less congested. The path between Alberta and BC is still the most congested path, and operates at its limit most of the year, as in the base case. Lower cost generation in $\mathrm{BC}$ and the Northwest is dispatched to displace higher cost resources in Alberta. Because the storage resource is placed at the source-side (Northwest) of the congested path, there is no congestion relieve on the Alberta-BC path. In fact, the Grand Coulee placement of the storage increases the hours of congestion on this path. To have a mitigating effect the storage must be on the receiving side of a congested path (in Alberta). Table 6.2 shows the number of hours per year that transfer paths identified in Figure 6.1 are at $100 \%$ of their limits.

Table 6.2. Number of Hours at 100\% Transfer Limits

\begin{tabular}{lcc}
\hline \multicolumn{1}{c}{ Interface } & $\begin{array}{c}\text { Without } \\
\text { Storage } \\
{[\mathrm{h}]}\end{array}$ & $\begin{array}{c}\text { With 1 GW/ } \\
\text { 10 GWh Storage } \\
{[\mathrm{h}]}\end{array}$ \\
\hline Alberta-BC (from BC to Alberta) & 8286 & 8470 \\
COB (from North to South) & 771 & 500 \\
Idaho-Montana (from MT to ID) & 153 & 156 \\
Idaho-Sierra (from Sierra to ID) & 153 & 126 \\
Montana-Northwest (from MT to ID) & 440 & 477 \\
Midpoint-Summer Lake (from Midpoint to SL) & 44 & 30 \\
PDCI South (from North to South) & 2631 & 2463 \\
\hline
\end{tabular}

Next, the simulations are carried out for different pumped storage sizes at Grand Coulee bus. The revenue is computed for each case using equation (6-1). The results are shown in Table 6.3.

It can be seen that the maximum revenue is obtained at the size of $700 \mathrm{MW}$. This presumes that the storage is cycled to maximize revenue from arbitrage. For the Grand Coulee location, a size of $700 \mathrm{MW}$ appears to be optimal from a revenue maximization objective of this particular storage project. As the size is increased beyond $700 \mathrm{MW}$, the feedback of energy arbitrage becomes increasingly apparent. The discharge of energy during peak periods reduces the higher cost generation sufficiently, such that the overall price differential at the margin is decreasing, reducing the very economic incentive for energy storage in the first place. While any larger energy storage size beyond $700 \mathrm{MW}$ is undermining the key revenue mechanism from the economic perspective of this individual project, there may be system-wide benefit that may warrant a size larger than the optimal size.

Furthermore, the sensitivity with respect to placement of energy storage is explored. The following case is considered where the $1 \mathrm{GW} / 10 \mathrm{GWh}$ resource is distributed over four different locations in equal size. 4 x $0.25 \mathrm{GW}, 2.5 \mathrm{GWh}$ energy storage systems are modeled at 4 different locations shown in Figure 6.3: Grand Coulee, John Day, Marion, and Malin. The revenue in this case is \$3.7 Million, an increase of about $40 \%$ over that at the Grand Coulee location. 
Table 6.3. Revenue vs. Storage Size

\begin{tabular}{rrr}
\hline $\begin{array}{c}\text { Capacity of Storage } \\
{[\mathrm{MW}]}\end{array}$ & $\begin{array}{c}\text { Annual Revenue } \\
{[\$]}\end{array}$ \\
\hline & 25 & 100,000 \\
& 50 & 550,000 \\
& 100 & $1,040,000$ \\
& 200 & $1,960,000$ \\
& 300 & $2,660,000$ \\
& 400 & $3,130,000$ \\
Max revenue & 500 & $3,450,000$ \\
& 600 & $3,550,000$ \\
& 700 & $3,660,000$ \\
& 800 & $3,070,000$ \\
& 900 & $3,010,000$ \\
& 1000 & $2,670,000$ \\
\hline
\end{tabular}

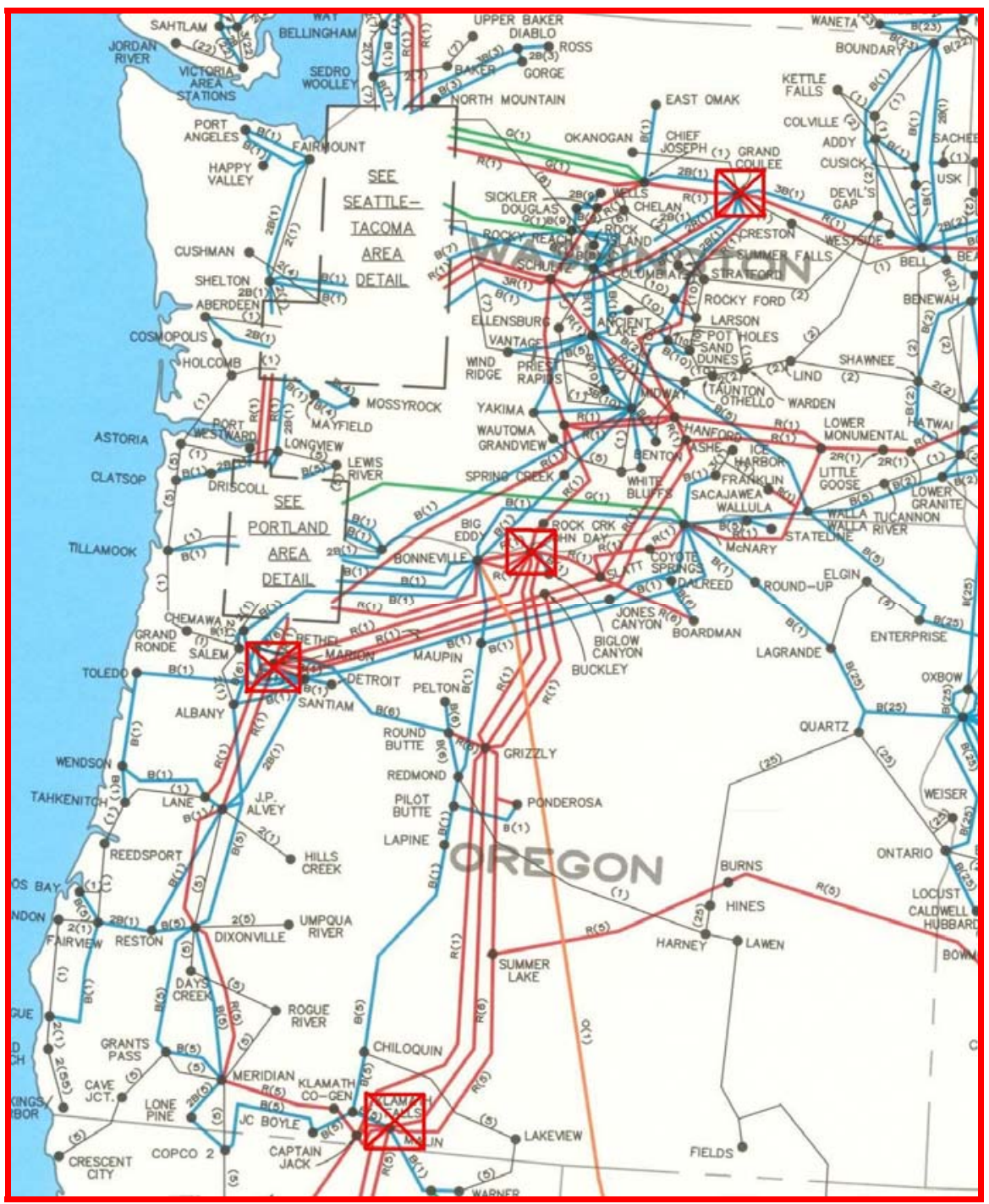

Figure 6.3. Storage Locations at four Arbitrarily Selected Locations 


\subsection{Basecase Variations}

To see the effect of more wind power in the system, an additional 3 GW (half in Washington and half in Oregon) of wind is introduced in the Mid-Columbia. Two side-cases with total storage size of $1 \mathrm{GW}$, $10 \mathrm{GWh}$ are considered:

- $1 \mathrm{GW}, 10 \mathrm{GWh}$ at Grand Coulee

- Four 0.25 GW, 2.5 GWh at 4 different locations: Grand Coulee, John Day, Malin, and Marion

Revenue for the two side-cases along with the original base cases is shown in Table 6.4. The revenues for the two side-cases are larger than those for the basecase. Also, revenues are larger for the distributed storage scenario. This clearly indicates that the additional $3 \mathrm{GW}$ of wind generates more congestion for the transfer of $3 \mathrm{GW}$ to California and Alberta which in turn drives up the price differential between peak and off-peak in the NW region. Whether the expected revenue potential derived from the arbitrage is sufficient to meet the cost recovery requirements will be discussed in the following sections.

Table 6.4. Revenue from $1 \mathrm{GW} / 10 \mathrm{GWh}$ Storage for the Base Case and the Two Side-Cases

\begin{tabular}{lc}
\hline \multicolumn{1}{c}{ Case Description } & Revenue \\
\hline Original TEPPC case & $\$ 2,670,000$ \\
Original TEPPC case. Add 3000 MW wind in OR and WA. Add 1GW energy storage at Grand Coulee & $\$ 5,020,000$ \\
Original TEPPC case. Add 3000 MW wind in OR and WA. Add 4 x 250 MW energy storage at Grand & $\$ 6,380,000$ \\
Coulee, JD, Malin, and Marion &
\end{tabular}

\subsection{Cost Effectiveness of Energy Storage as Arbitrage Instrument}

Cost effectiveness is defined here as meeting the debt servicing obligation from the capital investment by the revenue stream from energy arbitrage transactions of a $1 \mathrm{GW} / 10 \mathrm{GWh}$ pumped hydro energy storage project.

Figure 6.4 shows a histogram of the LMP differences at Grand Coulee between peak and off-peak periods as a result of the TEPPC case with additional $3 \mathrm{GW}$ of wind resources. The average peak and offpeak LMP are \$52/MWh and \$41/MWh, respectively. The average difference in LMP is \$11/MWh. The storage is operated as generator ( $1 \mathrm{GW})$ for about 1000 hours and as load $(0.8 \mathrm{GW})$ for about 1500 hours during the year, yielding an overall utilization of about $28 \%$.

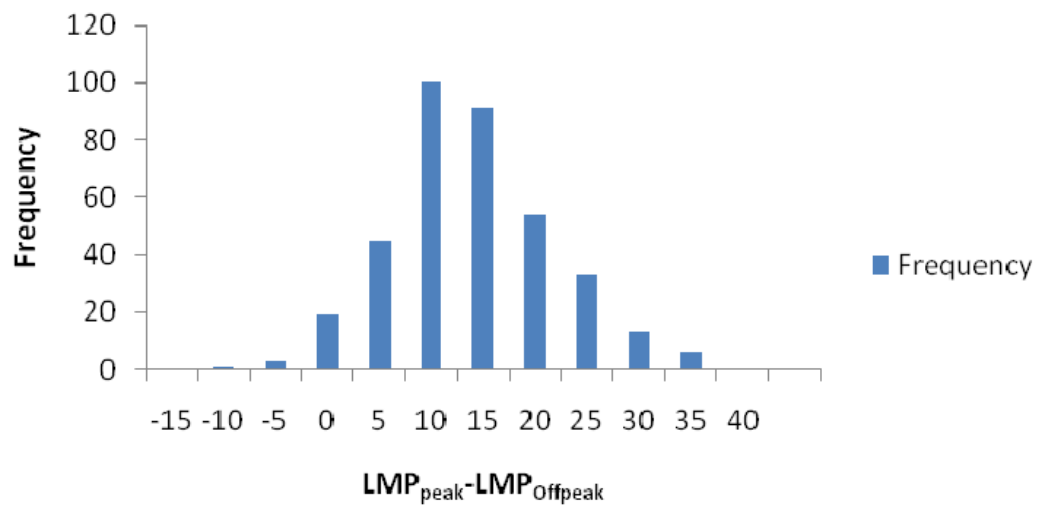

Figure 6.4. Histogram of LMP Difference Between Peak and Off-Peak Periods 
As seen in Figure 6.5, the arbitrage revenue expectations are falling significantly short of the necessary revenue requirements for cost recovery assuming similar economic considerations (discount rate, live of the project) as discussed in Section 5. It would take a significant increase in peak-to-off-peak differential for extended periods of time for this project to breakeven (see red line in Figure 6.5). Under the current projections of LMPs at the Grand Coulee bus, even in the $3 \mathrm{GW}$ of additional wind resources beyond the TEPPC base-case scenario, region is not sufficiently congested for energy storage to become cost effective. One key driver for this result is the location of the storage. Grand Coulee (Banks Lake) is not located at the end or sink of the congested path, where energy storage renders the largest benefits for congestion management, but rather at the source. With major congestions at the BC-Alberta path (from BC to Alberta), the COB (from Northwest to California), and Pacific DC Intertie South (Northwest to California), the Northwest (NW) does not appear to be heavily congested based on the infrastructure projections for generation and transmission capacity expansions developed by TEPPC for the 2019 time horizon.

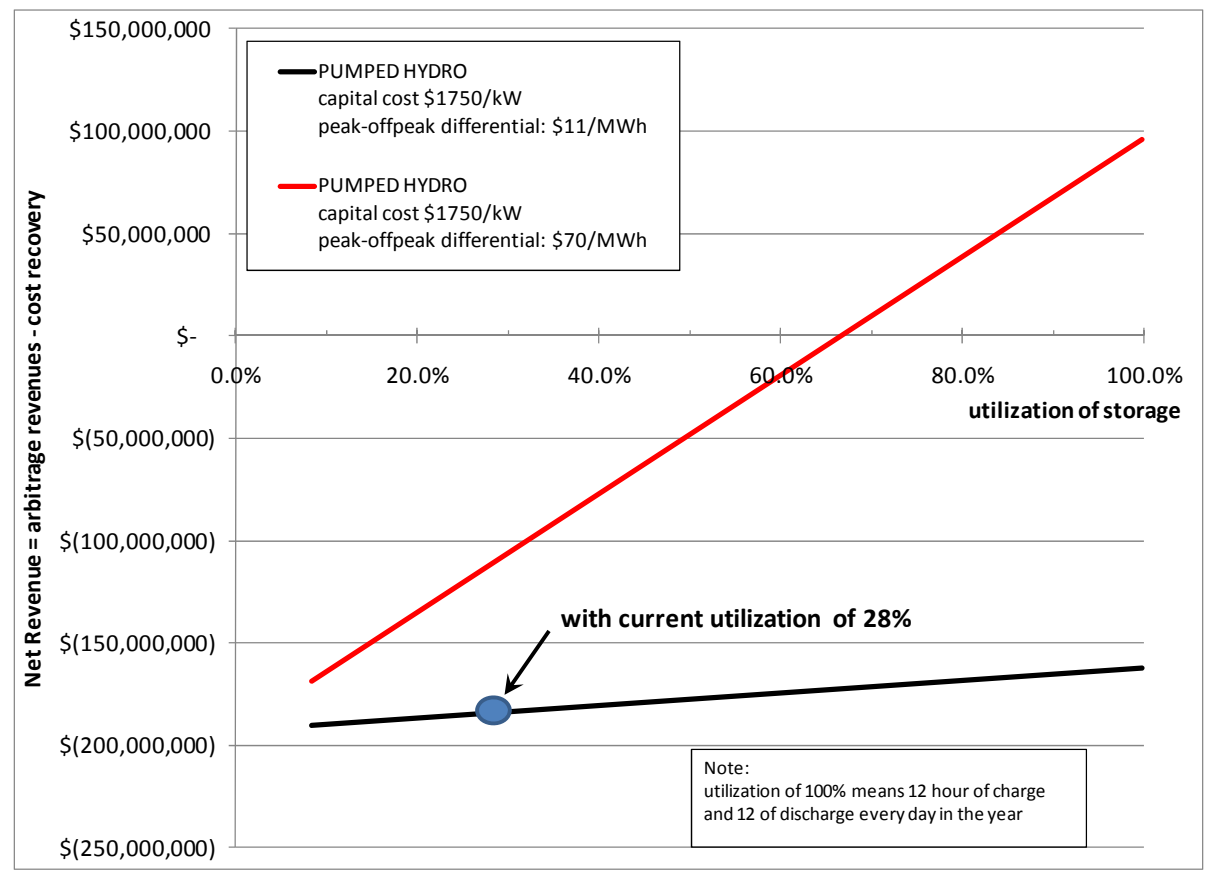

Figure 6.5. Cost-effectiveness Results of Pumped Hydro of 1 GW/10 GWh

The outcome of this analysis was qualitatively discussed with WECC/TEPPC members ${ }^{1}$, who were in general agreement with PNNL's findings of relatively little congestion in the NWPP footprint for the definition of the 2019 TEPPC base case. For an energy arbitrage opportunity to be cost effective as a sole revenue source, significant congestion must be prevalent for extended periods to warrant the high capital cost. With relatively little congestion inside the NWPP footprint, and the fact that the NWPP has a considerable low-cost generation resources that keep both the peak and off-peak prices relatively low, it is difficult for energy storage to generate sufficient revenues to pay for itself on energy transactions. Additional higher-valued ancillary services must be bundled to become economically attractive and viable.

\footnotetext{
${ }^{1}$ Phone conversation with Heidi Pacini, Mark Landauer, Bradley Nickell on 3/12/2010.
} 



\subsection{Summary and Conclusions}

The study estimated the total balancing requirements for the NWPP for a scenario of $14.4 \mathrm{GW}$ of wind energy in the 2019 time horizon. Under the assumption that the current individual balancing authorities (BAs) are consolidated to one single large balancing area, new total balancing requirements were determined. This assumption is likely to underestimate the new requirements if the current status quo in the grid operation for the pool is maintained. This assumption was made for no other reason but to manage the workload of this highly complex analysis. The results of this study estimated a total balancing requirement of approximately $4 \mathrm{GW}$ of inc. capacity and about $3.6 \mathrm{GW}$ of dec. capacity, using the BPA’s customary $99.5 \%$ probability bound.

The intra-hour balancing requirement was filtered out of the total balancing signal. The intra-hour balancing requirement is smaller than the total requirements, and tends to have higher ramp rate requirements. The intra-hour balancing requirements were estimated to be about $1.85 \mathrm{GW}$ in both directions (increment and decrement).

A life-cycle cost analysis was performed that sought the cost optimal technology investment to meet the total intra-hour balancing requirements of a 50-year lifetime. Considered were capital, O\&M costs, as well as fuel prices and typical prices for criteria emissions. The $\mathrm{CO}_{2}$ emissions were valued at a cost of $\$ 45 /$ ton $\mathrm{CO}_{2}$. Assumed was that all of the estimated balancing requirements will be met with new investments. Significant emphasis was placed on reviewing the literature regarding the characterization of storage option for grid applications, and on choosing plausible and defensible cost performance characteristic of the technologies under considerations. NaS, Li-ion batteries, and pumped-hydro energy storage, as well as demand response strategies, and conventional combustion turbine were considered in the analysis.

This study revealed several insights into the technology ranking under life-cycle cost optimality. First, the reference technology (CT) is not the least expensive option. Both batteries types (NaS and Liion) were comparatively less expensive to the CT. The following ranking (least cost to highest cost) was established for the base cases: $\mathrm{NaS}$ only, $\mathrm{NaS}+\mathrm{DR}, \mathrm{NaS}+$ pumped-hydro with many mode changes, Liion+DR, NaS+pumped-hydro with many mode changes+DR. The most costly cases were pumped-hydro with 2 mode changes and demand response alone.

The design of how pumped-hydro system is operated is critical for the overall size and, thus has direct impact on the lifecycle cost. For the 2-mode-change per day operation, the power rating must be doubled the size compared to the multiple-mode-change design. When only changing the mode twice a day, the machine must provide the full increment-to-decrement swing (inc/dec swing) in one single mode (pumping or generating). However, if the machine remains unconstrained in the number of mode changes a day, the full inc/dec swing (from maximum generation to full load pumping) can be utilized. The 4minute delay between modes, in which the machine is neither pumping nor generating, necessitates other resources to substitute (back-up resource). The size of the back-up is considerable for the multiple-modechange operation and relatively small when the pumped-hydro system changes modes only twice a day. Both the oversizing as well as the back-up resource requirements drive up the total life-cycle cost of pumped-hydro system when compared to a battery system. 
Demand response strategies by itself appears costly. The reason for this result follow a similar logic as for the 2-mode-change pumped-hydro storage. Unlike battery energy storage, which can be a load and a generator at times, DR must be large in capacity to perform the balancing only in the load mode. Thus, the total capacity size tends to be larger than the rate capacity of a battery. The size of the DR capacity (number homes) is determined by the lowest load condition just meeting the balancing requirement leaving a lot of capacity under-utilized for the remainder of the day. The most advantageous load profile for providing balancing services would be a flat profile achieving maximal utilization of the demand response resource. Because of a typical residential load shape, meeting all balancing requirements with demand response is unlikely to be economical. However, some DR capacity can reduce the energy requirements of the battery. There is an interesting trade-off between DR power capacity and the storage energy capacity when combining storage and demand response. Interesting shifts are seen in the optimal battery size as one adds demand response resource to the technology mix.

The economic analysis of arbitrage opportunities in the BPA service with a large 1GW/10GWh pumped hydro storage facility is unlikely to be economically viable. The revenue expectations are small for the case examined. The location analyzed at the Grand Coulee bus may not provide an optimal placement for the energy storage. Storage locations on the sink-side of a congested path provide better opportunities for congestion mitigations and energy arbitrage. The Grand Coulee location is situated on the source side of the major bulk power flows. Distributing energy storage with the BPA transmission network appeared to improve the economics somewhat by increasing the range of influence to mitigate congestion. Furthermore, it was found that a $1 \mathrm{GW} / 10 \mathrm{GWh}$ storage facility may not be an optimal size for arbitrage. A storage size at $700 \mathrm{MW}$ achieved the maximum revenue expectations for the Grand Coulee location. This outcome is very intuitive, reflecting the feedback of arbitrage on the cost differential between peak and off-peak. This confirms that maximizing the value of energy storage for arbitrage requires an optimal sizing and placement analytics.

The results clearly indicate that energy storage and particularly the electro-chemical storage technology are likely to compete with conventional combustion turbine technologies with and without accounting for the emission externalities. Energy arbitrage opportunities may not be the key driver for large deployment of energy storage, at least not in the near-term (2019 timeframe). Placement aspects appear very important for the economics of energy storage, giving electro-chemical storage devices an advantage over pumped-hydro system by not being constrained to a particular geographic topology and hydrological system. However there are other values that large scale energy storage may provide, that are difficult to model, which may support the economics. Grid flexibility for transmission outage management is likely to be improved with energy storage. Further studies with a particular focus on transmission system impacts are necessary to better reveal these values. 


\subsection{References}

Alstom. 2009. “Alstom Signs $€ 178$ Million Variable Speed Pumped-Storage Hydro Contract.” Press Release October 28, 2009. Accessed March 24, 2010 at http://www.alstom.com/pr corp v2/2009/corp/61513.EN.php?languageId=EN\&dir=/pr corp v2/2009/co rp/\&idRubriqueCourante=23132\&cookie=true (undated webpage).

Alstom. 2010. E-mail message from Alstom to Rick Miller "Pumped Hydro Costs “, February 10, 2010. Footnote 25

Altair Nanotechnologies. 2008. “Advanced Batteries Supply Ancillary Services.” POWER December 2008. Accessed March 24, 2010 at www.powermag.com (undated webpage).

Barnett B, D Ofer, C McCoy, Y Yang, T Rhodes, B Oh, M Hastbacka, J Rempel, S Sririramulu. 2009. “PHEV Battery Cost Assessment.” U.S. Department of Energy Annual Merit Review, May 19, 2009, Washington D.C.

Boyes J. Energy Storage Tutorial. Sandia National Laboratories, Albuquerque, NM. Accessed March 24,2010 at http://www.netl.doe.gov/technologies/coalpower/fuelcells/seca/tutorial/TutorialIII files/TutorialIII.pdf (undated webpage).

Chintawar PS. 2010. E-mail message from Prashant S. Chintawar (BASF) to V.V. Viswanathan Li-ion Battery Cost, February 3, 2010.

Divya KC, J Østergaard. 2009 “Battery Energy Storage Technology for Power Systems. Electric Power Systems Research 79(4):511-520.

Highlights of the 2001 National Household Travel Survey. BTS03-05. Table A-8. U.S. Department of Transportation, Bureau of Transportation Statistics, Washington DC.

Electricity Advisory Committee (EAC). 2008. Bottling Electricity: Storage as a Strategic Tool for Managing Variability and Capacity Concerns in the Modern Grid. Prepared by Energetics Incorporated for the Electricity Advisory Committee.

Energy Information Administration. 2008. “Annual Energy Outlook 2008.” Washington, D.C.

Energy Information Administration. 2010. “Annual Energy Outlook 2009.” Washington D.C.

U.S. Environmental Protection Agency (EPA) 1995, "Compilation of Air Pollutant Emission Factors, Volume 1: Stationary Point and Area Sources,” AP 42, Fifth Edition, Environmental Protection Agency, Washington, DC.

Evolution Markets. http://new.evomarkets.com/ Figueiredo FC, and PC Flynn. 2006. "Using Diurnal Power Price to Configure Pumped Storage.” IEEE Transactions on Energy Conversion EC 21(3): 804809. 
First Hydro Company. 2009. "Welcome to First Hydro Company.” International Power, June 4, 2009.

Fodstad LA. "Pumped Storage.” Staraft Energy AS, Oslo, Norway.

GE Energy. 2004. “GE to Provide Equipment for 1,000-Megawatt Hydropower Station in China.” Press Release March 15, 2004. Accessed March 24, 2010 at http://www.gepower.com/about/press/en/2004_press/031504a.htm (undated webpage).

Geadah A. 2009. "Introducing Pumped Storage in Lebanon: Towards a Prospective National Master Plan.” International Seminar on River Basin Management and Co-operation in the Euro-Mediterranean Region, October 6-9, 2009, Beirut, Lebanon.

Green Exchange. http://nymex.greenfutures.com/markets/6t.html\# Greenberg D, I Krepchin, and K Kamm. “Big Batteries Blooming.” Power. Accessed March 24, 2010 at http://www.powermag.com/print/environmental/Big-batteries-blooming 1042.html (undated webpage).

Gyuk IP, and S Eckroad. 2003. EPRI-DOE Handbook of Energy Storage for Transmission and Distribution Applications, 1001834 Final Report, December 2003. Prepared by Technology Insights and EPRI PEAC Corporation for the U.S. Department of Energy, Washington DC, and Electric Power Research Institute, Inc., Palo Alto, CA.

Gyuk IP, and S Eckroad. 2004. EPRI-DOE Handbook Supplement of Energy Storage for Grid Connected Wind Generation Applications, 1008703 Technical Update, December 2004. Prepared by Technology Insights and EPRI PEAC Corporation for the U.S. Department of Energy, Washington DC, and Electric Power Research Institute, Inc., Palo Alto, CA.

Hazel J. 2010. E-mail message from John Hazel (Lithium Technology Corporation) toVV Viswanathan (PNNL), “Li-ion Battery Cost”, February 3, 2010.

Howell D. 2009. “Annual Merit Review: Energy Storage R\&D Overview.” U.S. Department of Energy, Energy Efficiency and Renewable Energy.

Jenkinson P. 2005. “Introduction.” International Power First Hydro Analysis Conference, July 2005.

Kamibayashi M, DK Nichols, and T Oshima. 2002. "Development Update for the NAS Battery.” Transmission and Distribution Conference and Exhibition 2002: Asia Pacific, IEEE/PES 3:1664-1668. DOI: $10.1109 /$ TDC.2002.1176850.

KEMA. 2008. "Summary of KEMA Validation Report: Two Megawatt Advanced Lithium-ion BESS Successfully Demonstrates Potential for Utility Applications.”

Kishinevsky Y. 2006. “Long Island Bus Sodium Sulfur Battery Storage Project.” U.S. DOE Peer Review, Washington, D.C.

Lamont A. 2004. Improving the Value of Wind Energy Generation Through Back-up Generation and Energy Storage CWEC-2003-005, Table 4. Prepared for California Wind Energy Collaborative by Lawrence Livermore National 
Lipman TE, R Ramos, and DM Kammen. 2005. An Assessment of Battery and Hydrogen Energy Storage Systems Integrated with Wind Energy Resources in California PIER Final Project Report CEC500-2005-136, Table 1. Prepared by University of California, Berkeley for California Energy Commission, Public Interest Energy Research Program.

Lu N, and DJ Hammerstrom. 2006. "Design Considerations for Frequency Responsive Grid Friendly Appliances." In 2005/2006 IEEE/PES Transmission and Distribution Conference and Exhibition, 21-24 May 2006, Dallas, TX, USA, pp. 647-652. Institute of Electrical and Electronics Engineers, Piscataway, NJ.

Makarov, Y.; Shuai Lu; McManus, B.; Pease, J.; "The Future Impact of Wind on BPA Power System Ancillary Services”, Transmission and Distribution Conference and Exposition, 2008. T\&D. IEEE/PES, pp.1-5.

Makarov Y, M Kintner-Meyer, P Du, C Jin, H Illian. 2010, “Using DFT for Cycle Analysis of Energy Storage Capacity Requirement to Accommodate High Penetration of Renewable Resources in the WECC System.” IEEE PES Innovative Smart Grid Technologies Conference, January 19-21, 2010, Gaithersburg, MD.

Miller R. 2010. E-mail message from Rick Miller (Renewable Energy Services to V.V. Viswanathan (PNNL) “Pumped Hydro Cost and Performance” January 26, 27, and February 1, 2010.

Nelson PA, DJ Santini, and J Barnes. 2009. "Factors Determining the Manufacturing Costs of LithiumIon Batteries for PHEVs.” EVS24 International Battery, Hybrid and Fuel Cell Electric Vehicle Symposium, May 13-16, 2009, Stavanger, Norway.

NGK Insulators, LTD. Accessed at http://www.ngk.co.jp/english/index.html (undated webpage).

The Nevada Hydro Company, Inc. (NHC). 2007. "Lake Elsinore Advanced Pump Storage FERC Project Number 11858 and Talega-Escondido/Valley-Serrano 500-kV Interconnect (LEAPS/TE-VS).” CEC Joint Committee Workshop, Transmission Corridors, May 14, 2007.

Nourai A. 2007. Installation of the First Distributed Energy Storage System (DESS) at American Electric Power (AEP): A Study for the DOE Energy Storage Systems Program. SAND2007-3580. Sandia National Laboratories, Albuquerque, NM.

Nourai A. 2009. "Why and How Electric Vehicle Li-ion Batteries are Penetrating the Utility Market.” EV Li-ion Battery Forum, September 2-3, 2009, Shanghai, China.

Nourai A. 2010. E-mail message from Ali Nourai (American Electric Power) toV.V. Viswanathan (PNNL) “NaS Battery System Cost” February 2, 2010.

National Renewable Energy Laboratory (NREL). “About the Wind Integration Datasets.” Accessed March 24, 2010 at http://www.nrel.gov/wind/integrationdatasets/about.html (last updated November 24, 2009). p.24 f 27

Northwest Power and Conservation Council. 2010. “Sixth Northwest Power Plan.” Portland, OR. 
Pacini H, M Landauer. 2010. Phone conversation to Heidi Pacini (WECC ), Mark Landauer (WECC ). March 12, 2010. footnote 29

Parker Hannifin Corp. SSD Drives Division, http://www.ssddrives.com/usa/News/press_releases.php January 12, 2010 press release. Accessed on March 26, 2010

Pratt, R.; Conner, C.; Richman, E.; Ritland, K.; Sandusky, W.; Taylor, M.. 1989. Description of Electric Energy Use in Single-Family Residences in the Pacific Northwest. End-use Load And Consumer Assessment Program (ELCAP). DOE/BP-13795-21. Bonneville Power Administration, Portland, OR.

Rahman S. 1990. "Economic Impact of Integrating Photovoltaics with Conventional Electric Utility Operation.” IEEE Transactions on Energy Conversion 5(3):422-428. DOI: 10.1109/60.105264.

Rastler D, P Lemar, and S Price. 2007. Market Driven Distributed Energy Storage Requirements for Load Management Applications Technical Update 1014668. Prepared by Electric Power Research Institute, Resource Dynamics Corporation, and Energy Environmental Economics, Inc. for Electric Power Research Institute, Palo Alto, CA.

Riedel G. 2010. E-mail message from Gary Riedel (Compact Power, Inc.) to V.V. Viswanathan (PNNL) “Li-ion Battery Cost”, February 2, 2010. Cost includes battery management + mark-up footnote 11

Rousseau A, N Shidore, R Carlson, and V Freyermuth. 2007. Research on PHEV Battery Requirements and Evaluation of Early Prototypes. Argonne National Laboratory, Chicago, IL. Accessed March 24, 2010 at http://www.transportation.anl.gov/pdfs/HV/434.pdf (undated webpage). footnote 8

Schoenung SM. 2001. Characteristics and Technologies for Long vs. Short-Term Energy Storage: A Study by the DOE Energy Storage Systems Program SAND2001-0765. Sandia National Laboratories, Albuquerque, NM.

Schoenung S, J Eyer, J Iannucci, and S Horgan. 1996. "Energy Storage for a Competitive Power Market.” Annual Review of Energy and the Environment 21:347-370. DOI:

10.1146/annurev.energy.21.1.347.

Schoenung SM, and WV Hassenzahl. 2003 Long vs. Short-Term Energy Storage Technology Analysis SAND2003-2783. Sandia National Laboratories, Albuquerque, NM.

Fritz Spitzer and Gerhart Penninger, 2008, "Pumped Storage Power Plants-Different Solutions for Improved Ancillary Services through Rapid Response to Power Needs,” HydroVision 2008, July 2008

Technology Insights. 2005. "Overview of NAS Battery for Load Management.” CEC Energy Storage Workshop, February 2005.

Tokyo Electric Power Company (TEPCO). http://www.tepco.co.jp/en/index-e.html (undated webpage). Transmission Expansion Planning Policy Committee (TEPPC). 2010. 2009 Study Program Results Report. Western Electricity Coordinating Council (WECC), Salt Lake City, UT. 
United States Council for Automotive Research LLC (USCAR). 2007. "USABC Final Cost Model 2007-05-23.” http://www.uscar.org/guest/article_view.php?articles_id=143 (undated webpage).

Western Electricity Coordinating Council, 2010. Transmission Expansion Planning Policy Committee. 2009 Study Program Results Report. January 26, 2010. WECC, Salt Lake City, UT. 

Appendix A

\section{Detailed Technology Discussion}





\section{Appendix A}

\section{Detailed Technology Discussion}

\section{A.1 Sodium-sulfur (NaS) Battery}

\section{A.1.1 Battery Sizing Method}

Battery sizing depends on depth of discharge (DOD), which depends on the number of cycles needed from the battery during its life. The only NaS battery commercially available is from NGK Insulators, Ltd., which has an energy content of $\sim 6.8$ times the rated power (i.e., it has a storage capacity of 6.8 hours at rated power)(Nourai, 2007). Hence it is best suited for applications where a low DOD is desired for long life. As will be discussed later in section 3.0, the batteries will be sized to cycles that are much shorter than 6.8 hours; they will be in the order of $1 / 2-1$ hour. NaS batteries with a storage duration of $1 / 2$ hour don't currently exist. As a consequence we provide a discussion that adjusts the cost for the shorter duration battery storage given the battery sizes currently available.

Typically, NaS batteries can provide five times the rated power for up to 5 minutes (Kamibayashi et al. 2002). In our application, (as will be discussed in Section 3.2.3.1), the peak power occurs for only short durations of 1-2 minutes. Hence, using the peak power (rather than the rated power) would still be conservative as a sizing criterion for the battery. If the peak power needed is $1 \mathrm{MW}$ and energy needed is $1 \mathrm{MWh}$, the battery size currently available and sufficient for the $1 \mathrm{MW} / 1 \mathrm{MWh}$ requirements would be $0.2 \mathrm{MW} / 1.36 \mathrm{MWh}$, because the $\mathrm{E} / \mathrm{P}$ ratio is 6.8 for NaS batteries. Hence, sizing of the battery is determined by the peak power needs.

While the sizing discussion above is appropriate for batteries currently available, we have assumed that as energy storage applications in utilities become more diverse, $\mathrm{NaS}$ will be available in various energy/rated power ratios, with the batteries being able to deliver peak power equal to twice the energy content (1to 2MW/MWh) for 1-2 minutes. For Li-ion, the ability of batteries to provide 1to 2MW/MWh has been well demonstrated. Hence the batteries were sized per the energy requirements.

\section{A.1.2 Capital Cost}

The cost of the PCS was estimated from the $\$ / \mathrm{kW}$ values available in the literature. It should be noted that the rated power of PCS is typically specified for continuous power. For durations of seconds to minutes, the peak power would be at least two times higher than rated power for PCS, which would bring costs down.

An extensive search for capital costs of the NaS battery system was conducted. In some publications, the battery energy storage system costs were given in terms of $\$ / \mathrm{kW}$, while they were given as $\$ / \mathrm{kWh}$ in others. For NaS batteries, the long-term cost was $\sim$ \$250/kWh(Shoenung and Hassenzahl 2003, Schoenung 2001, Gyuk and Eckroad 2003, Boyes, Kamibayashi et al. 2002), while the cost for power conversion systems (PCS) was $\$ 150$ to $260 / \mathrm{kW}$. The cost of the batteries was $\$ 1800$ to $2000 / \mathrm{kW}$ (Greenberg et al., Kamibayashi et al. 2002), and \$3080/kW (EAC 2008). The cost for the battery system 
including PCS and BOP was $\$ 2400$ to 2500/kW(Nourai 2007, Kishinevsky 2006). While these numbers vary widely, it should be noted that the long-term costs provided in $\$ / \mathrm{kWh}$ are only projections, and are not necessarily reflective of actual costs.

A detailed explanation of PCS and BOP costs was provided by Gyuk and Eckroad (2003). Type I PCS is maintained in hot standby and is operated continuously for durations greater than 30 seconds. Type II PCS may be employed for applications allowing 10 minutes advance notice, while Type III is used for durations less than 30 seconds. For this work, Type I describes the PCS most closely. The cost for Type I PCS as a function of output power P is given by equation 3-1:

$$
\frac{\$}{k W}=300 \cdot p^{-0.3}
$$

This provides a range of $\$ 40-300 / \mathrm{kW}$ for applications needing $1 \mathrm{GW}-1 \mathrm{MW}$ power. Clearly, as the system power increases, costs for PCS drops. Type I PCS costs are also given by equation 3-2:

$$
\frac{\$}{k W}=13500 \cdot V^{-0.59}
$$

where $\mathrm{V}$ is the minimum voltage on the battery side, and ranges from $300-3000 \mathrm{~V}$. Since the power needs in this study are in the order of a few GWs, for a minimum voltage of $3000 \mathrm{~V}$, the PCS cost would be $\$ 120 / \mathrm{kW}$. For this work, we have assumed a cost of $\$ 200 / \mathrm{kW}$, where the power corresponds to half the peak power, (or $\$ 100 / \mathrm{kW}$ based on peak power).

BOP costs include various components: systems integration (in $\$ / \mathrm{kW}$ ) not covered by PCS, costs for project engineering, grid connection (transformers), land, foundation, buildings(Gyuk and Eckroad 2003). The BOP systems integration cost accounts for any underestimation of integration costs for PCS and energy storage, especially for pre-commercial systems. A value of $\$ 100 / \mathrm{kW}$ was proposed for precommercial systems, and \$50/kW for commercial systems(Gyuk and Eckroad 2003). For this work, only systems integration costs in terms of $\$ / \mathrm{kW}$ are included with the cost being $\$ 100 / \mathrm{kW}$, based on power corresponding to half of peak power.

Table A.1 summarizes the literature review of current and future capital cost for NaS battery systems. The value of $\$ 180-250 / \mathrm{kWh}$ provided by various sources is a long-term estimate. The $\$ 2500 / \mathrm{kW}$ value correspond to installed cost in the year 2006 for the Long Island Bus Project [9], while the $\$ 3000 / \mathrm{kW}$ provided by Nourai(Nourai 2010) was the actual installed cost for the year 2009 for a 7MW/48MWh battery system. The latter value was used for current price of a NaS system. The cost of the battery portion was estimated by subtracting $\$ 200 / \mathrm{kW}$ for PCS and $\$ 100 / \mathrm{kW}$ for BOP, to yield $\$ 2700 / \mathrm{kW}$. Using a factor of 6-6.8 for $\mathrm{E} / \mathrm{P}_{\text {rated }}$ for $\mathrm{NaS}$ batteries, the unit energy cost for the battery works out to $\$ 390-440 / \mathrm{kWh}$. Since the energy/power ratio varies for the different scenarios addressed in this report, the batteries have been costed using $\$ / \mathrm{kWh}$ numbers. For long-term cost, $\$ 250 / \mathrm{kWh}$ was used for the battery, along with $\$ 150 / \mathrm{kW}$ for PCS and $\$ 100 / \mathrm{kW}$ for BOP. 
Table A.1. Summary of Current Capital Cost Diversity for NaS systems

\begin{tabular}{|c|c|c|c|c|}
\hline $\begin{array}{l}\$ / \mathrm{kWh} \\
\text { current }\end{array}$ & $\begin{array}{c}\$ / \mathrm{kW} \\
\text { current }\end{array}$ & $\begin{array}{l}\$ / \mathrm{kWh} \\
\text { future }\end{array}$ & Notes & Source \\
\hline & & $180-250$ & Battery & $\begin{array}{l}\text { (Boyes, Kamibayashi et al. 2002, Shoenung and Hassenzahl } \\
\text { 2003, Gyuk and Eckroad 2003, Schoenung 2001) }\end{array}$ \\
\hline & & 818 & System & (Gyuk and Eckroad 2003) \\
\hline & 1800 & & Battery & (Greenberg et al ) \\
\hline & 3080 & & Battery & EAC 2008 \\
\hline & $2400-2500$ & & System & (Nourai $2007^{1}$, Kishinevsky $2006^{2}$ ) \\
\hline & 3000 & & System & (Nourai 2010) \\
\hline & $150-240$ & & PCS & $\begin{array}{l}\text { (Shoenung and Hassenzahl 2003, Schoenung 2001, } \\
\text { Kamibayashi et al. 2002, Boyes) }\end{array}$ \\
\hline & 100 & & BOP & (Kamibayashi et al. 2002) \\
\hline \multirow[t]{3}{*}{50} & & & BOP & Boyes \\
\hline & 100 & & BOP & (Gyuk and Eckroad 2003) \\
\hline & $150-450$ & & $\mathrm{PCS}^{3}$ & (Gyuk and Eckroad 2003) \\
\hline
\end{tabular}

The life cycles relationship with DOD of NaS battery is depicted in Figure A.1.Therefore, in the battery sizing model, we put one variable called sizing factor to size up or size down the battery energy capacity, thus determining cycle life. It is also assumed that the calendar life of the batteries is 15 years.

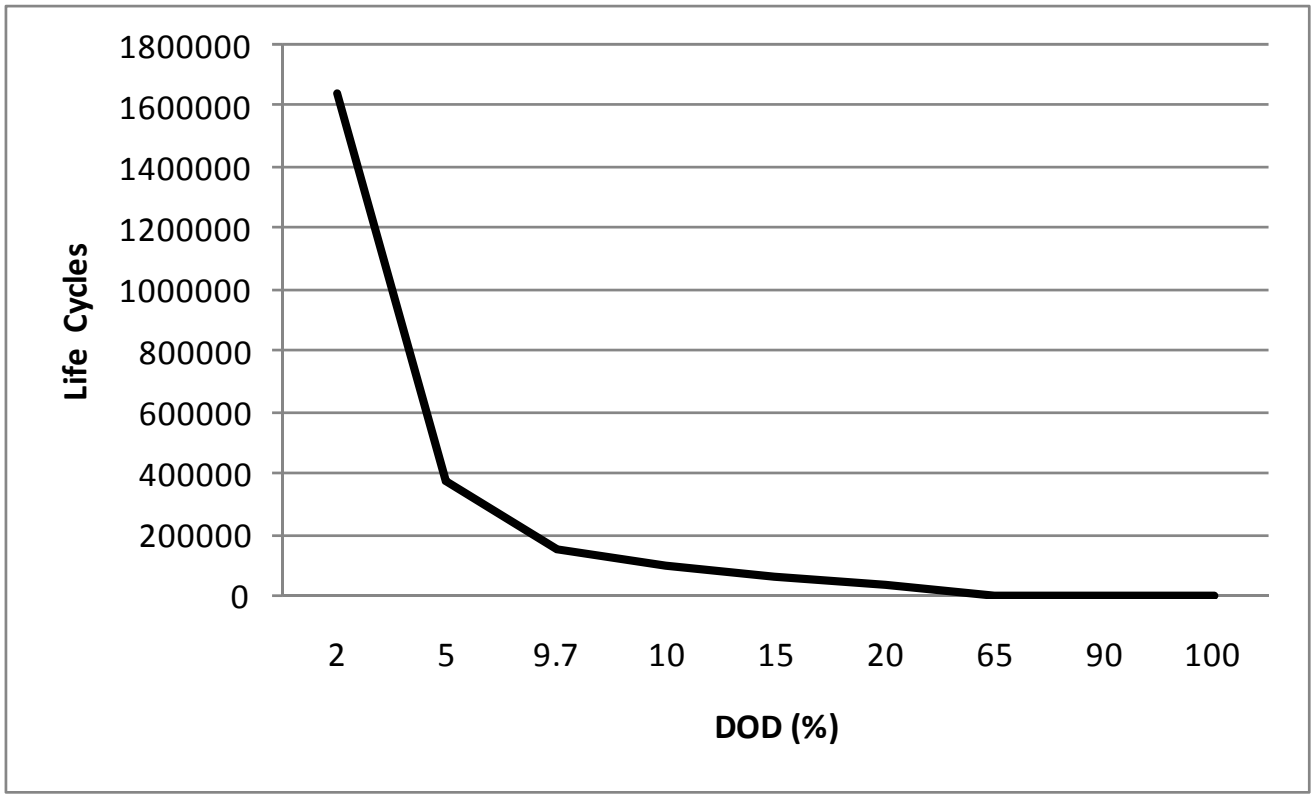

Figure A.1. NaS Life Cycles Versus DOD Curve

\footnotetext{
${ }^{1}$ more reliable 2007 numbers

${ }^{2}$ Reliable - 2006 Long Island Bus actual installation numbers

${ }^{3}$ For short duration application, cost is low, for long duration cost is higher
} 


\section{A.1.3 Fixed O\&M Cost}

The PCS consists of equipment necessary for energy transfer between the grid and energy storage system. The BOP is a catch-all for anything not covered by PCS. This includes project engineering, construction management, transformers for grid connection, land, foundation, building etc. The O\&M costs for BOP has not been included in this analysis, since such costs are expected to be uniform across all technologies. For NaS batteries, fixed O\&M costs given in the literature varied from over a wide range without any consistency on what services are included and which are excluded from the fixed O\&M cost. The low figures start at \$0.5/kW-year(Lamont 2004, Gyuk and Eckroad 2004) and go up to \$51/kW-year (Shoenung and Hassenzahl 2003, Gyuk and Eckroad 2003), which includes insurance and property taxes. For the purpose of this study, we used $\$ 3 / \mathrm{kW}$-year as the fixed O\&M cost, which corresponds to $\$ 0.46 / \mathrm{kWh}$ for $\mathrm{E} / \mathrm{P}$ of 6.5 . Since the $\mathrm{E} / \mathrm{P}$ ratio for the batteries used varies, we have used $\$ 0.46 / \mathrm{kWh}$ as fixed O\&M cost in this report.

\section{A.1.4 Variable O\&M Cost}

Variable costs have traditionally been reported in cents/kWh, and ranged from 0.4-0.7 cents/kWh, where kWh is the cumulative energy out of the battery (Lamont 2004, Schoenung et al. 1996). The variable O\&M cost for NaS systems for various applications ranged from \$2.6-13.4/kW-year (Gyuk and Eckroad 2003). An average of these values yields $\$ 7 / \mathrm{kW}$-year, while conversion of this to $\$ / \mathrm{kWh}$ yields 0.4-0.8 cents $/ \mathrm{kWh}$. Table A. 2 summarizes the O\&M cost estimates as found in the literature.

Table A.2. Summary of O\&M fixed and Variable Costs for NaS Battery

\begin{tabular}{lll}
\hline \multicolumn{1}{c}{ Fixed O\&M (\$/kW-year) } & \multicolumn{1}{c}{ Variable O\&M } & \multicolumn{1}{c}{ Reference } \\
\hline 3 & $16.9(\$ / \mathrm{kW}$-year) & $\begin{array}{l}\text { Gyuk and Eckroad 2004 } \\
\text { (Shoenung and Hassenzahl 2003) }\end{array}$ \\
20 & & (Gyuk and Eckroad 2003) \\
$13-51$ (\$2/kW-year for PCS) & $2.6-13.4(\$ / \mathrm{kW}$-year) & (Lamont 2004) \\
0.5 & 0.7 cents $/ \mathrm{kWh}$ & (Schoenung et al. 1996) \\
1.5 & 0.5 cents/kWh & Selected for study \\
$\mathbf{\$ 0 . 4 6 / k W h}$ & $\mathbf{0 . 7}$ cents $/ \mathbf{k W h}$ & \\
\hline
\end{tabular}

\section{A.1.5 Efficiency}

For NaS batteries, the AC-AC efficiency was in the range of 0.75-0.85(Kishinevsky 2006, Shoenung and Hassenzahl 2003, Schoenung 2001, Technology Insights 2005). We chose a roundtrip efficiency of 0.78. For the Li-ion battery, the efficiency was estimated to be 0.8 Rastler et al. 2007. These figures correspond to battery system efficiencies that include all of the losses in the PCS. The specific PCS efficiency was estimated to be 0.95 . The roundtrip efficiency is expected to change as a function of charge and discharge rate. For this analysis, the efficiency is kept constant for all rates. 


\section{A.2 Li-ion Battery}

\section{A.2.1 Battery Sizing}

Li-ion batteries from various applications have various power to energy (P/E) ratios, ranging from 60 for hybrid electric vehicles (HEVs) to 4-16 for plug-in hybrid electric vehicles (PHEV) batteries ${ }^{1}$. In the transportation sector, $\mathrm{P}$ is defined as the power delivered by the battery for 2 seconds. For our application, the minimum resolution is 1 minute. Typically, Li-ion batteries can be discharged continuously at the maximum rate of $2 \mathrm{C}$ for $\sim 20$ minutes, with a $\mathrm{P} / \mathrm{E}$ ratio of 1.3 , where $\mathrm{C}$ is the energy capacity of the battery in Wh. For 1-2 minute duration, it can be assumed that the P/E for Li-ion batteries is $\sim 2$. This value will vary with the battery design, with high power battery having larger P/E ratios. Hence, in order to determine actual cost of battery, it must be determined whether power or energy is limiting, needs to be done. It is important to consider not just the maximum power requirements, but how long this maximum power will be needed continuously. This will fix the smallest battery energy content that would meet the power requirement after taking into account battery degradation.

\section{A.2.2 Capital Costs}

Present day Li-ion batteries cost ranges from $\$ 1015-1450 / \mathrm{kWh}$ (Divya and Østergaard 2009)and $\$ 1000 / \mathrm{kWh}$ (Howell 2009). Other cost values given in \$/KW are $\sim \$ 1070 / \mathrm{kW}$ (EAC 2008) and \$970/kW (Gyuk and Eckroad 2003) with the higher cost including PCS and BOP costs. These numbers can be confusing, since the $\$ / \mathrm{kW}$ cost would equal $\$ / \mathrm{kWh}$ for a 1 -hour application, while it would be twice the $\$ / \mathrm{kWh}$ value for a 2-hour application. Telephone conversations with various battery manufacturers yielded a current price of $\$ 700$ to $1500 / \mathrm{kWh}$, with the price for large volume sales of 1000 batteries or more in 5 years estimated at $\$ 600 / \mathrm{kWh}$. Cost estimation models from Argonne National Laboratory (ANL), Tiaxx and The US Advanced Battery Consortium (USABC) (Nelson et al. 2009, Barnett et al. 2009, USCAR 2007), when normalized to the same total energy, provided a cost of $\$ 440,415$ and $450 / \mathrm{kWh}$ respectively for large-volume production, or $\sim \$ 420 / \mathrm{kWh}$. Taking the average of $\$ 600 / \mathrm{kWh}$ and $\$ 420 / \mathrm{kWh}$, the cost to be used for this study was assumed to be $\$ 510 / \mathrm{kWh}$ long-term for high volume production. The long-term costs were $\$ 510 / \mathrm{kWh} * 2.35=\$ 1200 / \mathrm{kW}$. Table A.3 summarizes the cost information for Li-ion batteries:

\footnotetext{
${ }^{1}$ http://www.transportation.anl.gov/pdfs/HV/434.pdf
} 
Table A.3. Summary of Current Capital Cost Diversity for Li-ion Systems

\begin{tabular}{|c|c|c|c|}
\hline$\$ / \mathrm{kWh}$ current & $\$ / \mathrm{kW}$ current & $\begin{array}{c}\text { \$/kWh } \\
\text { high volume }\end{array}$ & Source \\
\hline 700-1000 Euros & -- & -- & (Divya and Østergaard 2009) \\
\hline \multirow[t]{3}{*}{1000} & -- & & (Howell 2009) \\
\hline & $\begin{array}{c}1070 \text { includes PCS } \\
\text { and BOP }\end{array}$ & & (EAC 2008) \\
\hline & 970 & & (Gyuk and Eckroad 2003) \\
\hline $\begin{array}{l}1500 \text { (60,000 } \\
\text { cells/year) }\end{array}$ & & $\begin{array}{c}1000-1250 \\
(180,000 \text { cells/year })\end{array}$ & $\begin{array}{l}\text { Lithium technology Corp. } \\
\text { (LTC) (Hazel 2010) }\end{array}$ \\
\hline 700 & & & $\begin{array}{l}\text { Lithium technology Corp. } \\
\text { (LTC) (Hazel 2010) }\end{array}$ \\
\hline $\begin{array}{c}1000-1200(1000+ \\
\text { batteries/year) }\end{array}$ & & $\begin{array}{l}\text { 500-700 (5 years } \\
\text { from now) }\end{array}$ & Compact Power (Riedel 2010) \\
\hline \multirow[t]{4}{*}{1000} & & & BASF (Chintawar 2010) \\
\hline & & 415 & ANL( Nelson et al. 2009) \\
\hline & & $440^{(a)}$ & TIAXX ( Barnett et al. 2009) \\
\hline & & 450 & USABC（USCAR 2007) \\
\hline
\end{tabular}

The life cycles versus DOD curve of Li-ion batteries is shown in Figure A.2.

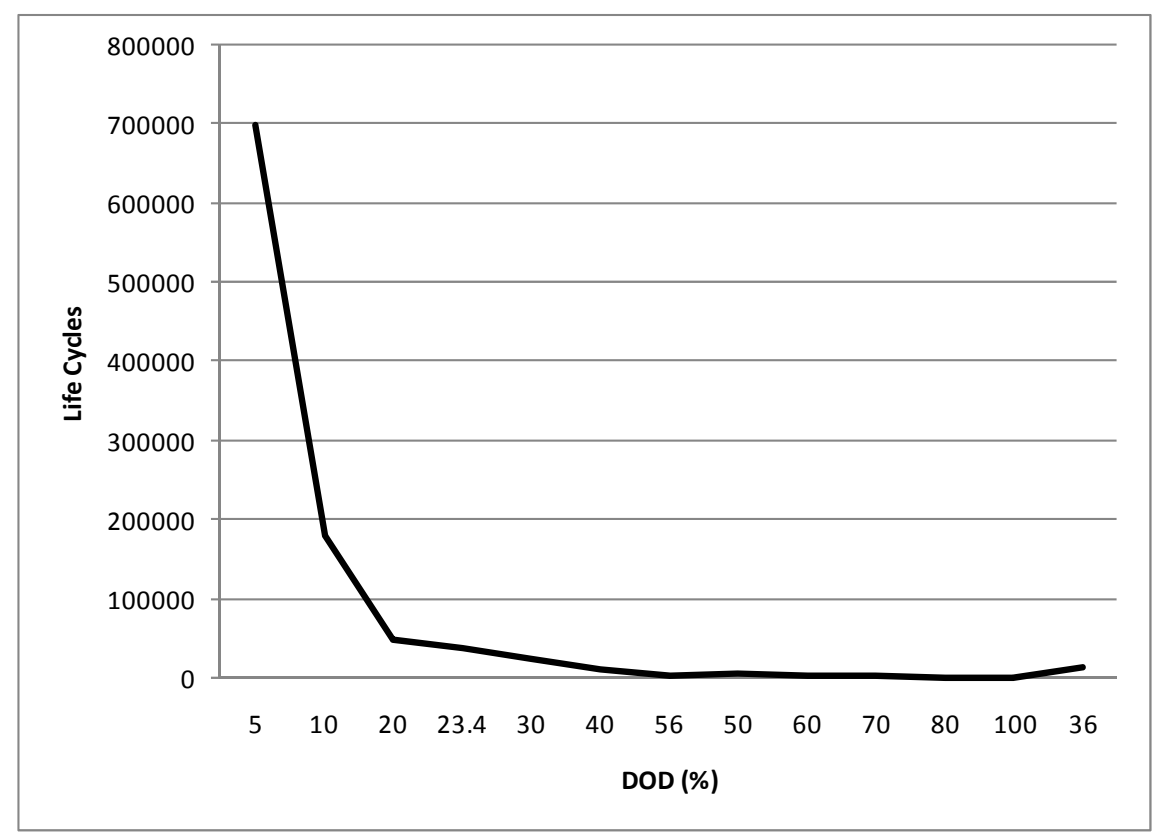

Figure A.2. Li-ion Battery Life Cycle versus DOD Curve 


\section{A.3 Pumped Hydroelectric (PH) Systems}

\section{A.3.1 Capital and O\&M Costs}

For $\mathrm{PH}$ systems, the capital cost are provided in $\$ / \mathrm{kW}$. Most systems provide this information by including PCS and BOP costs. For this analysis, BOP costs for PH will be neglected, since the values provided in the literature are as small as $\$ 4 / \mathrm{kWh}$. Additional capital cost information was provided by Rick Miller of Renewable Energy Services in several email communications (Miller 2010) ${ }^{19,25}$. The capital costs for single speed PH systems is in the range of $\$ 1500$ to $2500 / \mathrm{kW}$, while the range for variable speed pumps is $\$ 1800$ to $3200 / \mathrm{kW}$. This cost is broken down into three parts:

1. pump/turbine and motor/generator costs, $(\$ 600 / \mathrm{kW}$ for single-speed and $\$ 850 / \mathrm{kW}$ for variable-speed units)

2. Hydro-mechanical equipment, transformers, switchgears, remaining BOP

3. owner's costs, engineering/design services, civil construction, excavations and construction for water conveyance system, upper and lower dams and reservoirs.

The pump and turbine costs typically for pumped hydro projects varies significantly, and has been reported to be as low as $\$ 78 / \mathrm{kW}$ to $264 / \mathrm{kW}$ (GE Energy 2004, Alstom 2009). Since these costs are about $33 \%$ of total system cost, they also contribute to large variation in system cost, in addition to siting related contribution.

A range of values was obtained from the literature on capital costs, O\&M fixed and O\&M variable for PH systems is shown in Table A.4. While replacement costs are minimal the generators need rewinding every $20-25$ years.

The overall efficiency is 80 to $82 \%$, and does not include transmission losses. It should be noted that the reported $75 \%$ efficiency probably includes transmission losses. 
Table A.4. Capital Costs for Pumped Hydro Systems

\begin{tabular}{|c|c|c|c|c|}
\hline$\$ / \mathrm{kW}$ & $\begin{array}{l}\text { O\&M fixed } \\
\$ / k W \text {-year }\end{array}$ & $\begin{array}{l}\text { O\&M Variable } \\
\text { cents/kWh }\end{array}$ & $\begin{array}{l}\text { Efficiency } \\
\text { AC-AC }\end{array}$ & Reference \\
\hline 1000 & 2.5 & Very small & 0.75 & (Shoenung and Hassenzahl 2003) \\
\hline 600 & 3.8 & 0.38 & 0.87 & (Schoenung 2001) \\
\hline 1483 & & & & (Geadah 2009) \\
\hline 1552 & & & & (Geadah 2009) $^{(\mathrm{a})}$ \\
\hline \multirow[t]{3}{*}{$>350 € / \mathrm{kW}$} & & & $0.70-0.80$ & Fodstad \\
\hline & & 2 & 0.75 & (Rahman 1990) \\
\hline & & & 0.75 & (First Hydro Company 2009, Jenkinson 2005) \\
\hline 1500 & & & 0.82 & $(\text { NHC 2007) })^{(\mathrm{c})}$ \\
\hline 1000 & & & & (Boyes) \\
\hline $1800-3200^{(d)}$ & & & $0.78-0.82$ & (Miller 2010) \\
\hline $517,583^{(e)}$ & 4.6 & & $0.80^{(\mathrm{f})}$ & (Figueiredo et al. 2006) \\
\hline $1100-2000^{(g)}$ & 4.3 & $0.43^{(\mathrm{h})}$ & $0.60-0.78$ & (Lipman et al. 2005) \\
\hline $1700^{(\mathrm{i})}$ & & & & (Miller 2010) \\
\hline
\end{tabular}

(a) 2016-2020 costs

(b) At Dinorwig (1800 MW 1.5 min start-up)

(c) $500 \mathrm{MW}$ fully dispatchable in 15 seconds with unit spinning, 10 min black start

(d) $\$ 1500-2500 / \mathrm{kW}$ for single speed

(e) $\$ 517 / \mathrm{kW}$ Grand Cache $218 \mathrm{MW}$, \$583/kW Kneehills $194 \mathrm{MW}$

(f) Efficiency set at 0.8, not measured

(g) Projected cost for year 2020 was $\$ 800 / \mathrm{kW}$

(h) Referenced Schoenung et al. 1996

(i) $\$ 245 / \mathrm{kW}$ for pump turbine, motor generator and power electronics

\section{A.3.2 Duration between various modes}

The response time for $\mathrm{PH}$ systems is fast, achieving high ramp rates as high as3 MW/s (First Hydro Company 2009). The calendar life was estimated to be 50 years (Schoenung 2001). Figure A.3 shows typical start and stop times for PH systems. 


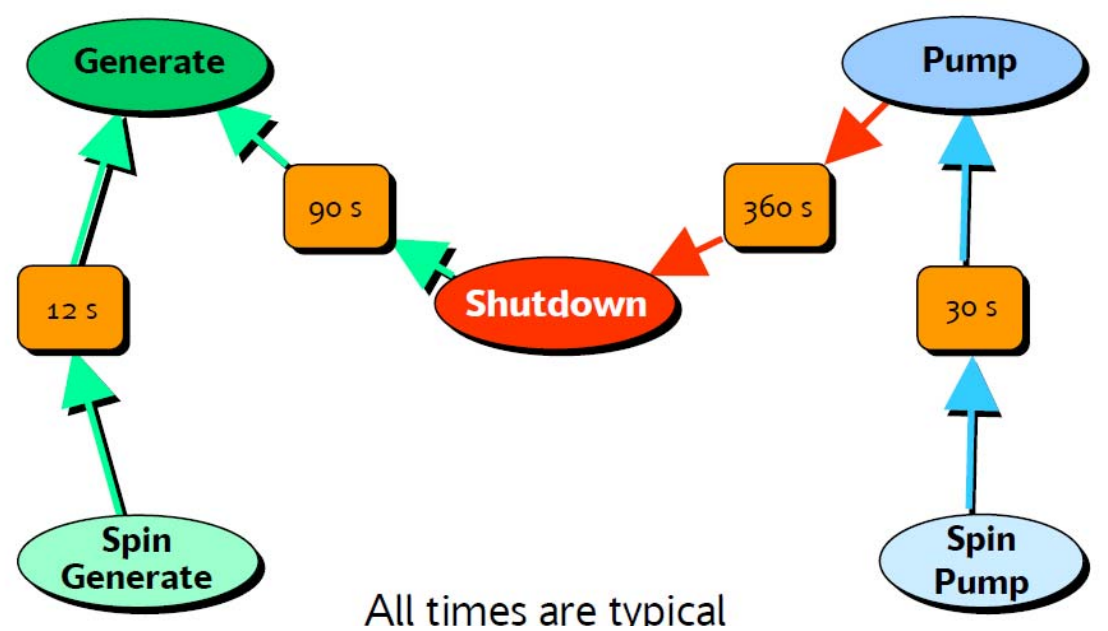

Figure A.3. Typical duration between various modes at Dinorwig PH system (Jenkinson 2005)

After several consultations with turbine and pumped hydro storage system experts, we assume a delay of 4 minutes to switch operating modes in each direction (pumping to generation and vice versa). 

Appendix B

\section{Specific Operational Strategies to Meet Balancing Requirements}





\section{Appendix B}

\section{Specific Operational Strategies to Meet Balancing Requirements}

To explore different operational strategies and how their selection will impact balancing requirements, several technology cases were introduced in Section 3.2. Table 3.4 provided a brief outline of the different cases, and is replicated on the next page as Table B.1 for convenience. A more detailed description of each case in Table B.1 is presented in the sections of this appendix.

\section{B.1 Case 1: Combustion Turbines}

The base case for operational strategies involves the use of only combustion turbines (CTs) for energy balancing requirements. Part load efficiencies are considered in the CT implementations. This scenario represents a case similar to current operational procedures.

\section{B.2 Case 2: NaS batteries + CC}

The second scenario utilizes NaS batteries and combined cycle (CC) generation to meet balancing requirements. Figure B.1 shows the power output of the NaS battery storage and combined cycle generator over a two-day period. Combined cycle generation is used to compensate for the efficiency loss of the batteries, and to provide a constant energy source for the batteries to assure a net zero energy change over the course of the entire day. As such, the NaS contributions are actually the difference between the blue line and red line at each interval. If above the red line, the $\mathrm{NaS}$ battery is discharging into the system. If below the red line, the storage is charging.

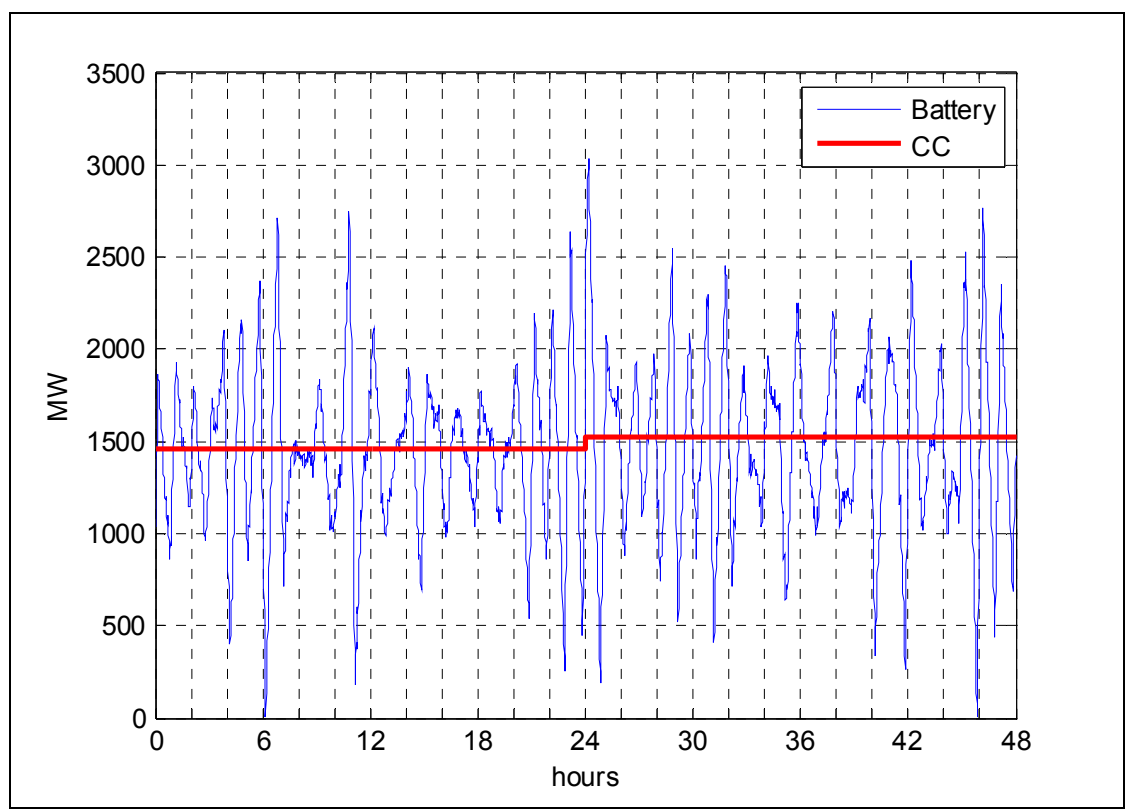

Figure B.1. Power Output of NaS Battery and Combined Cycle Generation for 2-day Period 
Table B.1. Definition of Technology Cases

\begin{tabular}{|c|c|c|c|}
\hline & Case & Technology & Comments \\
\hline \multirow{6}{*}{ 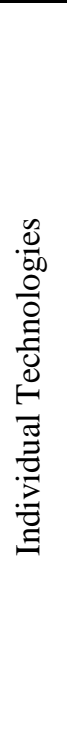 } & $\mathrm{C} 1$ & Combustion turbine & Conventional technology considered as the reference case \\
\hline & $\mathrm{C} 2$ & $\mathrm{NaS}$ & Sodium-sulfur battery only \\
\hline & $\mathrm{C} 3$ & Li-ion & Lithium-ion battery only \\
\hline & $\mathrm{C} 4$ & PH with multiple mode changes & $\begin{array}{l}\text { Pumped hydro with a 4-minute waiting period for mode changes } \\
\text { (pumping-generation and vice versa). This machine allows to } \\
\text { multiple mode changes during the day. NaS battery is assumed } \\
\text { to make up operations during } 4 \text { minute waiting period. }\end{array}$ \\
\hline & C5 & PH with 2 mode changes & $\begin{array}{l}\text { Same as (C4), except only two mode changes. Balancing } \\
\text { services will be provided during pumping mode at night (8pm- } \\
\text { 8am) and during generation mode during the day (8am-8pm). } \\
\text { NaS battery is assumed to make up operations during } 4 \text { minute } \\
\text { waiting period. }\end{array}$ \\
\hline & C6 & $\mathrm{DR}$ & $\begin{array}{l}\text { Demand response only. This assumes that balancing services } \\
\text { will be provided as a load. Only considered are two residential } \\
\text { end-uses: } 1 \text { ) hot water heating and 2) PHEV charging at home. } \\
\text { Resources will expressed in MW of DR capacity as well as in } \\
\text { numbers of homes having one hot water heater and one PHEV }\end{array}$ \\
\hline \multirow{6}{*}{ 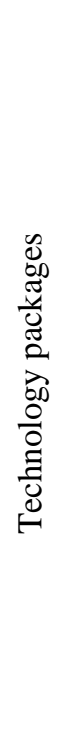 } & C7 & $\mathrm{NaS}$ & Sodium-culfur battery and demand resnonse combined \\
\hline & & DR & 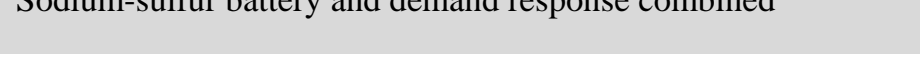 \\
\hline & $\mathrm{C} 8$ & $\begin{array}{l}\text { Li-ion } \\
\text { DR }\end{array}$ & Lithium-ion battery and demand response combined \\
\hline & C9 & $\begin{array}{l}\text { PH with multiple mode chances } \\
\mathrm{NaS}\end{array}$ & $\begin{array}{l}\text { Pumped hydro with no constraints for mode changes with NaS } \\
\text { battery. The balancing requirement is allocated to } 25 \% \text { to } \\
\text { pumped hydro and } 75 \% \text { to NaS battery. This share is set } \\
\text { arbitrarily. }\end{array}$ \\
\hline & $\mathrm{C} 10$ & $\begin{array}{l}\text { PH with } 2 \text { mode changes } \\
\mathrm{NaS}\end{array}$ & $\begin{array}{l}\text { Pumped hydro with two mode changes per day (see C5) with } \\
\text { NaS battery. The balancing requirement is allocated to } 25 \% \text { to } \\
\text { pumped hydro and } 75 \% \text { to NaS battery. This share is set } \\
\text { arbitrarily. }\end{array}$ \\
\hline & C11 & $\begin{array}{l}\text { PH with multiple mode changes } \\
\text { NaS/DR }\end{array}$ & $\begin{array}{l}\text { Pumped hydro with no constraints for mode changes with NaS } \\
\text { battery and DR. The balancing requirement is allocated to } 25 \% \\
\text { to pumped hydro, } 20 \% \text { DR (about } 1 \text { million homes and PHEVs) } \\
\text { and } 55 \% \text { to NaS battery. This share is set arbitrarily. }\end{array}$ \\
\hline
\end{tabular}

\section{B.3 Case 3: Li-ion + CC}

The third scenario focuses on the use of Li-ion batteries and combined cycle generation. The scenario is executed in an identical manner to Case 2 above, but the higher efficiency NaS batteries are replaced with Li-ion batteries. Combined cycle generation is once again utilized to compensate for efficiency losses in the battery storage and to ensure a balanced energy transfer over the day. The efficiency of Liion batteries was nearly identical to that of $\mathrm{NaS}$ batteries for this case (78.9\% compared to $80 \%$ ), so the power output of Figure B.1 is representative of the Li-ion battery and combined cycle case as well. 


\section{B.4 Cases 4: Pumped Hydro with Multiple Mode Changes + CC}

Technology Case 4 utilizes pumped hydro generation for the primary balancing requirement. For this particular case, the pumped hydro has no mode switching limit. The pumped hydro storage can switch between pumping and generation modes as many times as necessary during the day. This results in approximately 40 mode changes a day, which can cause a considerable drop in the expected lifetime of the equipment (Spitzer and Penninger 2008). Mode changes experience a 4-minute changeover delay. During the changeover, NaS batteries are utilized to cover the balancing requirements. Figure B.2 demonstrates this implementation. As with the previous cases, combined cycle generation is utilized to compensate for the efficiency losses of both the NaS battery and pumped hydro, as well as balance the energy consumption in the storage.

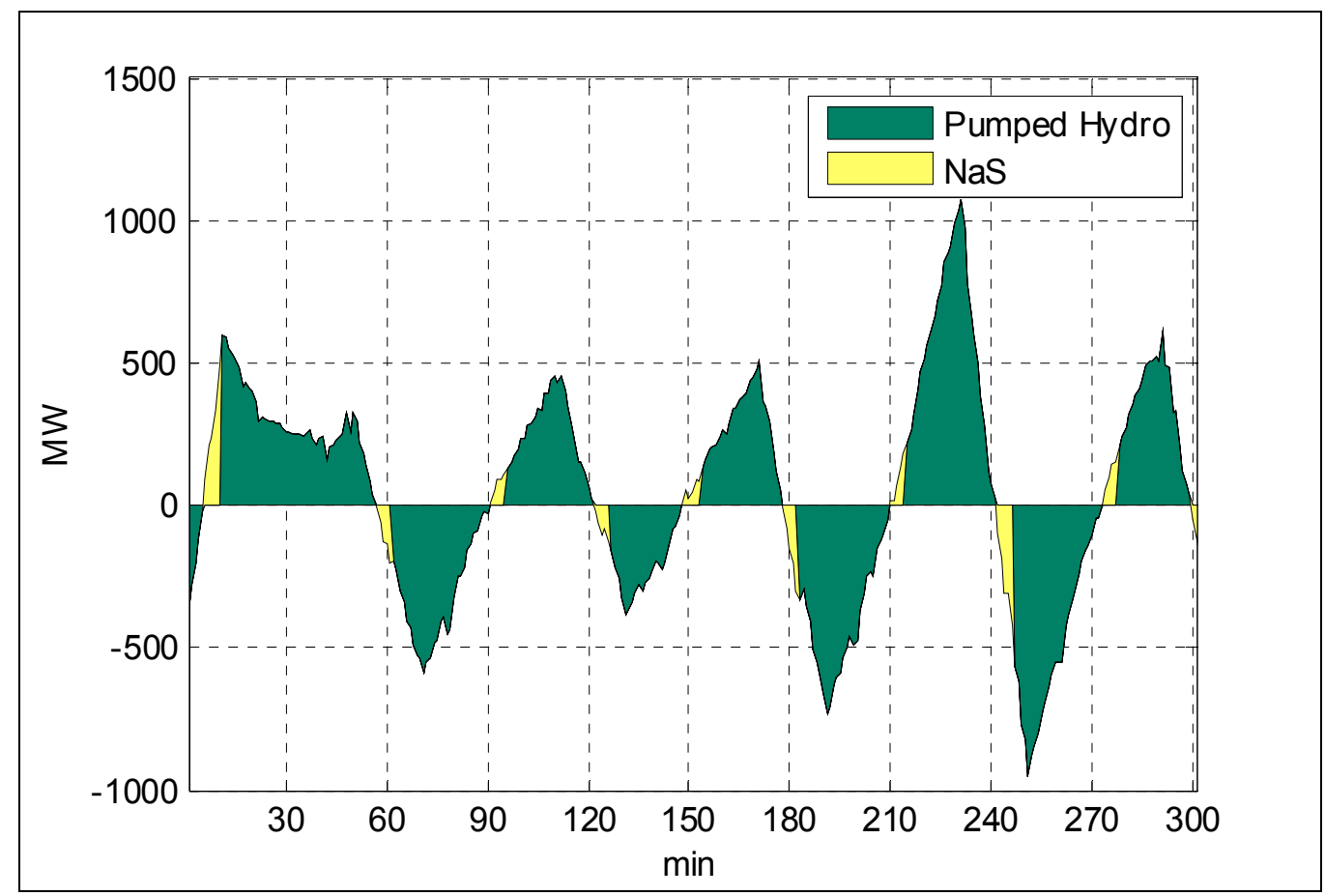

Figure B.2. Balancing Signal Taken by Pumped Hydro and NaS Battery When the Changeover Delay is Modeled

\section{B.5 Case 5: Pumped Hydro with Two Mode Changes + CC}

Technology Case 5 is very similar to scenario in Case 4. However, the pumped hydro storage is restricted to two mode changes per day. The pumped hydro operates in pump mode from 8 PM to 8 AM, and operates in generation mode from $8 \mathrm{AM}$ to $8 \mathrm{PM}$ each day. This reduced number of mode changes increases the expected lifetime of the equipment, when compared to Case 4. As with Case 4, a 4-minute changeover delay is incorporated into the pumped hydro system. This changeover delay is again handled by supplementary NaS battery storage. Combined cycle generation is not only utilized to compensate for efficiency losses in the battery and pumped hydro storage, but also to provide additional pumping power. Figure B.3 represents the power output of the pumped hydro storage when restricted to only two operating modes. The yellow areas associated with the NaS storage are not visible on this plot, as they only represent 8 minutes out of the 24-hour period. 


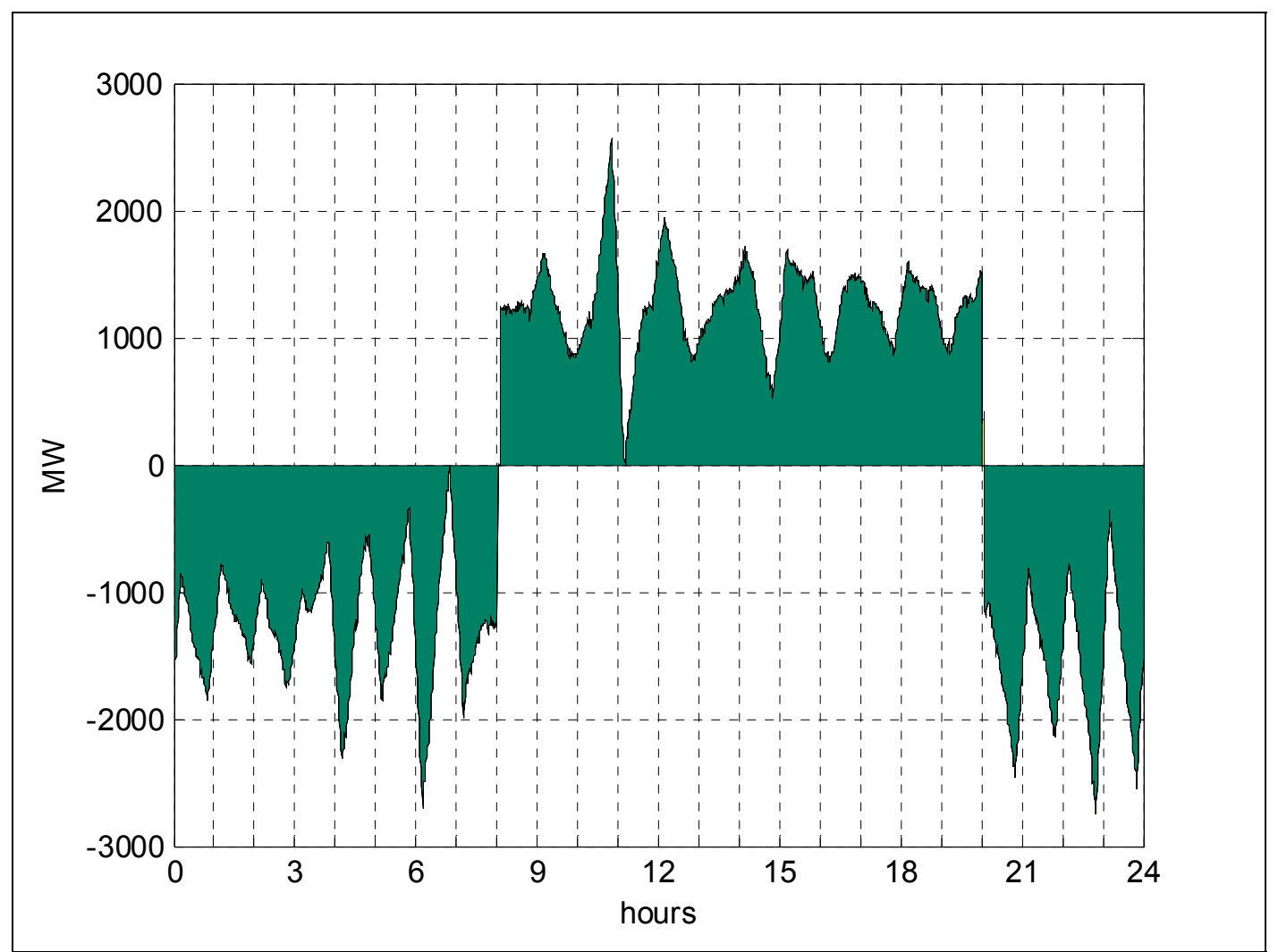

Figure B.3. Power Output of Pumped Hydro with Only Two Mode Changes Per Day

\section{B.6 Case 6: Demand Response}

Technology Case6 utilizes a different scenario to meet the balancing requirements. Using demand response, the load of the system is adjusted to meet the varying energy demands of the system, rather than using an energy storage solution. Pure demand response balancing was accomplished using three different device combinations: PHEV charging where both home and work charging was assumed available; water heater control; and a combination of home-only PHEV charging and water heater control.

The energy capabilities of the demand response studies were based on two basic assumptions. The first is the overall loading curves for the PHEV charging scenarios and water heater control follow the trends shown in Figure B.4. Theses curves represent the load from a single device of each type. This capacity was then scaled by number of devices required to meet the balancing requirements for the simulation interval. These quantities are shown in Table B.2. 


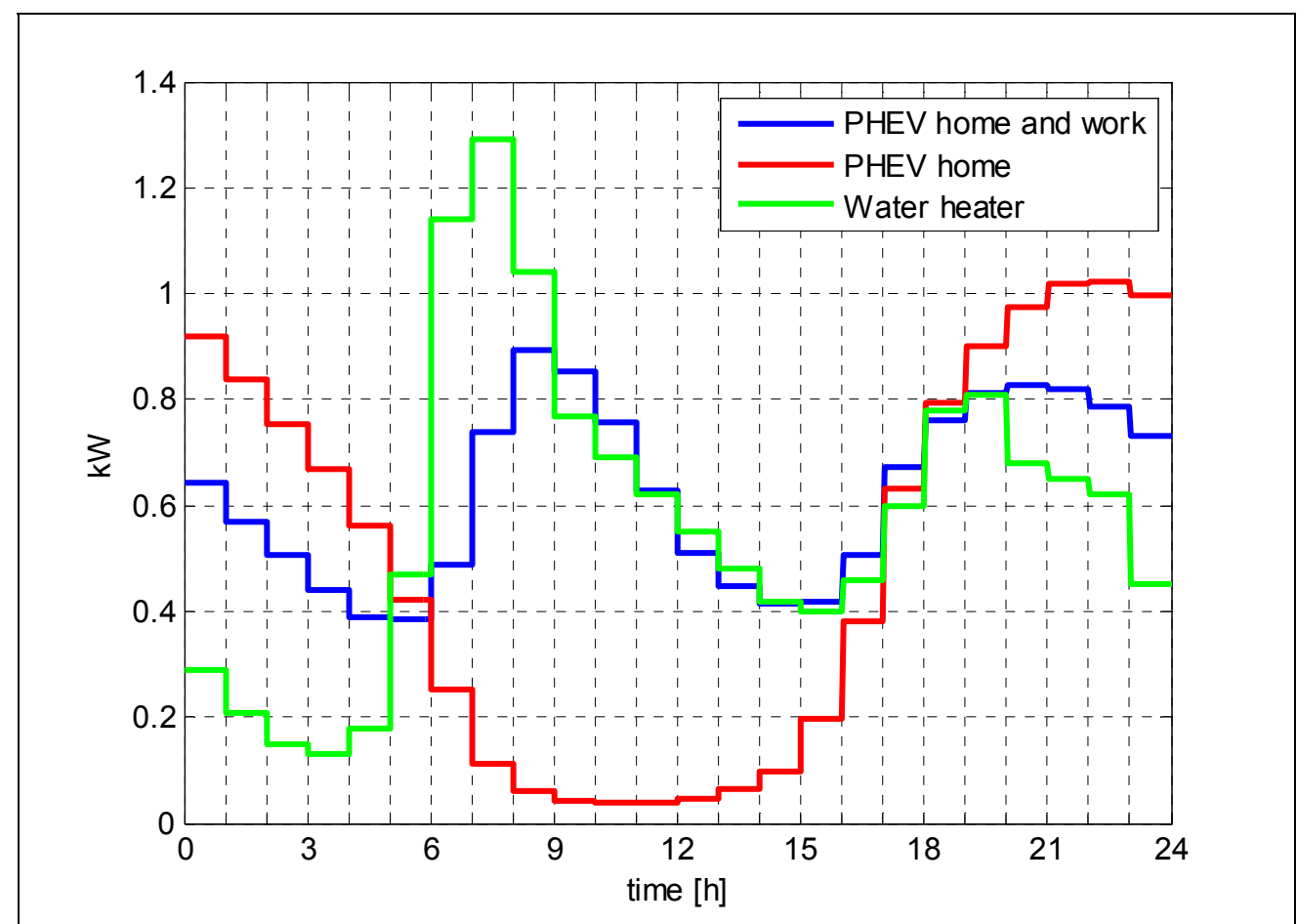

Figure B.4. Load Curves for PHEV with Home and Work Charging, PHEV with Home Charging, and Water Heater

Table B.2. Number of Demand Response Devices Necessary to Provide Total Balancing Services

\begin{tabular}{llcc}
\hline \multicolumn{1}{c}{ Demand Response Scenario } & \multicolumn{1}{c}{ Description } & $\begin{array}{c}\text { Number of } \\
\text { Devices }\end{array}$ & $\begin{array}{c}\text { Maximum } \\
\text { Resource }\end{array}$ \\
\hline PHEV only & PHEV - home \& work & 9 Million & $8 \mathrm{GW}$ \\
Water heaters only & Water heaters - Week day & 21.8 Million & $28 \mathrm{GW}$ \\
PHEV + Water heaters & PHEV - home & 5 Million & $8.6 \mathrm{GW}$ \\
& Water heaters - Week day & 5 Million & \\
\hline
\end{tabular}




\section{B.6.1 DR - PHEV with Home and Work Charging}

The first equipment demand response equipment scenario utilizes PHEV charging that is available both at home and during work hours. After scaling by the number of devices in Table B.2, the demand curve seen in red in Figure B.5 is produced. The numbers obtained in Table B.2 represent the number of devices (PHEVs), $M$, that are required to meet the balancing requirement. The balancing signal available from this PHEV charging scheme is shown in blue in Figure B.5.

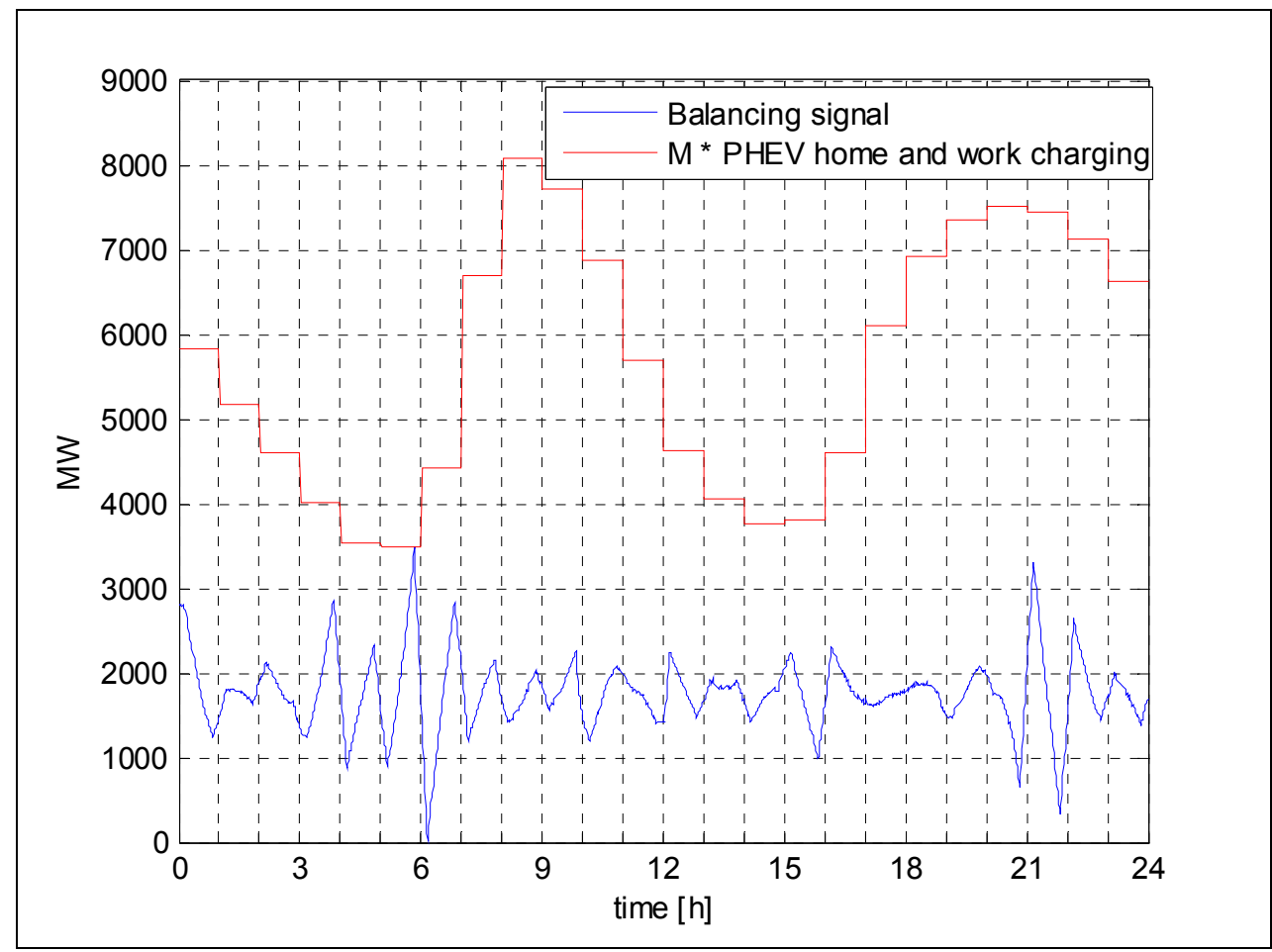

Figure B.5. Balancing Signal and Demand Response Requirement from PHEV Only With Home and Work Charging 


\section{B.6.2 DR - Water Heaters}

The second equipment scenario utilizes only water heaters for demand response capabilities. The larger peak value and larger number of available water heaters results in the demand curve shown in Figure B.6. It is useful to point out the difference in the load curve means significantly more water heater load is required for demand response to meet the balancing requirements.

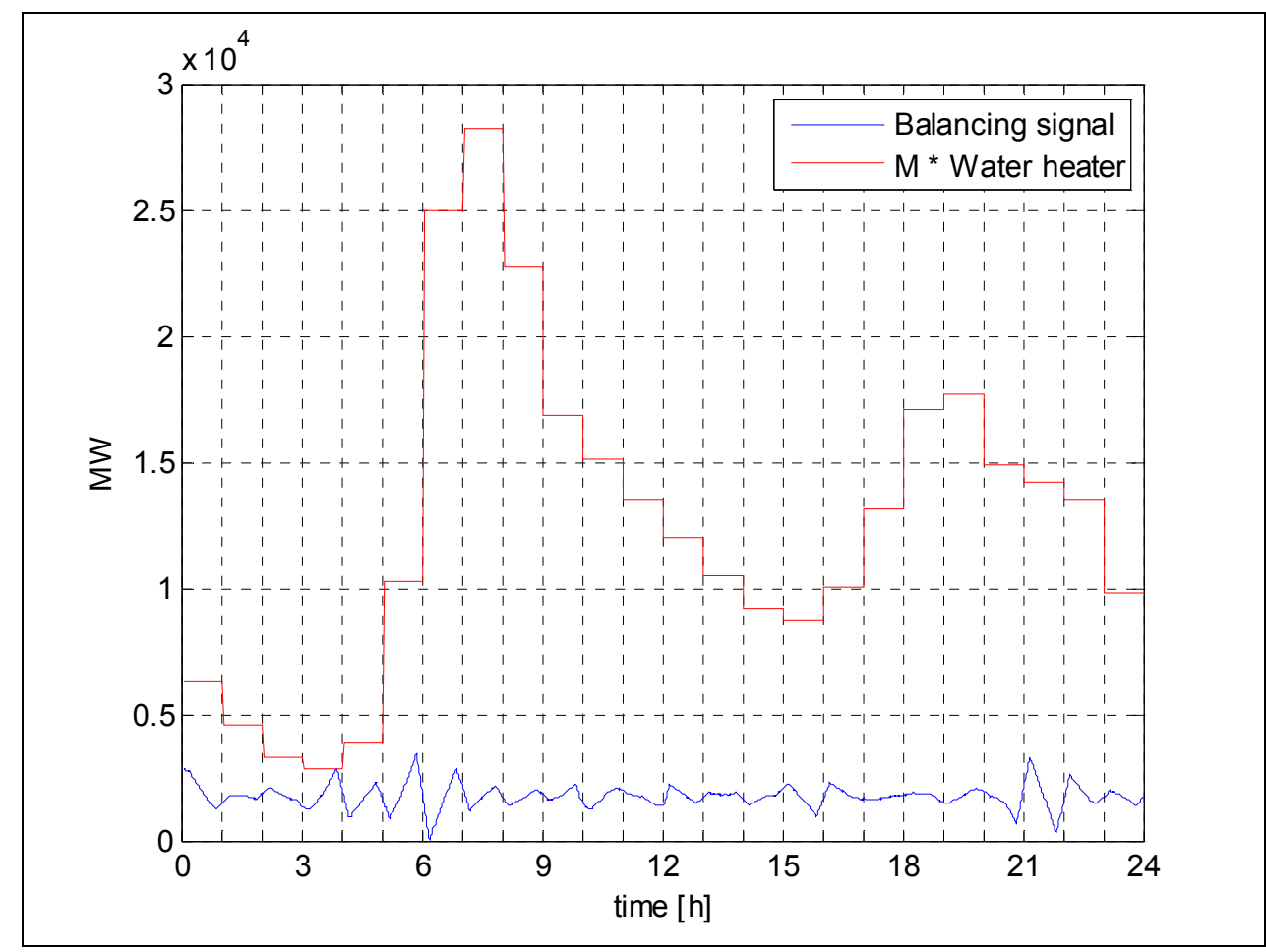

Figure B.6. Balancing Signal and Demand Response Requirement From Water Heaters Only 


\section{B.6.3 DR - Water Heaters}

The final equipment scenario utilizes both PHEV-charging and water heaters for demand response. Unlike the first equipment set, the PHEV is assumed to only charge when it is at home. The combination of the PHEV and water heater loading curves results in the curve of Figure B.7. As Figure B.7 indicates, the peak associated with the demand response devices is significantly lower than the curve associated with the water heater-only scenario. Table B.2 reinforces this observation with a much smaller requirement in the number of demand-response capable devices.

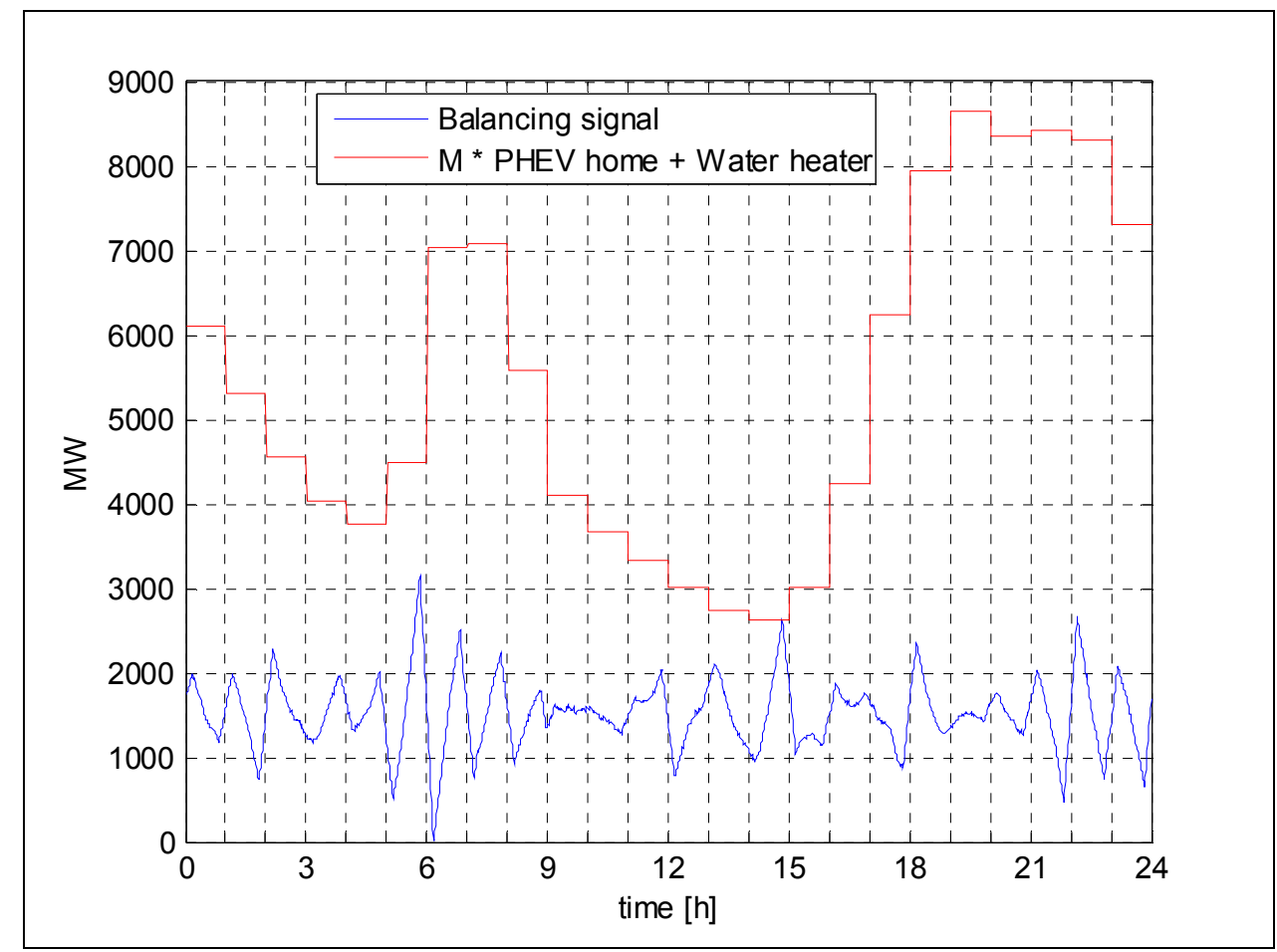

Figure B.7. Balancing Signal and Demand Response Requirement from Water Heaters and PHEV with Home Charging

\section{B.7 Case 7: CC + NaS + DR}

The seventh technical case utilizes a combination of combined cycle generation, NaS battery storage, and demand response to meet the balancing requirements. Without ramp-rate constraints, the balancing requirements were divided proportionally between the NaS storage and demand response. Demand response capabilities were modeled after the "PHEV-home charging and water heater control" example of the previous technology case. Figure B.8 shows the required scaling to meet the demand response portion of the balancing requirement. Supplemented with NaS battery storage, the amount of demand response required is significantly less than the previous technology case. Figure B.9 shows the NaS battery storage portion of the balancing requirement. As with the previous battery cases, combined cycle generation was used to compensate for battery efficiencies, as well as meet the net energy constraints for the battery storage. 


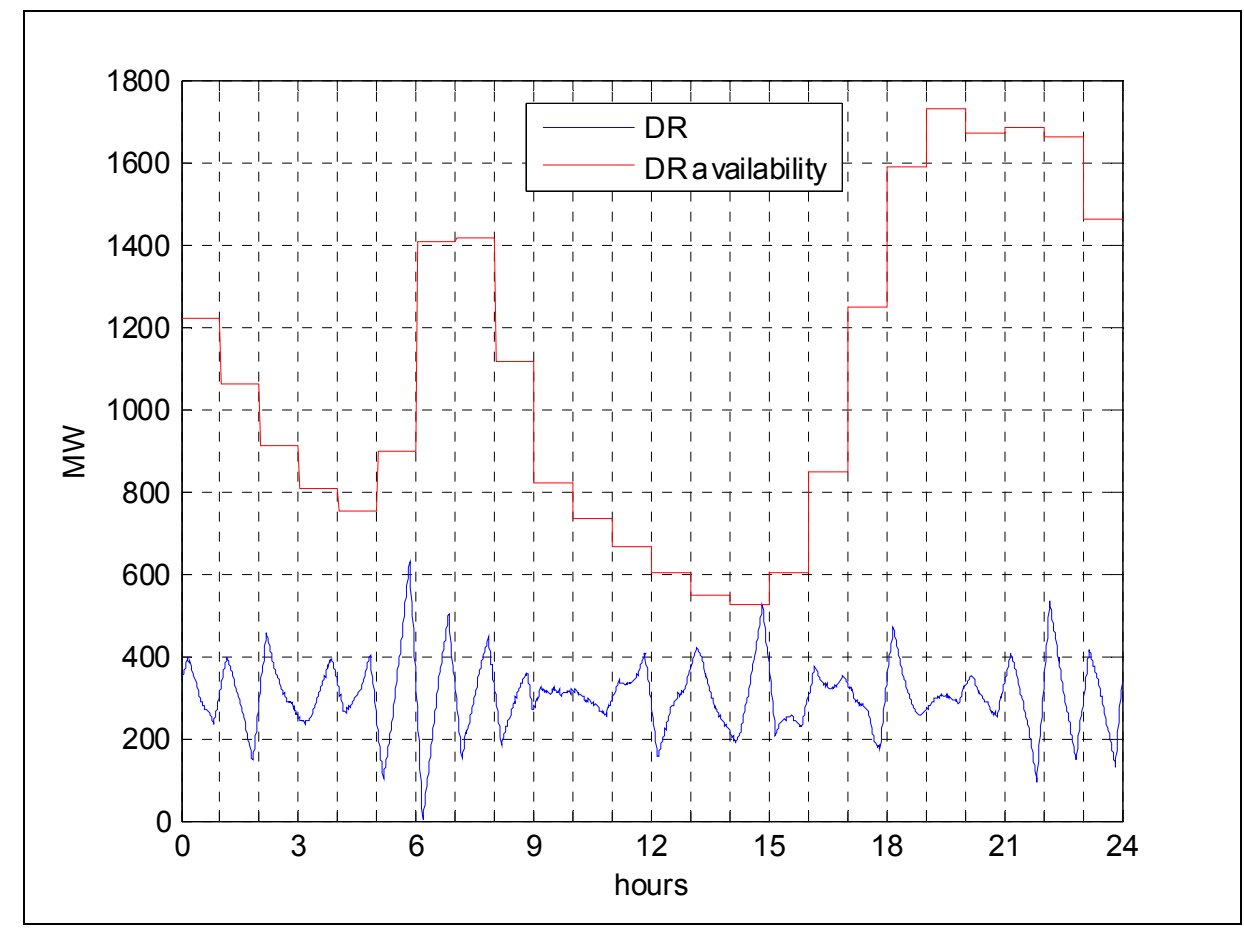

Figure B.8. Demand Response (DR) Availability and Balancing Signal Followed by DR

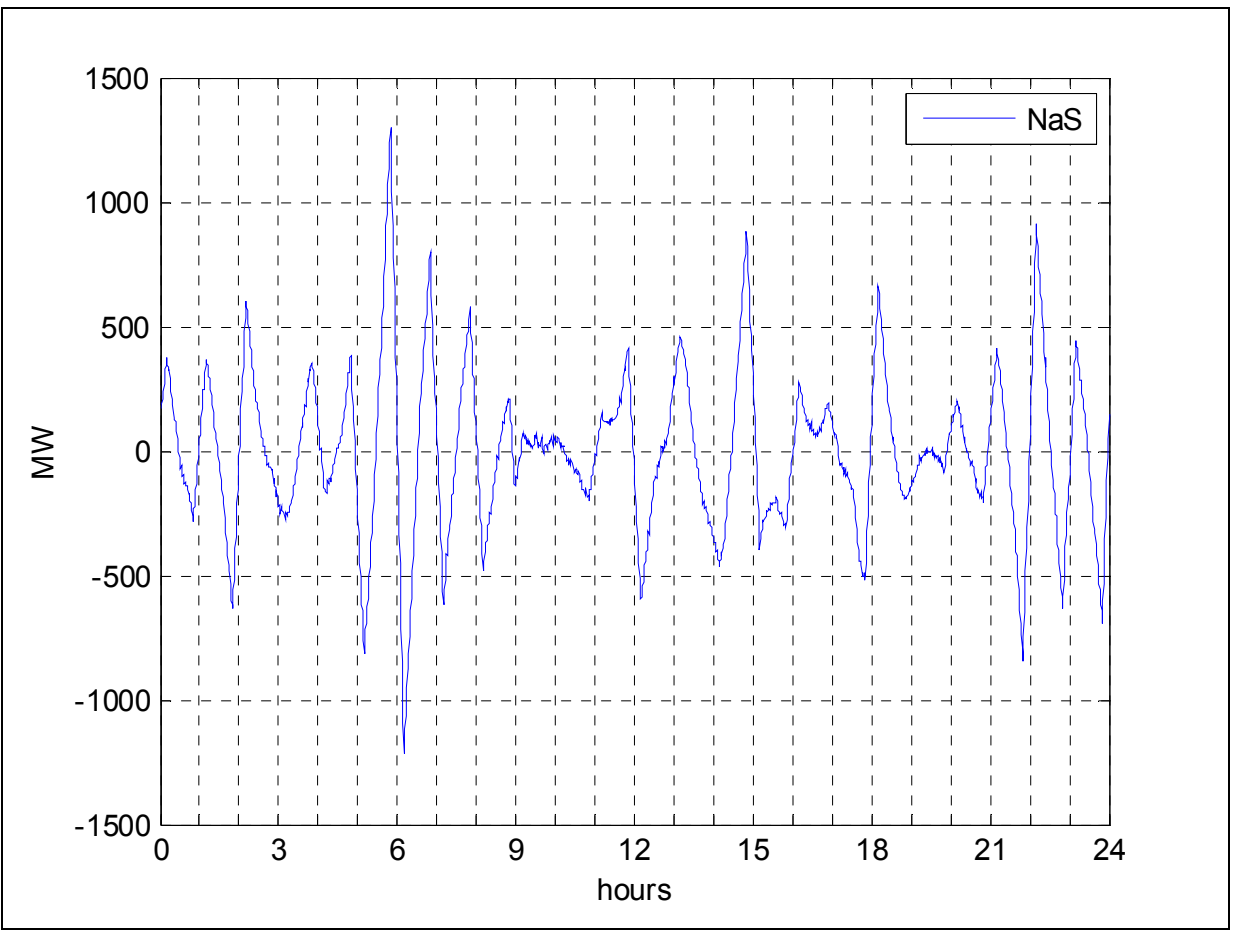

Figure B.9. Balancing Signal Followed by NaS Battery for the First Day 


\section{B.8 Case 8: CC + Li-ion + DR}

This case is similar to Case 7 discussed in the previous subsection; there is only a difference in the battery efficiency. The results shown for Figures B.8 and B.9 are representative of the Li-ion battery storage as well.

\section{B.9 Case 9: NaS + CC + Pumped Hydro with Multiple Mode Changes}

Technology Case 4 earlier utilized pumped hydro storage with multiple mode changes in a day, which was supplemented by NaS battery storage. This technology case supplements that analysis with a larger amount of $\mathrm{NaS}$ battery storage available. Unlike Case 4, the balancing requirements are divided between the $\mathrm{NaS}$ and pumped hydro storage. As such, the $\mathrm{NaS}$ is providing part of the balancing requirement continuously, not just during the 4-minute long changeover periods of the pumped hydro storage. Combined cycle generation is again utilized for energy balance, as well as compensating for battery efficiency.

Figure B.10 shows the power output of the pumped hydro for one day of analysis. Figure B.11 shows the power output of the NaS battery storage for the same day. Due to the proportional division of the balancing requirements, the two signals are nearly identical in shape. The largest difference is the flat periods on the pumped hydro, which are associated with mode changes.

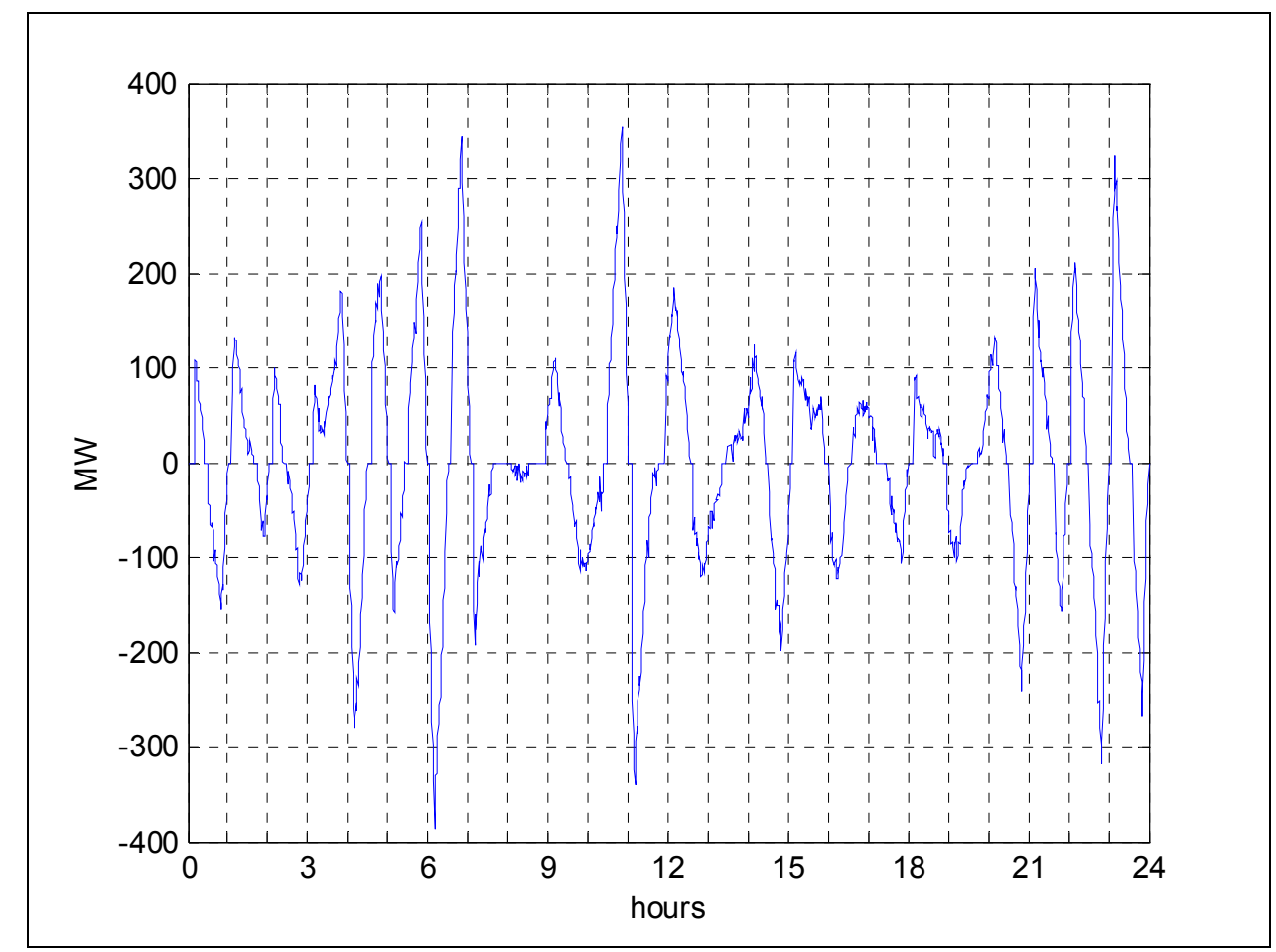

Figure B.10. Power Output of Pumped Hydro with Multiple Mode Changes per Day with NaS + CC 


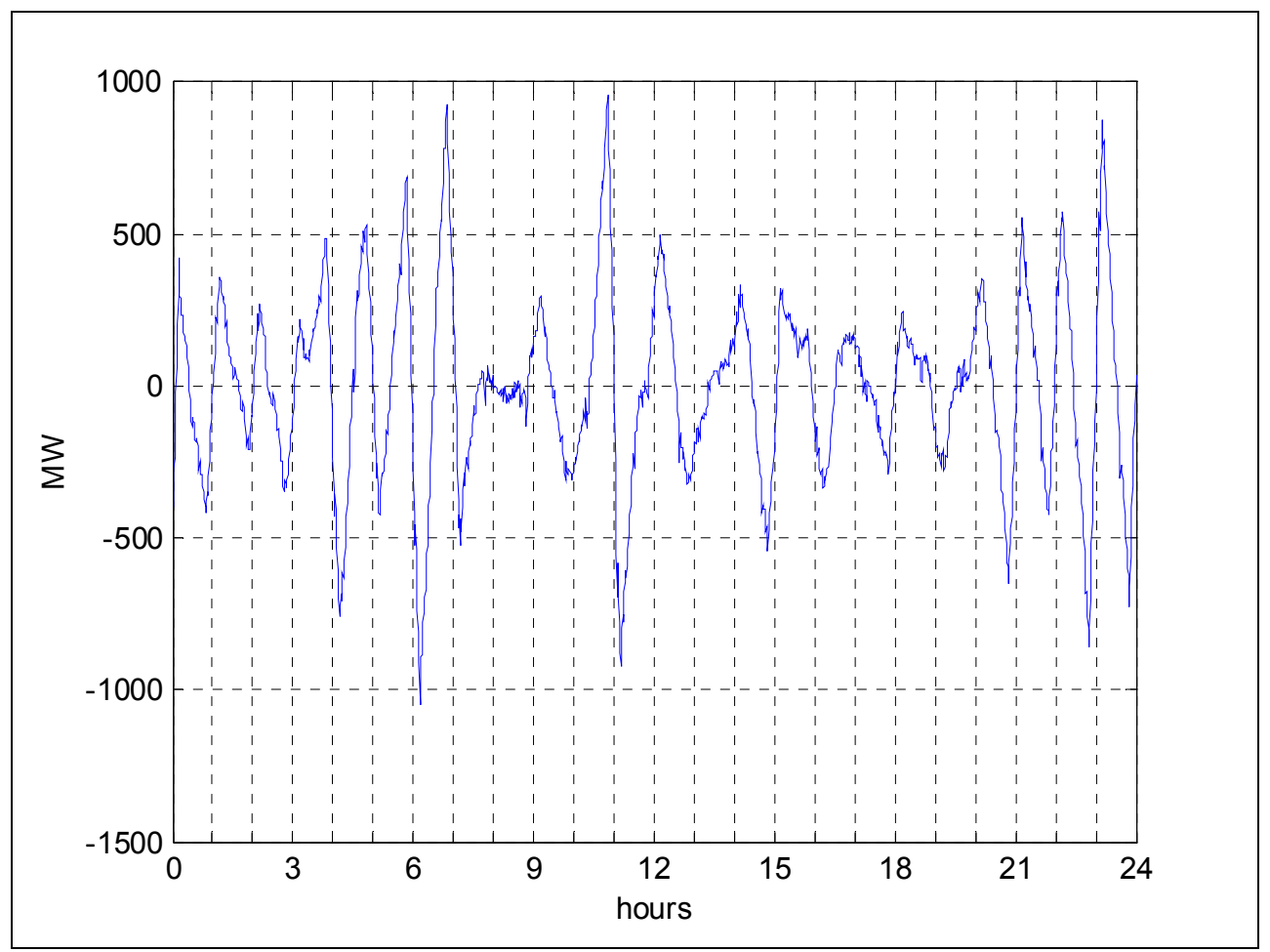

Figure B.11. Power Output of NaS Battery for NaS + Pumped Hydro + CC scenario

\section{B.10 Case 10: NaS + CC + Pumped Hydro with Two Mode Changes}

Similar to Case 9, the pumped hydro and NaS battery technology Case 5 was re-evaluated with large NaS storage available. The pumped hydro storage was restricted to a night pump and day generation cycle, as per Case 5. However, the NaS battery storage capacity was increased. As with Case 9, these two storage technologies divided the balancing requirements proportionally. Combined cycle generation was utilized for energy balancing, and compensating for battery efficiency.

Figure B.12 shows the power output of the pumped hydro for this technology case. Figure B.13 shows the power output for the NaS battery storage. As with Cases 4 and 5, the pumped storage requirement is higher in the two mode change-only case. However, the addition of the NaS battery storage helps alleviate the amount of pumped storage required. It is useful to note that the proportions of the balancing requirements handled by each storage device were the same as Case 9, so the NaS storage output looks nearly identical. Closer inspection would reveal slight differences around the changeover times of Case 9, as Case 10 only has two changeovers during the course of the day. 


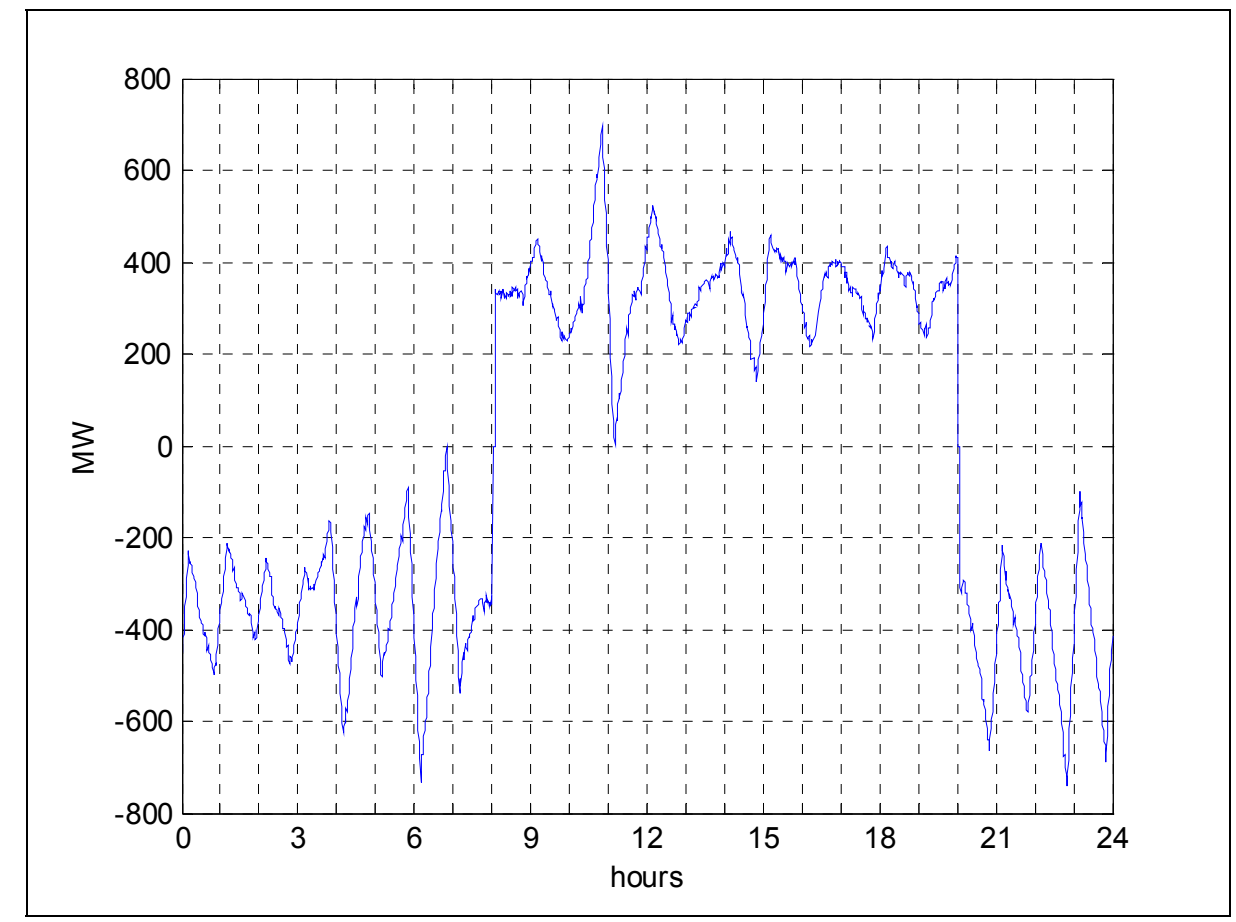

Figure B.12. Power Output of Pumped Hydro with Only 2 Mode Changes per Day

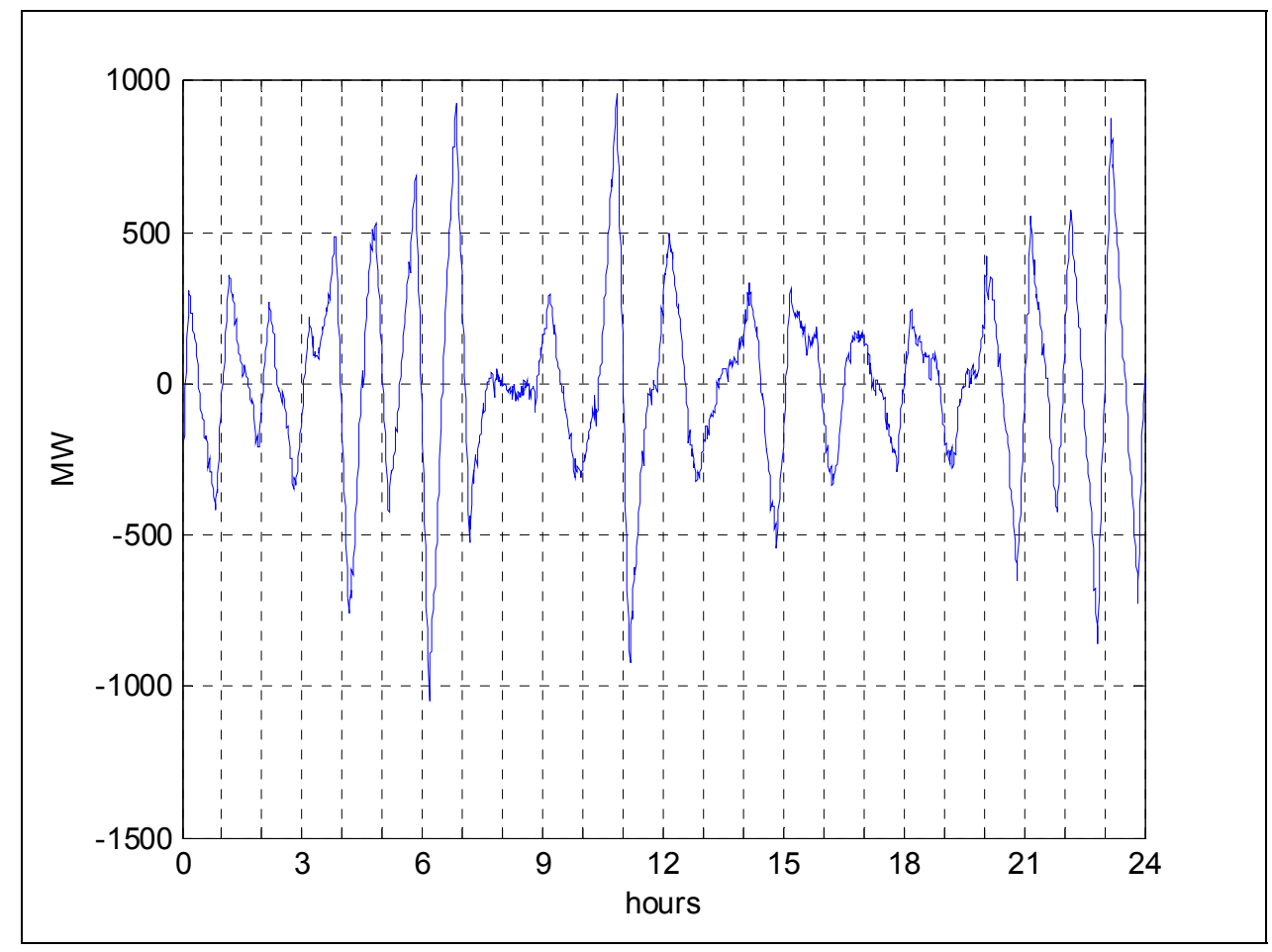

Figure B.13. Power Output of NaS battery for 2 Mode Changes per Day 


\section{B.11 Case 11: Pumped Hydro + NaS + CC + DR}

In the final technology case presented, a combination of pumped hydro, NaS battery storage, demand response, and combined cycle generation are proportionally utilized for the balancing requirements. The pumped hydro handles $27 \%$ of the requirements and is a multiple changeover per day scenario, with approximately 40 mode changes every day. The NaS batteries handle about $53 \%$ of the balancing requirements. Demand response, based around the PHEV-home charging and water heater control method presented earlier, handles the remaining 23\%. The NaS battery and demand response cover the full balancing requirements during the pumped hydro's 4-minute changeover periods.

Figure B.14 represents the power output for the pumped hydro over the course of the day, which is identical to Case 9's pumped hydro output. Figure B.15 shows the NaS battery output over the course of the day, and Figure B.16 represents both the balancing requirement and availability of the demand response portion. Compared with earlier cases, amount of demand response availability and NaS battery output required is significantly smaller.

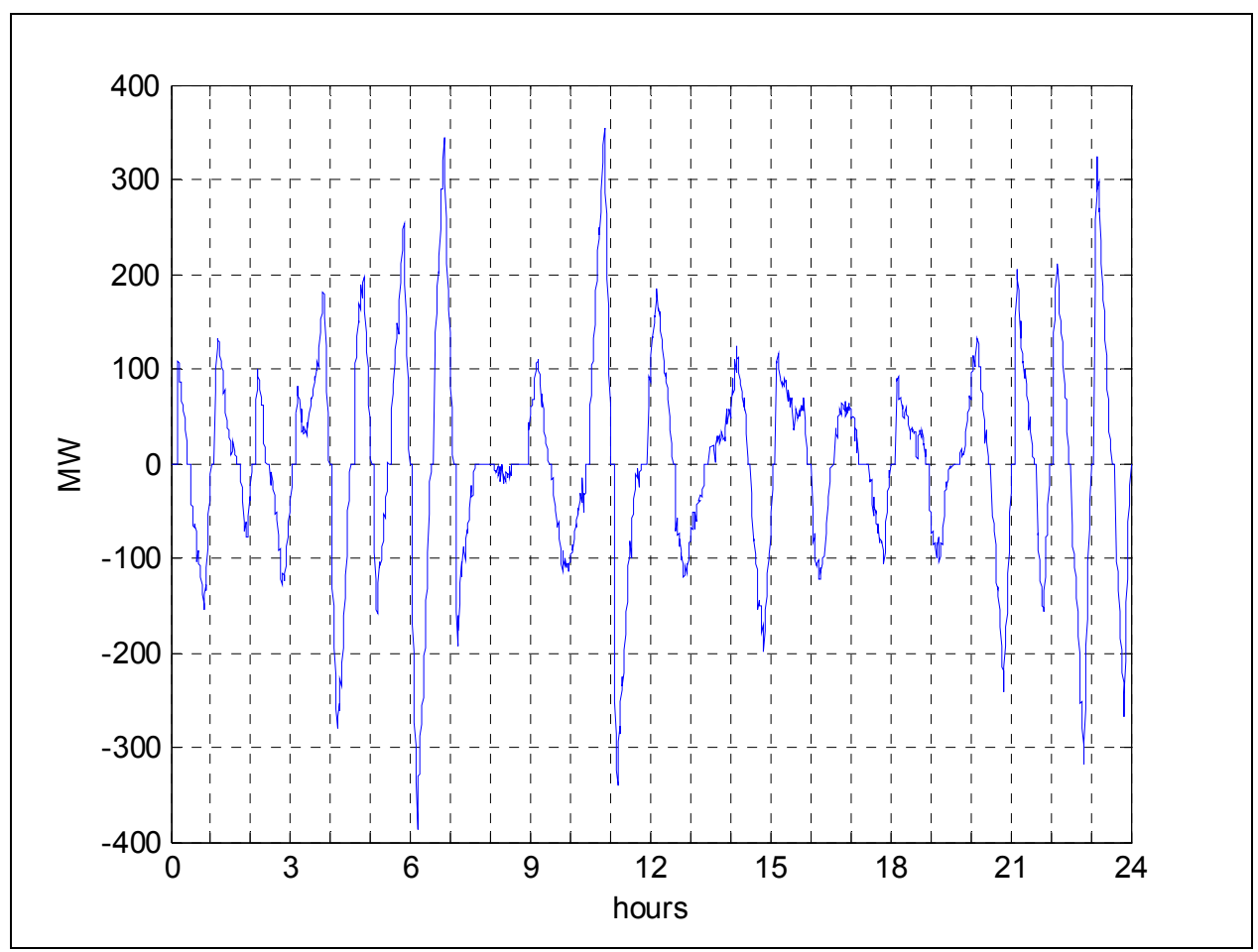

Figure B.14. Power Output of Pumped Hydro with Only 2 Mode Changes per Day with NaS + CC 


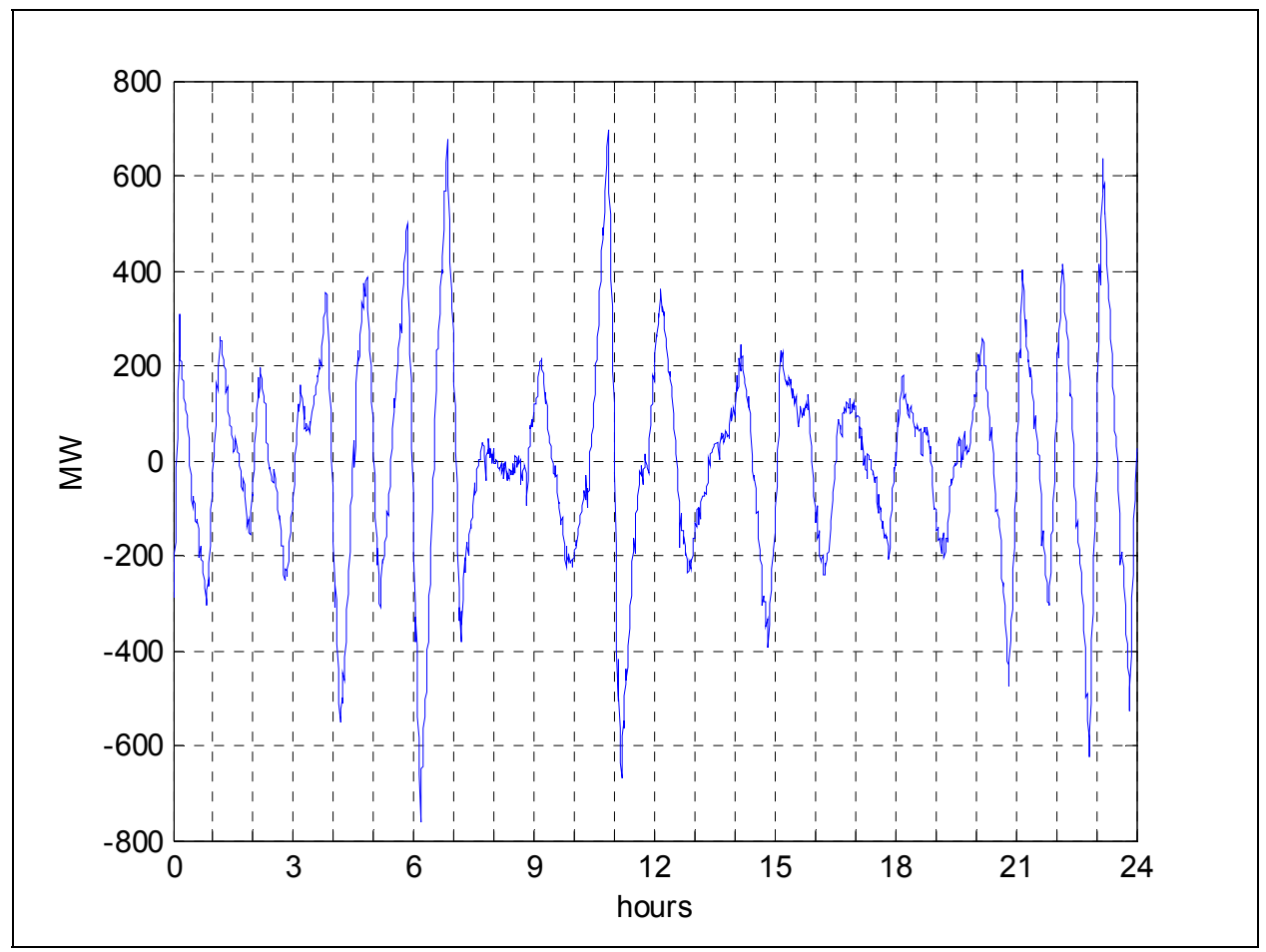

Figure B.15. Balancing Signal Taken by NaS Battery in the First Day

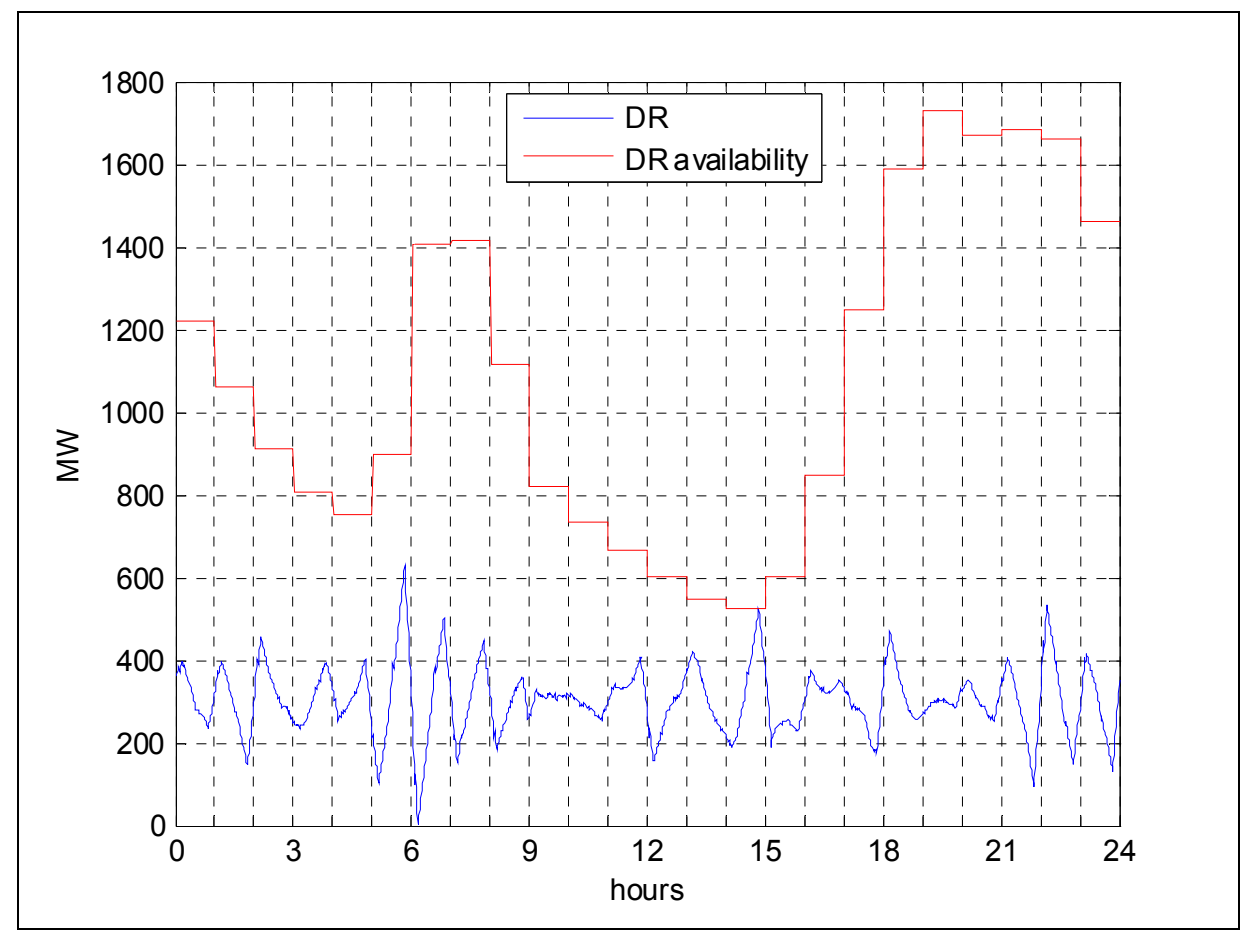

Figure B.16. Demand Response (DR) Availability and Balancing Signal Followed by DR 


\section{B.12 Wind Spillage}

The balancing requirements are produced when there is over-generation and under-generation in the system. Balancing requirements caused by over-generation can be compensated using wind spillage, that is, wind generators can be controlled to generate less power than the available wind resource would allow. This action is called wind spillage in this study. Wind spillage can curtail the peaks of the overgeneration balancing signal. However, as it is illustrated in this section, wind spillage does reduce the capacity requirements (MW) slightly, but increases the energy capacity requirements (if energy storage is used). This is an non-intuitive result and is explained below.

Wind spillage introduces asymmetry to the balancing signal, since the peaks curtailments are only performed when there is over-generation and the under-generation peaks remain unchanged. As a result, the power requirements for balancing services are not considerably reduced. What is more, the energy requirements for balancing services increase due to the introduction of asymmetry in the balancing signal. An illustration of this phenomenon is given in this section.

Consider the case where the balancing requirements are meet by NaS batteries only (Case 2, Section B.2). If the complete over-generation part of the balancing signal is curtailed by wind spillage, the balancing signal taken by the NaS batteries is as shown in Figure B.17. Charging and discharging of the NaS batteries is decided by the difference between the balancing signal and a daily fixed power output of a combined cycle (CC) generator as shown in Figure B.18. It can be seen from Figure B.18 that the maximum power requirement for $\mathrm{NaS}$ batteries (difference between balancing signal and constant power output of CC) is not considerably reduced by curtailing half of the balancing signal using wind spillage. What is more, the energy requirements for NaS batteries are larger than the energy requirements without wind spillage as it can be seen comparing Figure B.19 and Figure B.20.

Figure B.21 and Figure B.22 show the energy and power requirements for several levels of wind spillage. $100 \%$ wind spillage means that the complete over-generation side of the balancing signal is curtailed by wind spillage. It can be seen in Figure B.21 and Figure B.22 that wind spillage increases the energy requirements while it does not considerably reduces the power requirements. Therefore wind spillage by itself is not a good strategy to provide balancing services.

A reduction in the energy balancing requirements through wind spillage could be only achieved if the balancing signal is also curtailed in the under-generation peaks. Demand response can be used to curtail under-generation peaks. Symmetry in the balancing signal can be maintained by using both demand response and wind spillage. 


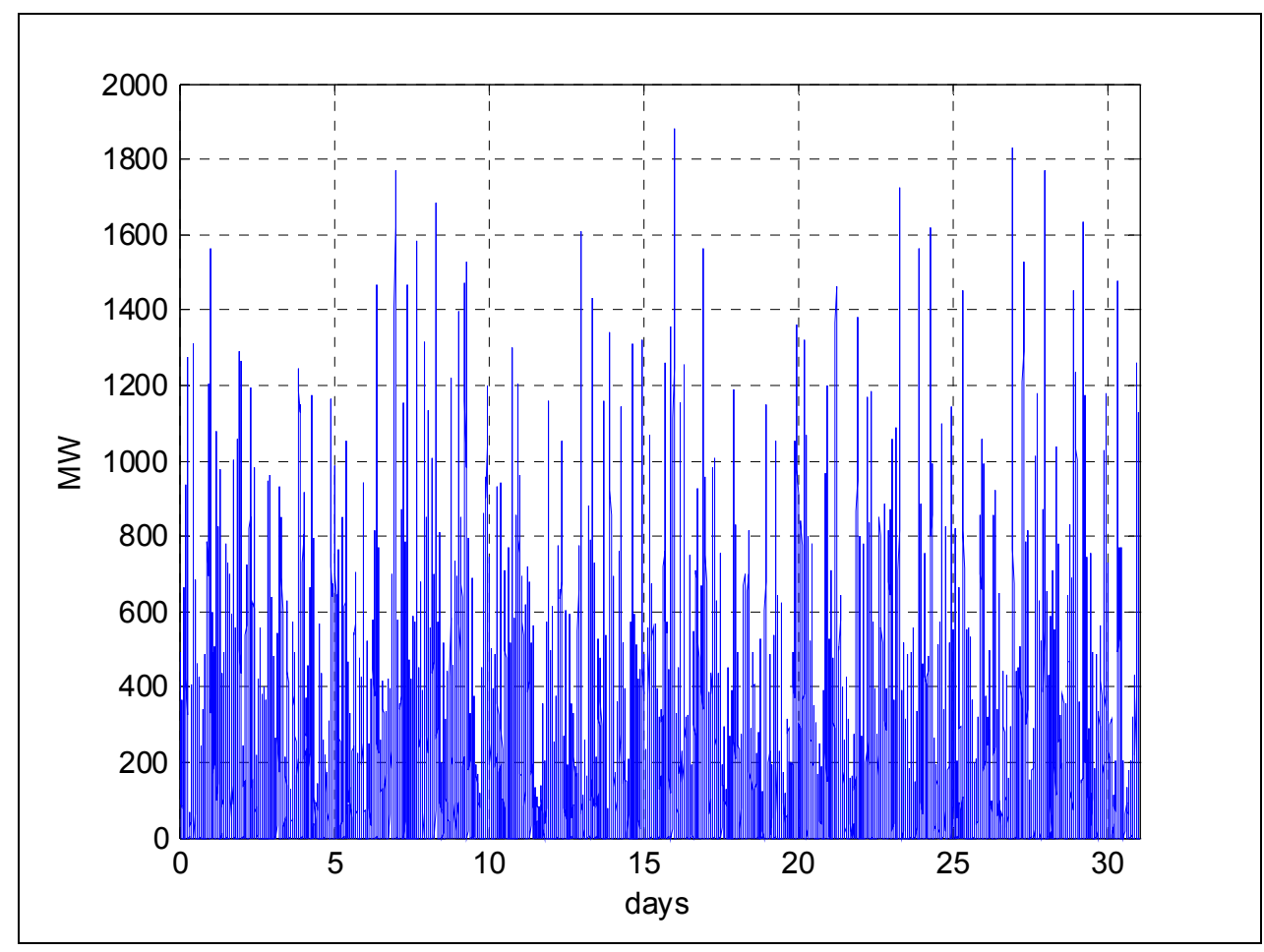

Figure B.17. Balancing Signal Taken by NaS Batteries After the Complete Over-Generation Component is Curtailed by Wind Spillage

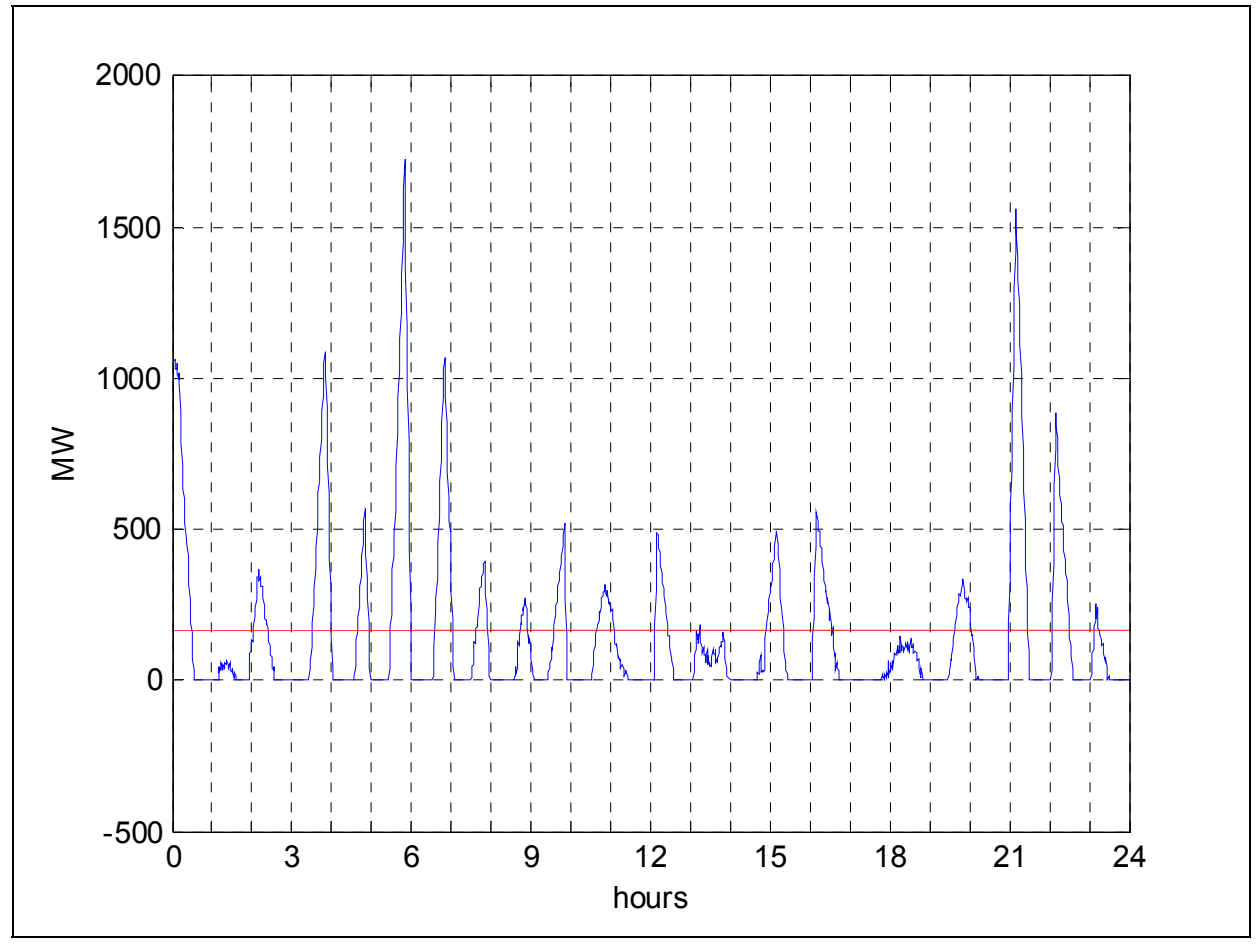

Figure B.18. Balancing Signal Taken by NaS Batteries After the Complete Over-Generation Component is Curtailed by Wind Spillage, and Constant Power Output of Combined Cycle Generation 


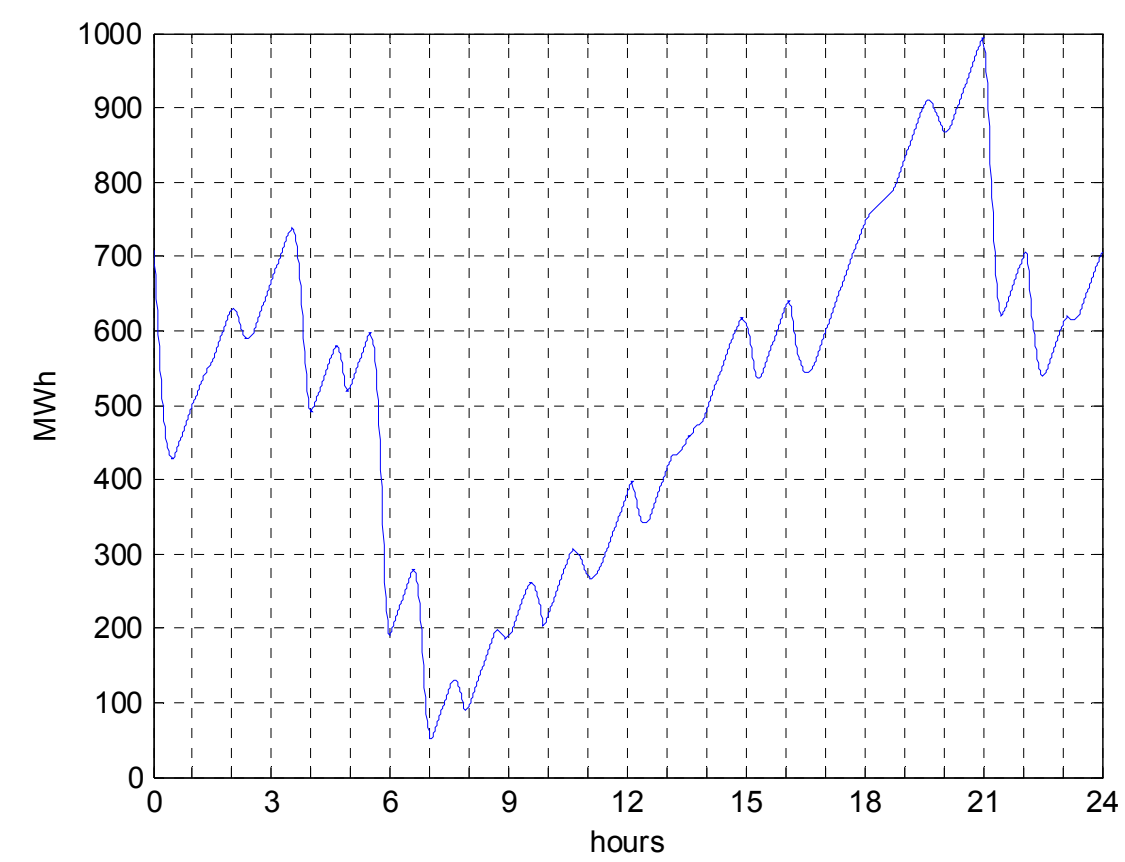

Figure B.19. Charging Status of NaS Batteries, for Day 24, After the Complete Over-Generation Component is Curtailed by Wind Spillage

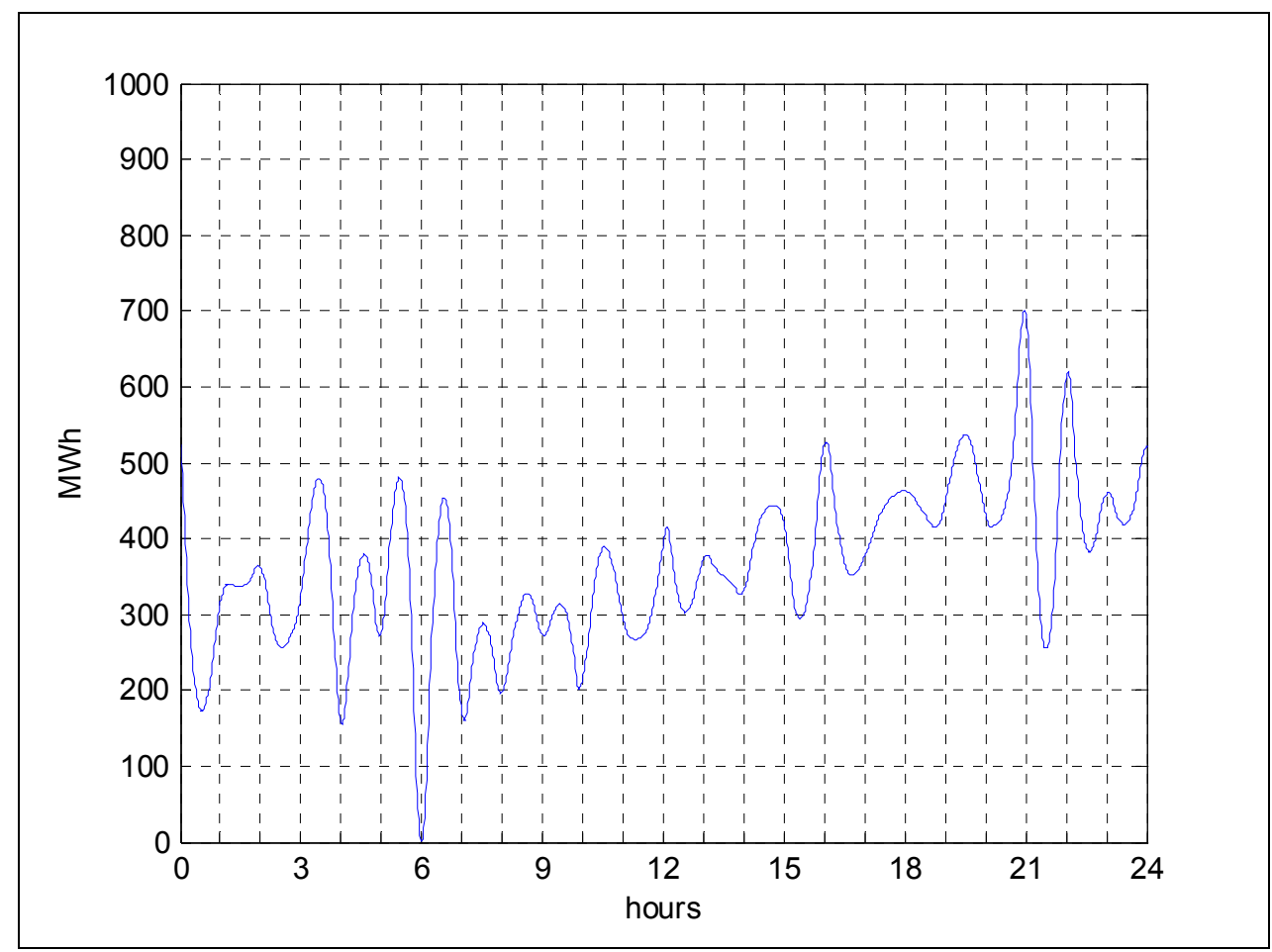

Figure B.20. Charging Status of NaS Batteries Without Wind Spillage for Day 24 


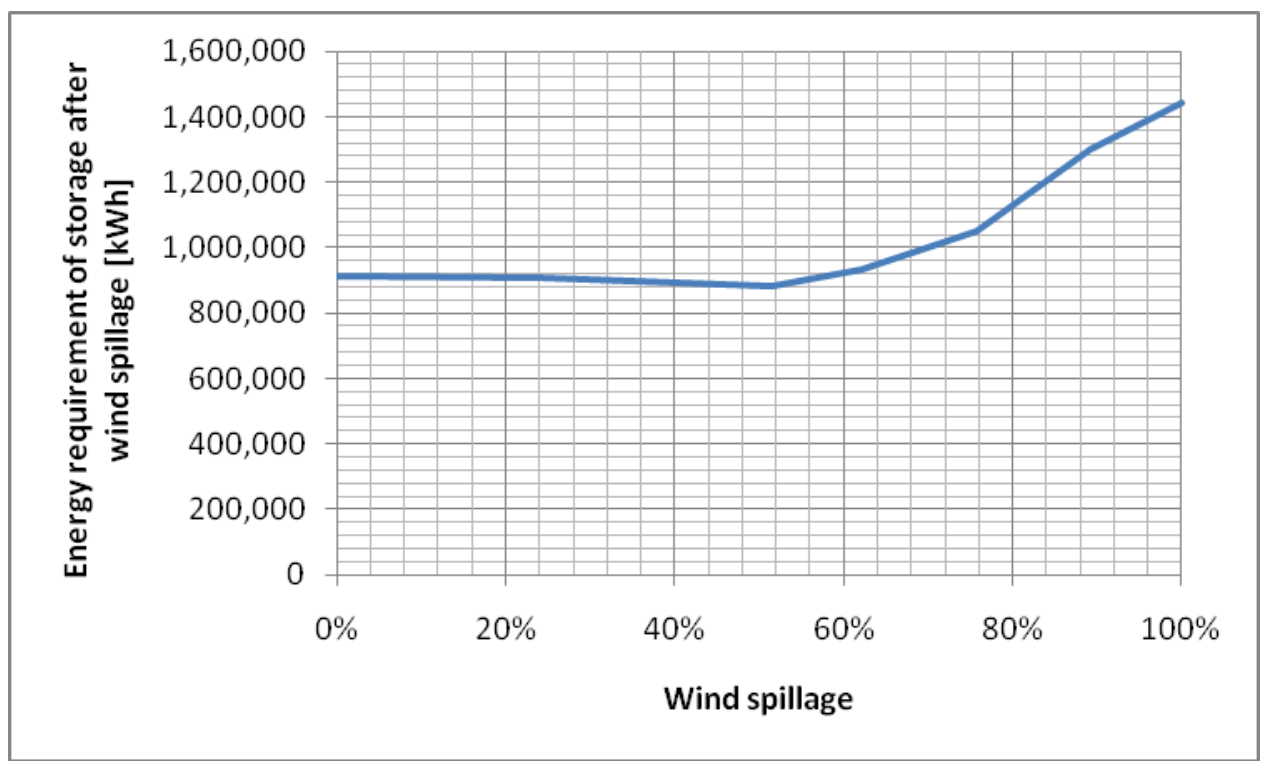

Figure B.21. Energy Requirements for Storage after Wind Spillage is Applied

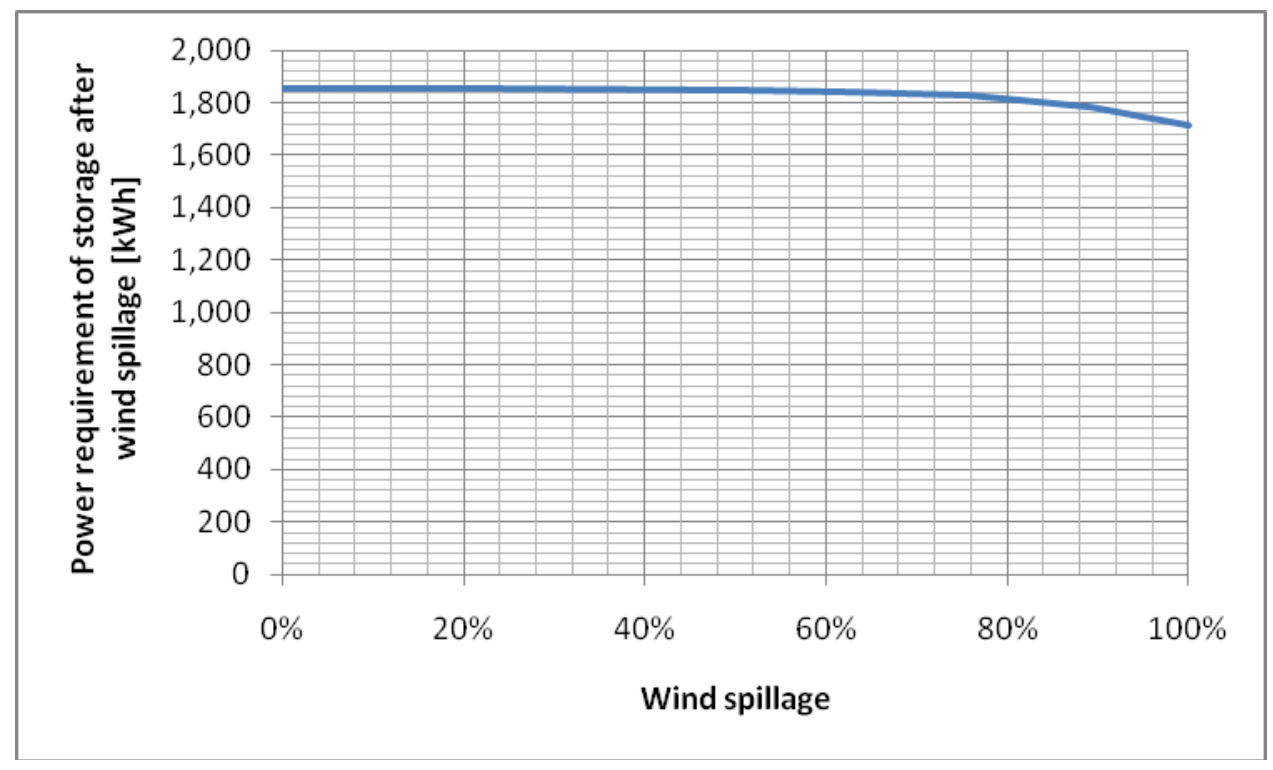

Figure B.22. Power Requirements for Storage After Wind Spillage is Applied 


\section{Distribution}

No. of

Copies

\# Name

Organization

Address

City, State and ZIP Code

\# Organization

Address

City, State and ZIP Code

Name

Name

Name

Name

Name (\#)

\# Name

Organization

Address

City, State and ZIP Code
No. of

\section{Copies}

\section{\# Foreign Distribution}

\# Name

Organization

Address

Address line 2

COUNTRY

\# Local Distribution

Pacific Northwest National Laboratory

Name

Name

Mailstop

Name

Name

Name
Mailstop

Mailstop

Mailstop

(PDF) 




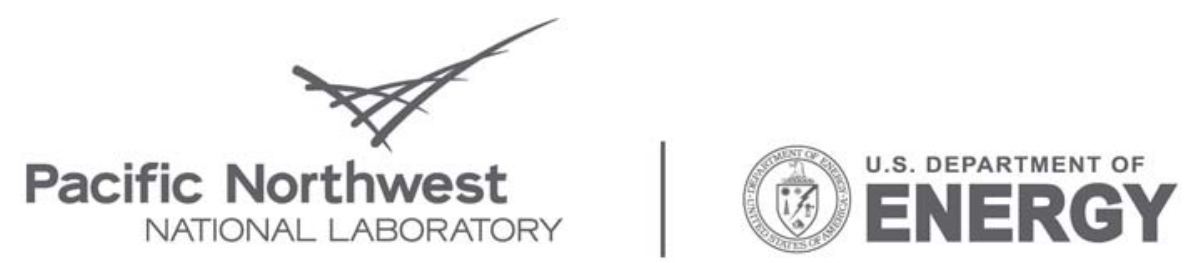

Proudly Operated by Battelle Since 1965

902 Battelle Boulevard

P.O. Box 999

Richland, WA 99352

1-888-375-PNNL (7665)

www.pnl.gov 